Wirtschaftswissenschaftliche

Fakultät

\title{
The fair-minded rich and healthy? (Youth) unemployment, inequality and fairness concerns in preferences for redistribution
}

A publication of the Center of Business and Economics (WWZ), University of Basel.

(c) WWZ 2020 and the authors. Reproduction for other purposes than the personal use needs the permission of the authors. wwz.unibas.ch

\section{Corresponding Author:}

Stephanie Armbruster

+ 41 (0)612073253

stephanie.armbruster@unibas.ch 


\title{
The fair-minded rich and healthy?
}

\section{(Youth) unemployment, inequality and fairness concerns in preferences for redistribution}

\author{
Stephanie Armbruster*
}

March 12, 2020

\begin{abstract}
Do rising inequality and youth unemployment affect preferences for redistribution? Using country-level European survey data from 2002 to 2015 , I show that changes in market inequality and the rise of (youth) unemployment increase preferences for redistribution. The findings are supported by the respondents' fairness concerns. Estimated effects exhibit substantial heterogeneity. There is systematic variation among fairness concerns with respect to income and health, which are triggered by market income inequality and (youth) unemployment. The preferences of the relatively rich and healthy are more responsive to the level of inequality and youth unemployment. At very high youth unemployment rates, even the rich might be in favor of redistribution. Results suggest that "income- and health-dependent fairness concerns" exist.
\end{abstract}

Keywords: Preferences for redistribution, Inequality, Fairness concerns, Income-dependent altruism, Healthdependent-altruism, Youth unemployment, unemployment, Meltzer-Richards, Inequality, Market inequality JEL codes: A13, D10, D31, D63, H23, C3

${ }^{*}$ University of Basel, Peter-Merian-Weg 6, CH-4002 Basel, and University of Freiburg, Tennenbacher Str. 4, DE-79106 Freiburg. stephanie.armbruster@ere.uni-freiburg.de 


\section{Introduction}

Nearly all countries in the world are experiencing an increase in top income and wealth shares Alvaredo et al. 2017) and inequality is at the forefront of the political discourse. At the same time, global youth unemployment is on the rise (International Labour Office, 2016). Governmental redistribution is one way of addressing the widening income gap and helping the unemployed. However, redistribution implies higher taxation, which can hamper economic growth (see, e.g., Alesina and Perotti, 1996 Saint Paul and Verdier, 1996, Okun, 2015). Consequently, there will be net payers, and it is not clear that societies will agree on more redistribution in response to widening inequality and (youth) unemployment.

The traditional starting point for investigating preferences for redistribution is the Meltzer and Richard (1981) (MR) model. According to the MR model, individuals are self-interested and only care about their own welfare. The MR model predicts that the poor (relative to the mean income group) are in favor of redistribution, while the rich reject it, i.e. redistribution wins in a majority vote if the median household has income below the mean. This is the so-called "income-effect". Hence, if the majority of the electorate receives a below-average income, the demand for redistribution increases as market inequality rises. If market inequality rises as the rich become richer, this leads to more support for redistributive policies. Empirical evidence focusing on income inequality and size of the government is mixed ${ }^{1}$ and there are other arguments, such as fairness concerns, implying that as inequality and potentially youth unemployment increase, even the rich could favor redistribution (see, e.g., Tyran and Sausgruber, 2006).

The goal of this paper is to investigate the effect of an increase in inequality and (youth) unemployment on preferences for redistribution in different income and health groups, using data from the vast European Social Survey (2016), 2002 - 2015, combined with European macro-level variables (World Bank, 2015; Eurostat, 2017; OECD, 2017; Solt, 2019; World Inequality Database, 2019).

Deviations from self-interested behavior and the existence of fairness concerns are well established

\footnotetext{
${ }^{1}$ See Dotti (2020) for a detailed overview of the empirical literature. The empirical evidence does depend on the type of redistribution (in-cash such as progressivity of the tax system and the amount of transfers) vs. in-kind policies such as public good provision and services. A further overview is giyen by Houle (2017).
} 
(see Fehr and Schmidt (2003) for an excellent overview). Theory (Galasso, 2003; Alesina and Angeletos, 2005: Alesina and Giuliano, 2011b), experiments (e.g. Ackert et al., 2007; Hoechtl et al., 2012; Klor and Shayo, 2010; Durante et al., 2014) and empirical evidence based on survey data (Fong, 2001; Alesina and Ferrara, 2005; Alesina and Angeletos, 2005, Giuliano and Spilimbergo, 2014) propagate evidence for fairness concerns leading to a demand for redistribution. Theory predicts that if people have fairness concerns, they choose higher tax rates than voters who are purely egocentric (see, e.g., Tyran and Sausgruber, 2006; Galasso, 2003; Murray et al., 2018). Alesina and Angeletos (2005) model social beliefs about the fairness of social competition (inequality in opportunities) together with monetary incentives, which determine preferences for redistribution. If pure luck is the reason why some have a higher or lower position on the income ladder, fairness concerns matter. If however, lower income is attributed to low effort, there are no fairness concerns ${ }^{2}$

The empirical literature using survey data, confirms that there are fairness concerns in broader terms (e.g. being leftist, equity principles) in preferences for redistribution (Fong, 2001; Alesina and Ferrara, 2005, Alesina and Angeletos, 2005 ${ }^{3}$ and fairness concerns related to macro-inequality in the economy (Dimick et al., 2016; Roth and Wohlfart, 2018) ? $^{4}$ In addition to inequality, social issues such as growing (youth) unemployment might trigger fairness concerns which are relevant in relation to preference for redistribution. Fairness concerns towards the unemployed youth might be higher than fairness concerns towards the unemployed in general, as youth unemployment is beyond individual control and generally not a lack of effort to find a job 5 This establishes the first hypothesis: changes in

\footnotetext{
${ }^{2}$ Similarly, Tyran and Sausgruber $(2006)$ show that fairness preferences induces inequality avers rich voters to vote against material self-interest which induces redistribution (i.e. the acceptance of a redistribution referendum) if the rich are in majority. Closely related to Alesina and Angeletos (2005) is Galasso (2003) who extends the MR model based on Fehr and Schmidt (1999) and includes a fraction of "fair-minded" voters. These fair-minded individuals do not only care about their own well-being but also about society, here, the degree of equity in the economy. In contrast to the MR model, individuals with income above the mean may vote in favor of some redistribution, if they have sufficient fairness concerns. Fehr and Schmidt (1999) describes "reference-dependent inequity aversion". The utility of an individual does not only depend on his own income, but also on the allocation of resources within his reference group. One key implication is advantageous inequality aversion (loss because others are worse-off) and disadvantageous inequality aversion (the loss to poorer-than-average because others are better-off).

3 Fong (2001) differentiates self-interest from social preferences and examines the characteristics of redistributive preferences in the U.S.. She finds that people in general hold strong principles of equity. Alesina and Ferrara (2005), Alesina and Angeletos (2005) and Giuliano and Spilimbergo (2014) complement this finding and show that fairness concerns are based on the belief that luck determines income and one's position on the social ladder, which in turn has a strong and significant effect on the probability of being leftist (Alesina and Ferrara, 2005) as well as preferences for redistribution (Alesina and Angeletos, 2005, Giuliano and Spilimbergo, 2014).

${ }^{4}$ This strand of literature is closely related to "Happiness research" measuring the relation of income inequality on subjective well-being. See Clark and D'Ambrosio (2015) for a comprehensive overview.

${ }^{5}$ This builds on Alesina and Angeletos (2005) who claim that fairness concerns matter only in preferences for redistribution when social competition is perceived as unfair.
} 
aggregated inequality and (youth) unemployment lead to a higher demand for redistribution (H1) ${ }_{[}^{6}$ It is, however, not clear which type of inequality matters (e.g. income, consumption or wealth inequality, measured by net vs. market Gini or Top $1 \%$ income and wealth concentration) and how different measures are associated with preferences for redistribution, which I study in this paper.

Using a country, region and year fixed effects model, results show that market inequality is associated with higher preferences for redistribution. In line with MR, I find that the higher pre-tax and pre-redistribution inequality is, the higher is the demand for redistribution. However net income inequality and Top $1 \%$ income concentration do not affect preferences for redistribution. This indicates that respondents are for redistribution in absolute terms.7 In addition, not only market inequality increase the demand for redistribution, but also youth unemployment (H1). The data further allows me furthermore to identify a very clear pattern of the self-interest-driven income-effect as predicted by the MR model. I find that the poor (relative to the mean income), are in favor of redistribution and the rich oppose it.

Second, the average effect of fairness concerns in voting for redistribution may obscures relevant heterogeneity. I argue that fairness concerns are state dependent, varying with income (H2) and health (H3). Health (income) state dependence can be defined as the effect of health (income) on the marginal utility of a constant amount of consumption (see, Finkelstein et al., 2009). Experimental and empirical evidence shows that fairness concerns vary with income (Hoechtl et al., 2012, Dimick et al. 2016) 8 People have decreasing marginal utility in income which implies that increase in macroinequality will lead to a larger increase in support for redistribution from the fair-minded millionaire than from the poor. An increase in redistribution to reduce inequality is less costly to a richer person

\footnotetext{
${ }^{6}$ Thereby, controlling for personal employment status and the insurance motive. The insurance motive represents the possibility of increasing demand for the insurance of individuals due to lower expected income with increasing financial risk or uncertainty.

${ }^{7}$ The question forming the dependent variable is quite vague. In particular, it is not clear whether it is meant as a general or a marginal statement about redistribution. These two interpretations are quite different, but unfortunately, there is no way of knowing which interpretation an individual respondent had in mind. The interpretation has implications for the appropriate measure for inequality. I argue that the market Gini is the relevant measure in the general interpretation, whereas in the marginal interpretation, it is the net Gini that should matter.

8 Hoechtl et al. (2012) demonstrate experimentally that fairness concerns increase with income level, i.e. the rich are more responsive to changes in inequality than the poor. Hoechtl et al. (2012) experimentally analyze conditions under which fairness concerns influence one's preferences towards redistribution. They show that an asymmetry exists in voting for redistribution with respect to income classes, i.e. there are higher fairness concerns if there is a rich majority.
} 
than to a poorer person $\sqrt[9]{ }$ I examine whether fairness concerns in preferences for redistribution in Europe vary systematically with income level (H2).

Furthermore, health status can affects the form of utility functions such that severe health impacts hinder individuals ability to derive utility from additional consumption (see Viscusi (2019) for an up-to-date overview) ${ }^{10}$ Finkelstein et al. (2009, 2013) demonstrate empirically that individual utility between healthy and sick states of the world varies indeed with consumption. With respect to preference for redistribution, this could lower the ability to derive utility from fairness. Although I assume that a poor health condition leads to favoring redistribution due to stronger insurance motives against potential lower income, I expect that utility from fairness decreases with poor health and increase with a good health, which in turn affects preferences for redistribution establishing $H 3$. The intuition of hypothesis $H 3$ is the following: Being ill, one worries more about one's own situation and has less room to care about others (regardless of any monetary losses that can occur). However, when completely healthy (controlling for income), there is no need to worry about one's own health. Instead, one has the capacity to focus on social problems and care about society because of fairness concerns. To the best of my knowledge, no previous study has investigated whether the health condition has an effect on fairness and preferences for redistribution.

I find that a positive subjective health decreases the demand for redistribution, while the contrary is true for individuals who are in a bad health state. Concentrating on fairness concerns towards inequality in society and the unemployed youth, I find relevant heterogeneity with respect to income and health, confirming (H2) and (H3). If societies experience rising market inequality and growing (youth) unemployment, the rich become more concerned with income differences and the unemployed (youth) such that their strong opposition is weakened. The effect of an increase in market inequality and both, unemployment and youth unemployment is positive for the rich (H2), and, at very high

\footnotetext{
${ }^{9}$ To illustrate, suppose person $A$ has income $X$, and another person $B$ has income $Y>X$. If inequality increases, then the desire for redistribution by person $B$ increases by more than the desire of person $A$. Of course, with increased inequality, there would be more people that have income of less than X, and/or more people that have more than Y. However, the income of the people who have been compared does not change.

${ }^{10}$ One exemplary argument is the standard utility function of a risk-averse individual, which increases with wealth, but at a diminishing rate. If death is treated equally to a drop in income, then death boosts the marginal utility of income, which is unreasonable. Viscusi and Evans (1990) stress the fallacy of not differentiating between health problems (and death) and monetary loss, and therefore proclaim a health-dependent utility function.
} 
levels of youth unemployment, even the rich are in favor of redistribution. The very poor increase the demand for redistribution when market inequality rises, as this potentially reinforces the weak financial situation of the poor. Fairness concerns do not only dependent on the level of income but also on the individual's health (Н3). Increases in market inequality and youth unemployment increase preferences for redistribution of individuals in a good health state.

A further validation gives the additional measure for fairness concerns i.e. the general interest in "helping others". Results also shows systematic heterogeneity with respect to income and health. They are higher for the rich than for the poor, and fairness concerns of the healthy are significantly higher than fairness concerns of the sick. The results jointly support the existence of "income- and health-dependent fairness concerns".

In addition, I expect that having children might influence preferences for redistribution positively as there are higher monetary requirements, such as higher food expenditures or educational expenditures (see Browning (1992) for a discussion). I find that the effect of having children is positive for net receivers and insignificant for net payers.

These findings contribute to the broad literature on preferences for redistribution (see Alesina and Giuliano (2011b) for an overview). The traditional MR model has been challenged by a number of theoretical and empirical works for multiple reasons. If one argues that individuals are guided purely by self-interest, the main critique is that the MR model does not take into account factors such as social mobility (Piketty, 1995, Alesina et al., 2018; Benabou and Ok, 2001), social competition (Corneo and Gruener, 2000; Gallice and Grillo, 2018), individual occupational status (Guillaud, 2013), institutions (Alesina and Fuchs-Schndeln, 2007) and culture (Alesina et al., 2004, Luttmer and Singhal, 2011). In particular, this research adds to the empirical literature investigating the effects of inequality on the demand for redistribution (Pittau et al., 2013, Kerr, 2014, Kuziemko et al., 2015; Dimick et al., 2016. Roth and Wohlfart, 2018). Pittau et al. (2013) show that the more unequal the income distribution (net Gini), the lower the preferences for redistribution in the U.S. for the period of 1980 - 1990. Kerr (2014) demonstrates for the U.S. that changes in inequality (net Gini) have a positive effect on the demand for redistribution. Kuziemko et al. (2015) provide U.S. individuals with different information treatments 
(income distribution, shocks to the income distribution and top income taxes) and investigates how the preferences for redistribution changes when survey participants receive information about income inequality. It turns out that the demand for redistribution among participants is mostly inelastic. Roth and Wohlfart (2018) examine whether the experienced level of income inequality in their home country (average level of income inequality (top 5\% earners) of respondents while they were between 18 - 25 years old) affects preferences for redistribution in Europe and the U.S.. They find that higher experienced inequality during life leads to less preferences for redistribution ${ }^{11}$ Results are inconclusive and mostly focuses on the U.S. and on (experienced) income inequality. This paper is most closely related to Dimick et al. (2016), concentrating on "income-dependent-altruism" in the U.S., where inequality is measured by the "Atkinson index". However, there exist substantial differences between Europeans and U.S. Americans concerning preferences for redistribution (Alesina et al., 2004). While Dimick et al. (2016) focus on the U.S. and find support for income-dependent altruism, I concentrate on Europe (controlling for year, country and region fixed effects) and ask whether changes in (youth) unemployment and different facets of inequality (market and net Gini, Top 1\% income and wealth concentration) might trigger income- as well as health- dependent fairness concerns.

The structure of the paper is as follows: Section 2 describes the data and explains the estimation strategy. Section 3 describes and analyzes the results and confirms the robustness, and Section 4 concludes the paper.

\section{Data and estimation strategy}

In this section, I present the data before I describe the empirical strategy.

\section{$2.1 \quad$ Data}

The base of the underlying empirical strategy is a merger of the European Social Survey (ESS) data (European Social Survey, 2016) and annual country-level measures from (World Bank, 2015), Eurostat (Eurostat, 2017), OECD (OECD, 2017), World Inequality Database (2019), Bundesamt fuer

${ }^{11}$ They argue that this effect operates through the respondents sense of fairness, i.e. they do not consider the prevailing inequality level as unfair as the experience with inequality changes the respondent's feeling of what is fair and unfair. 
Statistik Schweiz $(2019)$ and the Standardized World Income Inequality Database (SWIID) (Solt,

2019). The ESS offers the possibility of analyzing attitude developments in Europe over time. The comparative longitudinal survey is conducted biannually across Europe, monitoring public opinions within a dynamic context. In this paper, I use seven ESS rounds covering the period from 2002 to 2015. The data set is time-series cross-sectional (TSCS), with different individuals sampled every period 12 The initial sample consists of 331,871 observations for individuals covering 1,218 variables with country-year points for 32 countries ${ }^{13}$ The cumulative data set is merged with contextual macrodata. Table 1 provides an overview of all variables used, including the data source and description of creation.

\section{Dependent variable}

The dependent variable to measure preferences for redistribution is commonly used in the literature and constructed from the question 14 .

"To what extent do you agree or disagree with the statement? The government should take measures to reduce differences in income levels."

The possible answers are available on a five-point scale ranging from strong agreement to strong disagreement ${ }^{15}$ The variable is re-scaled in ascending order. The question only gives limited insights into the level of public support for redistribution, as it does not reflect the willingness to actually pay for it nor does it specify the type of redistribution (in-cash vs. in-kind) which is relevant (see, Dotti, 2020).

It is similarly not clear whether respondents understand the question in an absolute or marginal sense, i.e. that it expresses preferences for redistribution or preferences for more redistribution than it is currently the case. Figure 1 plots mean preferences for redistribution (x-axis) against average

\footnotetext{
${ }^{12}$ Thus, individual-specific autocorrelation is not present as observations are randomly drawn within a country.

${ }^{13}$ To be precise: Austria, Belgium, Bulgaria, Croatia, Cyprus, Czech Republic, Denmark, Estonia, Finland, France, Great Britain, Germany, Greece, Hungary, Iceland, Ireland, Israel, Italy, Lithuania, Luxembourg, Netherlands, Norway, Poland, Portugal, Russia, Republic of Slovakia, Slovenia, Spain, Sweden, Switzerland, Turkey, Ukraine.

${ }^{14}$ The same question is used by Corneo and Gruener (2002); Alesina and Ferrara (2005); Alesina and Angeletos (2005); Alesina and Giuliano (2011a); Luttmer and Singhal (2011); Yamamura (2012); Pittau et al. (2013); Guillaud (2013); Kerr (2014); Dimick et al. (2016) to measure redistributive preferences although from different data sources

${ }^{15}$ Answers "don't know/don't want" are excluded from the analysis.
} 
Table 1: Variable description

\begin{tabular}{|c|c|c|}
\hline Variable name & Survey question / Variable & Description \\
\hline Preference for redistribution & $\begin{array}{l}\text { Agreement: Government should reduce differences } \\
\text { in income levels }\end{array}$ & $\begin{array}{l}\text { Indicator variable: Rescaled in ascending order (1 } \\
\text { disagree - } 5 \text { agree strongly) }\end{array}$ \\
\hline \multicolumn{3}{|l|}{ Demographics: } \\
\hline Age & Calculated age of respondent & Calculated age of respondent \\
\hline Female & Gender & Dummy: Female $=1$, Male $=0$ \\
\hline Household size & People living in same household & Log of size \\
\hline Income & Household's total net income, all sources & Imputed, two different variables merged \\
\hline Married & Legal status & Dummy: Yes $=1$ \\
\hline Divorced or separated & Legal status & Dummy: Yes $=1$ \\
\hline Widowed & Legal status & Dummy: Yes $=1$ \\
\hline Never married & Legal status & Dummy: Yes $=1$ \\
\hline Education & Highest level of education, ES - ISCED & $\begin{array}{l}\text { Indicator variable: } 0 \text { no eductaon, } 1 \text { Primary educa- } \\
\text { tion, } 2 \text { secondary education, } 3 \text { Tertiary education }\end{array}$ \\
\hline Social mobility & Father's highest level of education, ES - ISCED & $\begin{array}{l}\text { Dummy: Comparing fathers level of education with } \\
\text { own level of education, } 1 \text { if higher, } 0 \text { otherwise }\end{array}$ \\
\hline Unemployed & $\begin{array}{l}\text { Any period of unemployment and work seeking } \\
\text { lasted } 12 \text { months or more }\end{array}$ & Dummy: Yes $=1$ \\
\hline Has a child in the household & Ever had children living in household & Dummy: Yes $=1$ \\
\hline Discrimination & $\begin{array}{l}\text { Member of a group discriminated against in this } \\
\text { country }\end{array}$ & Dummy: Yes $=1$ \\
\hline Paid work last week & Respondent has worked last week & Dummy: Yes $=1$ \\
\hline Metro & Lives in metropolitan area & Dummy: Yes $=1$ \\
\hline Born in an Eastern Bloc country & & Dummy: Yes $=1$ \\
\hline Occupational status & $\begin{array}{l}\text { Different types of occupation classified by isco } 08 \\
\text { e.g. Technicians, Management, Agriculture etc. }\end{array}$ & \\
\hline Current main activity & $\begin{array}{l}\text { Different types of main activity e.g. education, re- } \\
\text { tirement etc. }\end{array}$ & \\
\hline \multicolumn{3}{|l|}{ Risk aversion: } \\
\hline Self-employment & Employment relation & Dummy: Being self-employed $=1$ \\
\hline Adventurous & $\begin{array}{l}\text { Important to seek adventures and have an exciting } \\
\text { life }\end{array}$ & Dummy: 1 if yes, very much like me and like me \\
\hline \multicolumn{3}{|l|}{ Political orientation: } \\
\hline Left & Placement on left right scale (left 1-10 right) & Dummy: 1 if placement $1-4$ on the left scale \\
\hline Religion & $\begin{array}{l}\text { Type of religion; catholic, protestian, orthodox, } \\
\text { jewish etc. }\end{array}$ & $\begin{array}{l}\text { Dummy: Self declared religiousity ( } 1 \text { not at all }-10 \\
\text { very religious); use } 6-10\end{array}$ \\
\hline Union current and ever & Member of trade union or similar organisation & Dummy: Yes $=1$ if yes, currently and yes, previously \\
\hline Trust legal system & Trust in the legal system ( $0-10$ complete trust) & Dummy: Yes $=1(7-10)$ \\
\hline Trust parliament & $\begin{array}{l}\text { Trust in country's parliament }(0-10 \text { complete } \\
\text { trust) }\end{array}$ & Dummy: Yes $=1(7-10)$ \\
\hline \multicolumn{3}{|l|}{ Country level factors: } \\
\hline Crime rate (murder) & Total intentional homicides per year & Eurostat \\
\hline$G D P$ & $\begin{array}{l}\text { Gross domestic product at market prices, per } \\
\text { capita }\end{array}$ & Eurostat, OECD \\
\hline Unemployment & Percentage of unemployed from working population & Eurostat, OECD \\
\hline Youth unemployment & $\begin{array}{l}\text { Percentage of unemployed youth from working pop- } \\
\text { ulation }\end{array}$ & Eurostat, OECD \\
\hline \multicolumn{3}{|l|}{ Top $1 \backslash \%$ wealth shares } \\
\hline \multicolumn{3}{|l|}{ Top $1 \backslash \%$ income shares } \\
\hline Welfare state classification & Country number & $\begin{array}{l}\text { Indicator variable: } 1 \text { "Nordic" } 2 \text { "Liberal" } 3 \text { "Conti- } \\
\text { nental" } 4 \text { "Southern" } 5 \text { "Eastern and Central" }\end{array}$ \\
\hline Net Gini & Gini coefficient of equivalised disposable income & $\begin{array}{l}\text { The Standardized World Income Inequality } \\
\text { Database }\end{array}$ \\
\hline Mkt. Gini & Market Gini & $\begin{array}{l}\text { The Standardized World Income Inequality } \\
\text { Database }\end{array}$ \\
\hline
\end{tabular}

Note: The table presents construction of variables used in the estimation and the respective sources. 
relative redistribution (y-axis) per country and indicates that Denmark and Netherlands with high levels of relative redistribution ${ }^{16}$ have the lowest preferences for redistribution. But this pattern is not true per se: Sweden and Finland have high levels of relative redistribution but not exceptional low preferences for redistribution. Whether the understanding is marginal or absolute is probably mixed: some understand the question in a marginal sense, whereas others interpret it in absolute terms. The interpretation may only be different for the voter at the margin (i.e. when the answer changes from yes to no absolute terms). This argument is based on the MR model: Everyone below the median income will be in favor of redistribution in general (they are recipients), but also in favor of more redistribution (the extent of which is determined by the median voter). People below the median income are both in favor of redistribution and in favor of more redistribution (as they are inframarginal).And everyone above the median income will be against redistribution, both in general and on the margin. The median voter would answer "yes" to the general redistribution question (because the median income is below the mean income, making the median voter a net recipient), but "no" to the marginal question as the extent of redistribution exactly corresponds to his or her preferences. If the interpretation is marginal, then finding support for H2 could simply mean that the marginal utility of income decreases in income.

There are pitfalls which come with the question. Nonetheless, it is the best available to measure preferences for redistribution (see Nekby and Pettersson-Lidbom (2017) for further discussion on the reliability of survey measures for preferences for redistribution $\longdiv { 1 7 }$.

\section{Measuring fairness concerns}

Following Dimick et al. (2016) and Roth and Wohlfart (2018), I examine whether fairness concerns in preference for redistribution are triggered by rising macro-inequality. In addition, I hypothesize that fairness concerns in preference for redistribution are related to (youth) unemployment in the economy.

Distinct metrics of economic disparity exist, i.e. income, consumption and wealth inequality. It is not clear a prior which type of inequality matters in preference for redistribution. Among the most

\footnotetext{
${ }^{16}$ Estimated relative redistribution is the \%age reduction in market-income inequality due to taxes and transfers.

${ }^{17}$ Unfortunately, there are no additional variables available in the ESS cumulative data set to further specify different dimensions of preferences for redistribution as suggested by Nekby and Pettersson-Lidbom (2017)
} 


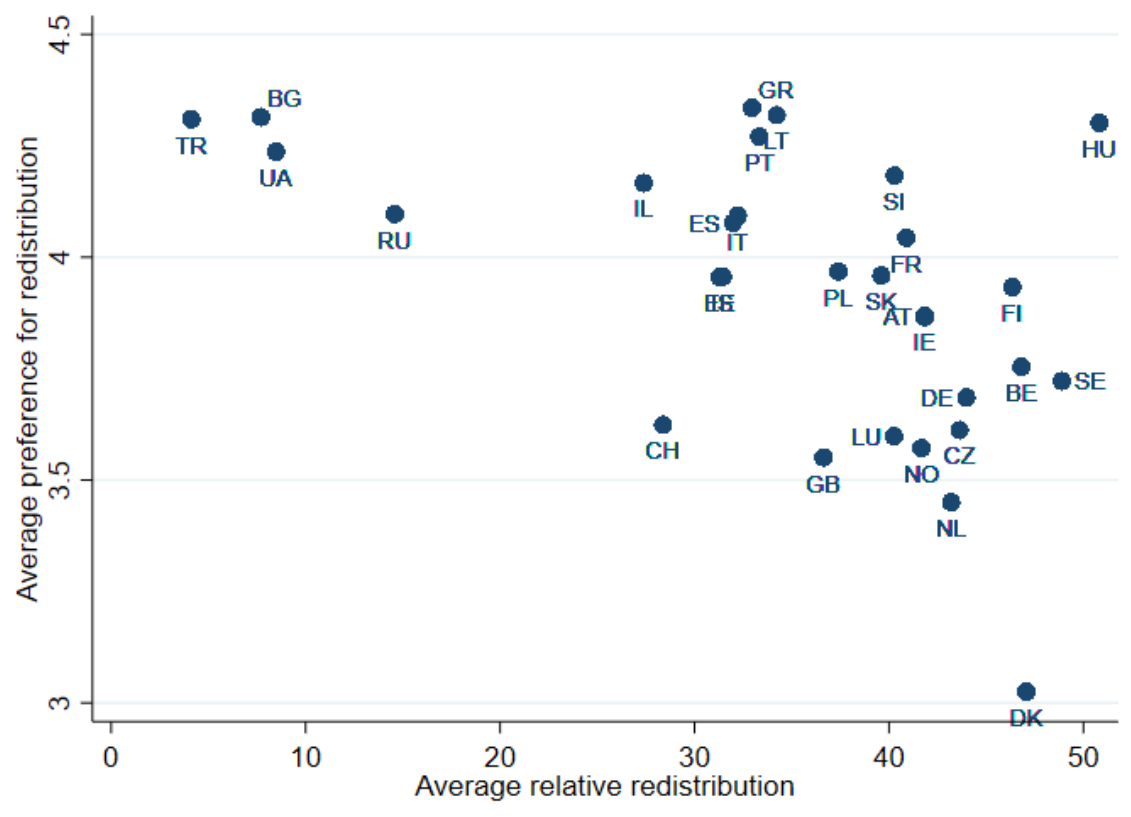

Figure 1: Preferences for redistribution and relative redistribution. Note: The graph plots mean preferences for redistribution constructed from the ESS data set by country 2000 - 2017 (y- axis) against mean relative redistribution 2002 - 2015 per country from the SWIID database (Solt, 2019) (x-axis).

poupular are the two different Gini indices, one with net (post-tax, post-transfer) income inequality and one with market (pre-tax, pre-transfer) income inequality. The two indices are related in the following way: Redistributive fiscal policies reduce net income inequality, given market inequality. The measure of inequality which I include in order to test for hypothesis $H 1-H 3$, is the net Gini and market Gini of the latest version of the Standardized World Income Inequality Database (SWIID) (Solt, 2019). Pensions, public social benefits such as unemployment and family benefits are classified as a government transfer in the SWIID.

Potentially, it matters how inequality enters the model and can provide information on how the dependent variable survey question is understood. If the net Gini index is relevant, this could indicate a preference for more redistribution whereas a significant market Gini might reflect preference for redistribution in an absolute sense. But in addition, the market Gini potentially plays a role when paid wages are very present as an orientation devise and people perceive a large discrepancy with respect to wages. However, market inequality also contains some governmental interventions such as public pension programs, job training programs, public education etc. This means for example that market inequality is exaggerated in a setting where public pensions are high, as they do not count as 
income. It is inequality in incomes after taxes and benefits that conveys differences in living standards and the net Gini might be important if respondents care about the total disposable income available for consumption.

Further measures for inequality which I include are the Top 1\% market income shares and Top 1\% wealth shares, which inform us adequately on the income and wealth levels of the richest individuals. To complement the analysis, I use income and wealth shares from (World Inequality Database, 2019). The WID.world combines national accounts and survey data with fiscal data sources (see Alvaredo et al. (2017) for a discussion). For the Top 1\% income shares, there is no data available for Israel, Russia and the Ukraine and there are no post-tax indicators. Top 1\% wealth shares are only available for France, Russia and Great Britain.

Furthermore, I include the overall unemployment rates as well as the youth unemployment rate from OECD (2017) and Eurostat (2017).

In addition, I include a dummy variable, recording the answer if respondents do voluntary work. Unfortunately, a variable measuring private donations to charity is not available in the ESS data. I assume that doing voluntary work measures a "warm-glow-motive." Andreoni (1989) argues that rich people do not only derive utility from the poor being better off (pure altruism), but also from the satisfaction derived from giving money to the poor ("warm-glow"), which is called "impure altruism". Pure altruism has often been rejected as an explanation for donations to private charities, for instance (Andreoni, 1988). However, with respect to redistribution, if the "warm-glow-of-giving" is relevant, people would presumably not want the government to redistribute, because this would diminish their own "warm-glow". If richer and healthier individuals are mainly interested in the warm-glow-ofgiving, I should find very little support for government redistribution. Under pure altruism, the rich and healthy only care about the outcome (the poor having more money), but for them it is better if another rich person makes the transfer. This leads to free-riding in the sense that the rich all want transfers to happen, but they don't want to be the ones making these transfers. In attempt to overcome the problem of free-riding, I argue that if the rich and healthy are in favor of a redistribution by the state, in case inequality or (youth) unemployment rises, this is evidence for pure altruism. I test 
this argument by investigating the effect of doing voluntary work proxying the "warm-glow" and the general interest in "caring about others", which I interpret as fairness concerns. The variable "helping others" is a dummy variable equal to 1 , if the respondent indicates a general interest in helping others. I assume that the question is understood such that it does not matter who helps. Consequently, the variable reflects fairness concerns such that I expect a positive effect.

\section{Health, income and having children}

The income variable was recorded in two distinct specifications within the cumulative ESS data. In rounds 1-3, available response options for the income deciles were identical for every country, i.e. with the same ranges expressed in euros or the equivalent in local currency. As of ESS round 4, a countryspecific decile approach was applied. Since then, categories of the income variable are national and based on deciles of the actual household income range in the given country. This change makes it difficult to use all five rounds for an analysis using an income variable. Merging the two distinct variables would cause a bias. To test for $H 1$ and $H 2$, the income variable has to be constructed. I use the midpoint of each income bracket as a proxy of family income and a random sorting by a two-stage procedure for the re-allocation to deciles (equivalent decile groups for rounds 1-4) which categorizes the ten income deciles defined for each country and year ${ }^{18}$ There is no income data for four countries (HR, EE, LT, UA). The ten income deciles allow a specific differentiation of the income effect.

So far, the health and having children are unaddressed personal-level predictors of preferences for redistribution in the existing literature; I include both predictors in my research. I expect that being in a bad health state will increase the demand for redistribution due to the insurance motive, and the opposite is true for being in a good health state. Potentially, the main effect of having children is related to higher monetary requirement, such as higher food expenditures etc. (see Browning (1992) for a discussion), but I expect that the effect on preferences for redistribution depends on being a net

\footnotetext{
${ }^{18}$ To be explicit, for each country-income-group a higher and a lower cut-off point are created to derive decile cut-offs by country and wave. Using uniform random values between the two cut-off-points, imputed income values are then constructed. At the second stage, country-specific decile groups are created and individuals are assigned to these deciles. This is done for each country wave respectively. As a last step, the now similar income variables are merged. Comparing the constructed measure income with the respective distributions from the original variables, the new variable seems reliable. See talkstats.com (2014) for further information.
} 
payer or net recipient in the transfer system. On the one hand, having children could increase the demand for redistribution with potential higher monetary requirements, which I expect to be true for net recipients. On the other hand, for net payers, I expect that more children lead to lower preferences for redistribution. This argument might also apply to health. Being ill and having children both are costly, so a net payer would want to redistribute less, and a net recipient would want to redistribute more. Thus, I further estimate an interaction term with having children, health as well as income.

\section{Controls}

Further control variables are added; I include individual-level variables reflecting self-centered-motives (unemployment, risk aversion, social mobility), political preferences (union membership, leftist party orientation, trust in the government) and demographics (age, gender, education, marriage, discrimination, religion) following the existing literature (Corneo and Gruener, 2002; Alesina and Ferrara, 2005: Alesina and Angeletos, 2005, Alesina and Giuliano, 2011a; Yamamura, 2012, Pittau et al., 2013, Guillaud, 2013; Dimick et al., 2016).

In the literature, being unemployed and risk aversion have been found to increase the support for redistribution with an amplified insurance motive of redistribution (Sinn, 1996). Risk aversion is proxied by a self-employment dummy following Alesina and Ferrara (2005) as individuals who are selfemployed are considered to be more risk-loving. Risk averse individuals are expected to be more likely in favor of redistribution. I proxy for social mobility by using the difference between the respondents' years of education of and those of their fathers as in Alesina and Ferrara (2005) 19 I further include political variables indicating union membership, trust in the legal system and leftist party orientation as well as religion. Following the argumentation of social-preference-models, union members and leftist voters having stronger fairness concerns could serve as an explanation for higher redistributive demand (Alesina and Ferrara, 2005).

On the country level, GDP per capita rates are obtained from the World bank data base (World ${ }^{19}$ The ESS does not contain any question that would allow to directly measure monetary social mobility. Theory suggests that past inter-generational mobility experience leads to less favorably redistributive policies (Piketty, 1995). Due to data limitations, variables controlling for social class affiliation apart from income class as in Corneo and Gruener (2002) or a variable controlling for prospects of social mobility is not available. Due to data availability, the construction of a measure with the difference between the respondents' years of education and those of the mother is not possible. 
Bank, 2015) and the OECD (OECD, 2017). I convert GDP to international dollars using purchasing power parity rates for each respective year and country. GDP, reflecting aggregated income, is expected to have an negative impact on voting for redistribution. I use crime rates and the welfare state classification in 3.5 as a robustness check.

\subsection{Estimation strategy}

My baseline regression is the following:

$$
y_{i j k t}=\alpha+\beta X_{i j t}^{l}+\gamma Z_{j t-1}^{m}+\theta_{t}+\omega_{k}+\nu_{j}+\epsilon_{i j k t} .
$$

$y_{i j t}$ is the self-reported measure for preferences for redistribution of individual $i$ in country $j$, in region $k$ in time period $t . \quad X_{i j t}^{l}$ is the vector of $l$ individual-level variables that account for the socioeconomic and demographic factors that may impact preferences for redistribution. $Z_{j t-1}^{m}$ contains the $m$ country-specific characteristics. They are lagged by one period $(t-1)$ to address potential endogeneity concerns ${ }^{20}$ Robustness checks with two and three period lags are available (see 3.5). I include country-fixed-effects $\nu_{j}$, which capture unmeasured (and constant) differences across countries (e.g. the aggregated inequality aversion across countries). $\theta_{t}$ are the year-fixed-effects, which ensure that the results are not driven by shocks or business cycles that affect everyone in a given year. The error term $\epsilon_{i j t}$ is the idiosyncratic error term, which accounts for unobservable factors and measurement errors in the model. Since the focus of my research is on the general influence of the outlined variables, and as period- and country-level-fixed-effects are included, I apply a linear mode 21 and I provide

\footnotetext{
${ }^{20}$ For instance, preferences for redistribution could have a reverse causality effect on the net Gini coefficient. If individuals prefer redistribution, then the net Gini should be lower, implying a negative relationship between preferences and the net Gini. If we regress preferences on the net Gini without controlling for the possibility of reverse causality, then we might end up getting a negative coefficient on net Gini only because of the negative effect of preferences on the net Gini. Although lagging explanatory variables by one period might not remove potential endogeneity, it is the best possible strategy I could think of with the current data. I can not think of a corresponding instrument for inequality which is not correlated with redistribution. Suggestions are warmly welcome.

${ }^{21}$ Although the dependent variable is cardinal such that ordered logit or ordered probit models are often used, Riedl and Geishecker (2014) show that there is no consistent estimator for an ordered logit or probit model that can explicitly incorporate fixed effects to control for heterogeneity. Additionally, they compare ordered probit and logit estimates with linear estimators. If the researcher is mainly interested in relative effects, i.e. in ratios of parameter estimates, the method of choice is simply a linear model delivering the same results as e.g. a binary recoding scheme. In addition, Van Praag et al. (2010) use happiness data to show that the problem of not including fixed effects, such as cross-country differences, is much more severe than a bias ignoring cardinality/ordinality with linear estimation. This work follows these recommendations using a linear model.
} 
robustness estimates of an ordered probit (OP) model (see 3.5). Standard errors are clustered on the country-level and the data is weighted to correct for design effect 22

Equation (1) provides the basis for (H1). To test for systematic differences in fairness concerns related to hypothesis (H2 - H3), I include cross-level interaction terms of country-level variables and individual-level variables. I estimate interaction terms to see whether there is a systematic variation with respect to income and health status. To be more explicit, I estimate interaction terms of income and health with inequality (net and market) and with unemployment (average and youth unemployment rate) as well as with having children. Here is an example for the interaction term of inequality and income:

$$
y_{i j k t}=\alpha+\beta X_{i j t}^{l}+\gamma Z_{j t-1}^{m}+\delta\left(\operatorname{Gini}_{j t-1} \times \text { Income }_{i j t}\right)+\theta_{t}+\omega_{k}+\nu_{j}+\epsilon_{i j k t} .
$$

Note that with an interaction term, the partial effect of e.g. changes in inequality consists now of two terms $\frac{\partial y_{i j t}}{\partial \operatorname{Gini}_{j t-1}}=\gamma+\delta$ Income $_{i j t}$. The interaction terms, $\delta$, tell us how inequality changes differ by income. The partial derivative with respect to e.g. income depends on inequality: $\frac{\partial y_{i j t}}{\partial \operatorname{Income}_{i j t}}=$ $\beta+\delta \operatorname{Gini}_{j t-1}$.

Table A.7 summarizes the variables used.

\section{Results}

First, I describe the most relevant results followed by a discussion of the different inequality measures in Section 3.2, Section 3.5 confirms the robustness of the results.

\subsection{Baseline results}

Table 2 presents the results of the estimation (1). The inequality and unemployment variables are added separately (except for GDP) due to possible multicollinearity, which could lead to unstable

\footnotetext{
${ }^{22}$ There is no clear advice on how to adequately weight TSCS bESS survey data using standard estimation methods. The consulted literature does not propose a unique method to apply (European Social Survey, 2014, Gelman, 2007, Graubard and Korn, 1996). I follow the advice of European Social Survey (2014) using a combination of post-stratification weight. Post-stratification weights apply additional information to reduce the sampling error and potential non-response bias weights correct for the fact that most countries taking part in the ESS have different population sizes but similar sample sizes. For more details see European Social Survey (2014).
} 
estimates 23

On the country-level, the market Gini and youth unemployment both have a significant and positive effect on preferences for redistribution. This confirms H1: The higher inequality and youth unemployment is, the higher the demand for redistribution. The result confirms the MR model, where more market inequality is associated with more redistribution and adds to Houle (2017) who finds that market inequality is associated with more redistribution. General unemployment and the net Gini are not significant. This indicates that respondents might understand the question of the dependent variable in an absolute sense. With a marginal understanding, the relevant measure for inequality would be net inequality, not market inequality.

Estimating equation (1) when health and income are treated as continuous variables do not change the results (see table A.8). I conclude that fairness concerns matter in preferences for redistribution and are triggered, not only by rising market inequality, but also by high youth unemployment (H1).

To learn more about the underlying mechanism, I turn to the remaining hypotheses stating that fairness concerns depend on income level (H2) and health (H3). I first focus on the single effect of income and health as well as the main control variables. The MR model suggests the higher the income of an individual, the less he or she favors redistribution. Individuals with an income below the mean income level (the "poor") are in favor of redistribution, while the contrary is true for individuals with an "income higher than the mean" (the "rich"). An overall negative income effect has been confirmed empirically (e.g. Fong (2001); Yamamura (2012); Guillaud (2013); Kerr (2014); Pittau et al. (2013); Alesina and Ferrara (2005)). The specification with income in ten income quantiles allows me to evaluate the income effect relative to median income (with the fifth income class as reference category). The results reflect predictions of the MR model: Monetary incentives leading to being in favor of redistribution for the poor are positive, while they are negative for the rich, as figure (2a) illustrates. These results imply that people do take the effect of redistribution on their own income into account. Also the absolute size of the negative coefficient above the mean income class increases with income level.

\footnotetext{
${ }^{23}$ Coefficient standard errors could become inflated.
} 
Table 2: Baseline regression

\begin{tabular}{|c|c|c|c|c|c|c|c|c|c|c|c|c|}
\hline & \multicolumn{3}{|c|}{$\begin{array}{c}(1) \\
\text { Net Gini }\end{array}$} & \multicolumn{3}{|c|}{$\begin{array}{c}(2) \\
\text { Mkt. Gini }\end{array}$} & \multicolumn{3}{|c|}{$\begin{array}{c}(3) \\
\text { Unempl. }\end{array}$} & \multicolumn{3}{|c|}{$\begin{array}{c}(4) \\
\text { Y. unempl. }\end{array}$} \\
\hline & Coef. & Stdv. & $\mathrm{p}$ & Coef. & Stdv. & $\mathrm{p}$ & Coef. & Stdv. & $\mathrm{p}$ & Coef. & Stdv. & $\mathrm{p}$ \\
\hline Income: & & & & & & & & & & & & \\
\hline Income 1 & 0.031 & 0.018 & 0.104 & 0.030 & 0.018 & 0.113 & 0.031 & 0.019 & 0.118 & $0.033^{*}$ & 0.019 & 0.087 \\
\hline Income 2 & $0.048^{* * *}$ & 0.016 & 0.007 & $0.048^{* * *}$ & 0.016 & 0.006 & $0.049^{* * *}$ & 0.017 & 0.007 & $0.051^{* * *}$ & 0.017 & 0.005 \\
\hline Income 3 & $0.055^{* * *}$ & 0.016 & 0.002 & $0.055^{* * *}$ & 0.016 & 0.002 & $0.058^{* * *}$ & 0.015 & 0.001 & $0.058^{* * *}$ & 0.016 & 0.002 \\
\hline Income 4 & 0.010 & 0.018 & 0.603 & 0.010 & 0.018 & 0.600 & 0.010 & 0.018 & 0.606 & 0.018 & 0.017 & 0.290 \\
\hline Income 6 & -0.014 & 0.015 & 0.356 & -0.014 & 0.014 & 0.356 & -0.011 & 0.015 & 0.449 & -0.007 & 0.014 & 0.621 \\
\hline Income 7 & $-0.075^{* * *}$ & 0.020 & 0.001 & $-0.075^{* * *}$ & 0.020 & 0.001 & $-0.075^{* * *}$ & 0.020 & 0.001 & $-0.073^{* * *}$ & 0.020 & 0.001 \\
\hline Income 8 & $-0.088^{* * *}$ & 0.020 & 0.000 & $-0.088^{* * *}$ & 0.019 & 0.000 & $-0.086^{* * *}$ & 0.020 & 0.000 & $-0.083^{* * *}$ & 0.020 & 0.000 \\
\hline Income 9 & $-0.147^{* * *}$ & 0.022 & 0.000 & $-0.148^{* * *}$ & 0.022 & 0.000 & $-0.146^{* * *}$ & 0.023 & 0.000 & $-0.141^{* * *}$ & 0.022 & 0.000 \\
\hline Income 10 & $-0.326^{* * *}$ & 0.034 & 0.000 & $-0.326^{* * *}$ & 0.033 & 0.000 & $-0.323^{* * *}$ & 0.034 & 0.000 & $-0.323^{* * *}$ & 0.035 & 0.000 \\
\hline Health: & & & & & & & & & & & & \\
\hline Health 1 & $0.111^{* *}$ & 0.042 & 0.014 & $0.109^{* *}$ & 0.042 & 0.016 & $0.110^{* *}$ & 0.043 & 0.018 & $0.105^{* *}$ & 0.046 & 0.032 \\
\hline Health 2 & 0.020 & 0.017 & 0.259 & 0.019 & 0.017 & 0.270 & 0.019 & 0.017 & 0.275 & 0.011 & 0.018 & 0.557 \\
\hline Health 4 & $-0.065^{* * *}$ & 0.011 & 0.000 & $-0.065^{* * *}$ & 0.011 & 0.000 & $-0.064^{* * *}$ & 0.011 & 0.000 & $-0.066^{* * *}$ & 0.011 & 0.000 \\
\hline Health 5 & $-0.099^{* * *}$ & 0.018 & 0.000 & $-0.099 * * *$ & 0.018 & 0.000 & $-0.097^{* * *}$ & 0.018 & 0.000 & $-0.102^{* * *}$ & 0.018 & 0.000 \\
\hline Age & $0.003^{* * *}$ & 0.001 & 0.001 & $0.003^{* * *}$ & 0.001 & 0.001 & $0.003^{* * *}$ & 0.001 & 0.001 & $0.003^{* * *}$ & 0.001 & 0.002 \\
\hline Children & $0.055^{* * *}$ & 0.011 & 0.000 & $0.055^{* * *}$ & 0.011 & 0.000 & $0.055^{* * *}$ & 0.011 & 0.000 & $0.057^{* * *}$ & 0.010 & 0.000 \\
\hline Log household size & $0.053^{* * *}$ & 0.013 & 0.000 & $0.053^{* * *}$ & 0.013 & 0.000 & $0.051^{* * *}$ & 0.013 & 0.001 & $0.045^{* * *}$ & 0.011 & 0.000 \\
\hline Discr. & $0.144^{* * *}$ & 0.019 & 0.000 & $0.142^{* * *}$ & 0.018 & 0.000 & $0.142^{* * *}$ & 0.019 & 0.000 & $0.139^{* * *}$ & 0.019 & 0.000 \\
\hline Female & $0.140^{* * *}$ & 0.015 & 0.000 & $0.141^{* * *}$ & 0.015 & 0.000 & $0.140^{* * *}$ & 0.015 & 0.000 & $0.141^{* * *}$ & 0.016 & 0.000 \\
\hline Ever had a paid job & $0.151^{* * *}$ & 0.053 & 0.008 & $0.107^{*}$ & 0.057 & 0.070 & $0.148^{* * *}$ & 0.050 & 0.006 & $0.145^{* * *}$ & 0.047 & 0.005 \\
\hline metro area & -0.013 & 0.018 & 0.460 & -0.012 & 0.018 & 0.502 & -0.013 & 0.018 & 0.493 & -0.010 & 0.018 & 0.596 \\
\hline Self-empl. & $-0.143^{* * *}$ & 0.026 & 0.000 & $-0.144^{* * *}$ & 0.026 & 0.000 & $-0.143^{* * *}$ & 0.027 & 0.000 & $-0.136^{* * *}$ & 0.026 & 0.000 \\
\hline Advent. & $-0.037^{* * *}$ & 0.010 & 0.001 & $-0.036^{* * *}$ & 0.010 & 0.001 & $-0.039^{* * *}$ & 0.010 & 0.001 & $-0.036^{* * *}$ & 0.010 & 0.002 \\
\hline Social mobility & -0.050 & 0.057 & 0.388 & -0.046 & 0.055 & 0.409 & -0.042 & 0.056 & 0.453 & $-0.102^{*}$ & 0.052 & 0.061 \\
\hline Years of educ. & $-0.010^{* * *}$ & 0.002 & 0.000 & $-0.010^{* * *}$ & 0.002 & 0.000 & $-0.010^{* * *}$ & 0.002 & 0.000 & $-0.011^{* * *}$ & 0.002 & 0.000 \\
\hline L.1 GDP_pC_US & -0.000 & 0.000 & 0.454 & -0.000 & 0.000 & 0.434 & -0.000 & 0.000 & 0.356 & -0.000 & 0.000 & 0.529 \\
\hline L.1 gini_disp & 0.014 & 0.031 & 0.669 & & & & & & & & & \\
\hline L.1 gini_mkt & & & & $0.039^{* *}$ & 0.016 & 0.023 & & & & & & \\
\hline L.1 unempl_m & & & & & & & 0.007 & 0.005 & 0.208 & & & \\
\hline L.1 yunempl_m & & & & & & & & & & $0.005^{* *}$ & 0.002 & 0.015 \\
\hline $\mathrm{r} 2$ & 0.1561 & & & 0.1566 & & & 0.1567 & & & 0.1569 & & \\
\hline $\mathrm{N}$ & 84252 & & & 84252 & & & 82809 & & & 80883 & & \\
\hline Year FE & $\checkmark$ & & & $\checkmark$ & & & $\checkmark$ & & & $\checkmark$ & & \\
\hline Country FE & $\checkmark$ & & & $\checkmark$ & & & $\checkmark$ & & & $\checkmark$ & & \\
\hline Region FE & $\checkmark$ & & & $\checkmark$ & & & $\checkmark$ & & & $\checkmark$ & & \\
\hline Add. controls & $\checkmark$ & & & $\checkmark$ & & & $\checkmark$ & & & $\checkmark$ & & \\
\hline
\end{tabular}

Note: The table shows the results estimating equation (1). The dependent variable is preference for redistribution. The fifth income class and the fair health class serve as the reference category. Additional controls are the martial status, the occupation type, religion and the current main activity, which are included. Data is weighted (design weight). Standard errors are clustered on the country level.*** Significant at the $1 \%$ level.** Significant at the $5 \%$ level.* Significant at the $10 \%$ level. 


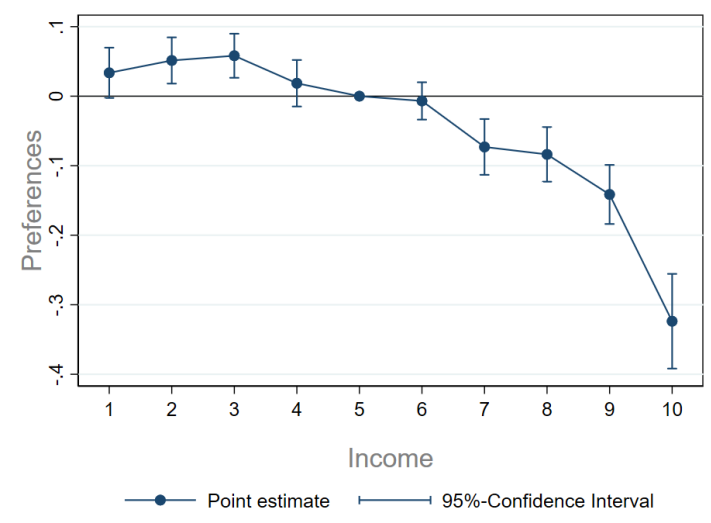

(a) Income effect

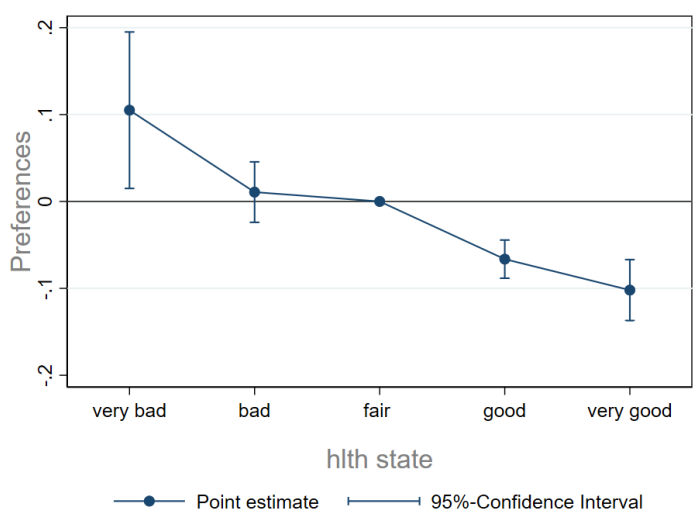

(b) Health effect

Figure 2: The effect of income and health on preferences for redistribution. Note: The graphs show point estimates and $95 \%$ confidence intervals from the estimation results presented in table 2 .

A positive subjective health decreases the demand for redistribution, while the contrary is true for individuals who are in a poor health state (using "fair" health state as reference category), see figure $2 \mathrm{~b}$. The effect shows that if someone has a poor health condition, there is a higher demand for redistribution. The worse the health, the stronger the effect is, i.e. the coefficient of "very bad" is bigger than the coefficient of being in a bad health state. Ill people have higher health costs and are more dependent on transfer payments than healthy people.

Results for further control variables are as follows. Having children is associated with a higher level of support for redistribution (significant on the $5 \%$ level), see table 2 . The interaction term of

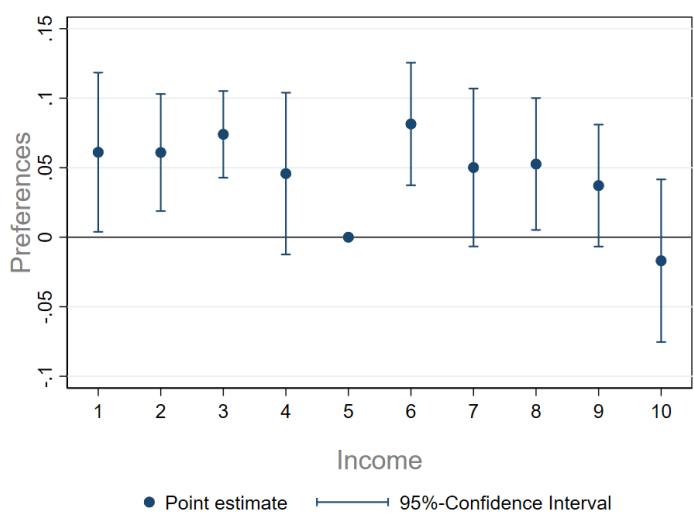

(a) Interaction having children and income

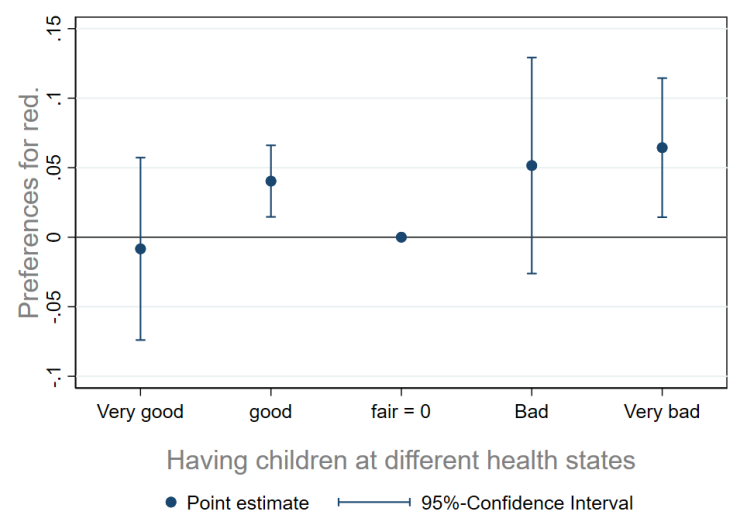

(b) Interaction having children and health

Figure 3: The effect of having children. Note: Values are calculated using the results of table A.11 in which interaction terms are included. Figure 3a shows the calculation of the total "having children" at different income levels and figure 3b shows the calculation of the total "having children" at different health levels.

"having children" with income reveals that the effect of having children is positive for net recipients, 
i.e. here the first - seventh income class. In contrast, for net payers (8th - 10th income class), the effect is not significant ${ }^{24}$ The interaction with health shows that individuals in a good health state who have children, have an increasing demand for redistribution. Effects for other health states are insignificant. The result controls for income and shows that being ill and having children both are costly, so a net payer would want to redistribute less, and a net recipient would want to redistribute more.

The effects of proxies for being self-interested are consistent with theoretical predictions (Piketty, 1995) and previous empirical work (Alesina and Ferrara, 2005; Alesina and Giuliano, 2011a; Fong, 2001; Pittau et al., 2013). Being unemployed increases preferences for redistribution strongly. As expected, being risk-loving, measured by being self-employed as well as being adventurous, significantly decreases the wish for redistribution. I interpret the effects of risk aversion (the contrary of risk-loving), health status, as well as personal unemployment as the insurance effect of the welfare state (Sinn (1995)), i.e. increasing demand for the insurance of individuals due to lower expected income. In contrast to the expectations, the proxy for social mobility is not significant. Alesina and Ferrara (2005) found a positive influence of educational achievements interpreted as social mobility 25 The results for included demographic controls are in line with previous work Alesina and Ferrara, 2005; Fong, 2001; Alesina and Giuliano, 2011a; Pittau et al., 2013). Consistent with other studies, being female and belonging to a minority ethnic group (discrimination) in the country increases the demand for redistribution. Being married is not significant. Education is highly significant, with an additional year of education in comparison to average education, the preferences for redistribution decreases. Prospects of upward mobility stemming from higher education could serve as an explanation.

\subsection{Income-- and health-dependent fairness concerns}

Table 3 presents the result of estimating the interaction terms with respect to income. The core results of table 3 are plotted in figure 4.

\footnotetext{
${ }^{24}$ The effect of having children may be related to other things such as altruism or frustration that goes beyond having higher expenses.

${ }^{25}$ Difference in education levels from previous generations might be a weak proxy for general overall trends toward higher education. With the average age of 47.5 in the data set, there is, in addition, the possibility that education levels of the parental generation are biased due to the Second World War.
} 


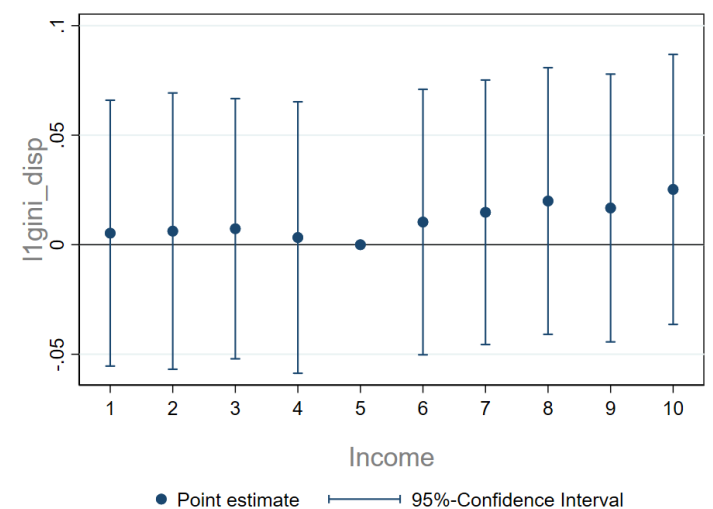

(a) The effect of net Gini at different income levels

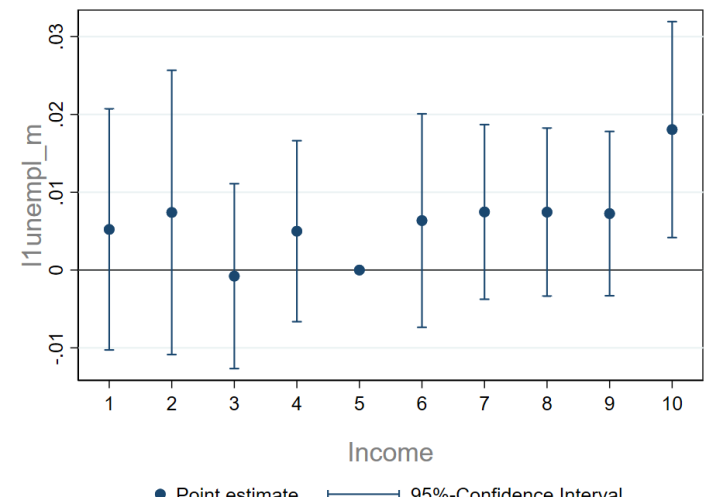

(c) The effect of unemployment at different income levels

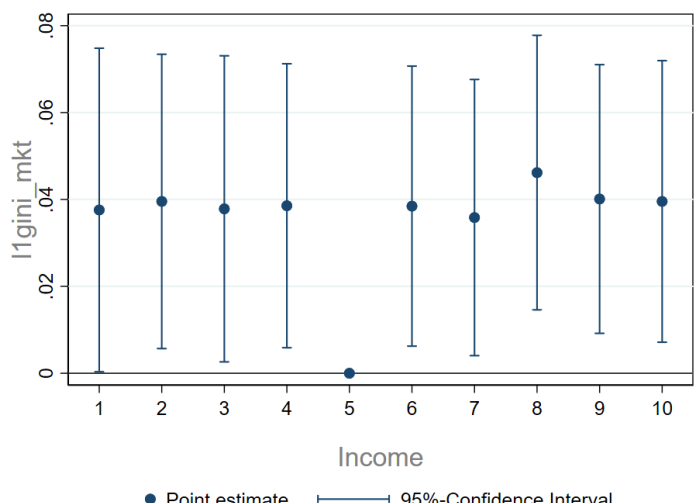

(b) The effect of market Gini at different income levels

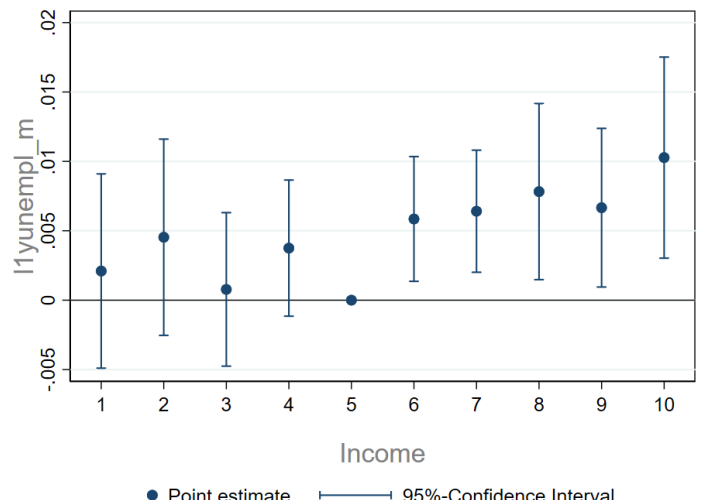

(d) The effect of youth unemployment at different income levels

Figure 4: Income interaction terms. Note: Values are calculated using the results of table 3 in which interaction terms are included. Figure 4a shows the calculation of the total net Gini effect at different income levels, column (1) of 3 . Figure 4b presents calculations of total market Gini effect, column (2) of 3 and figure $4 \mathrm{c}$ and $4 \mathrm{~d}$ display calculations of total (youth) unemployment effect, column (3) and $(4)$. 
The total effect of net income inequality for different income levels (i.e. the partial derivative with respect to the net Gini, which depends on income level) presented in figure 4a shows no significant effect. The total effect of the market Gini (figure 4b) illustrates that all income classes increase the demand for redistribution, when market inequality rises.

The interaction term with income and overall unemployment is only significant at the 10th income class (see figure 4c). With youth unemployment, the effect is even stronger, see figure 4d, which illustrates the effect of youth unemployment at different income classes. The coefficient for the poor is not significant. But above the mean income class, the effect is positive and significant. Alesina and Angeletos (2005) show that higher fairness concerns lead to a higher level of redistribution as individuals expect the government to intervene and correct economic outcomes when they feel that social competition is unfair. Results show that only the rich care about rising youth unemployment but not unemployment in general. This can be explained by the fact that youth unemployment is generally not conceived as a sign of a missing willingness to work but rather an economic and institutional failure. Youth unemployment moderates the richs opposition against redistribution. So in the case of youth unemployment, i.e. inequality which is the result of bad luck rather than lacking effort, the rich seem to have more fairness concerns.

H2 is supported by the evidence ${ }^{26}$ I interpret the positive effect of unemployment at the 10th income class and youth unemployment of the rich as fairness concerns. If one is well off (in terms of income), there is capacity to take care of others and deal with social problems since one has to worry less about one's own condition. Further discussion and analysis of the different inequality measures is given in 3.2 . The findings are in line with Hoechtl et al. (2012) who have shown in an experiment that inequality aversion matters more for redistribution outcomes in majority voting with a rich majority than with a poor majority. In addition, the findings support the theory of "incomedependent altruism" (Dimick et al., 2016) for Europe.

An alternative explanation would be that risk aversion matters, but not fairness concerns. Changes

\footnotetext{
${ }^{26}$ Note that the data demonstrates effects of "mean preserving" increases in inequality. To be precise, if inequality increases, there are more people that have an income of less than the mean, and more people that have an income higher than the mean one. I cannot capture this change in absolute income as I am using TSCS data and not panel data where I could track individuals over time and see this change. I do compare the deciles with the 5th income class, which are calculated for every period.
} 
in youth unemployment could be interpreted as increasing the risk of an unstable income and might thus increase the demand for social insurance. Two arguments are against this interpretation. First, the regression controls for risk aversion. Second, this effect should then be highly positive for the poor and not only for the top income classes. Only post-transfer inequality matters to the rich, which reflects the income distribution translating into available income for consumption. If the poor, despite redistribution, can afford little, this triggers fairness concerns. I conclude that fairness concerns matter in preference for redistribution 27 One further point to consider is that the elderly drive the effect due to pensions. Figure $10 \mathrm{~b}$ plots the point estimates, excluding pensioners, from the sample - the effect is still positive and significant for the rich.

As $H 3$ states, the degree of fairness concerns might not only depend on the level of income, but on the health as well. Table 4 presents the estimation results for interaction terms with health state and figure 5 plots the marginal effects.

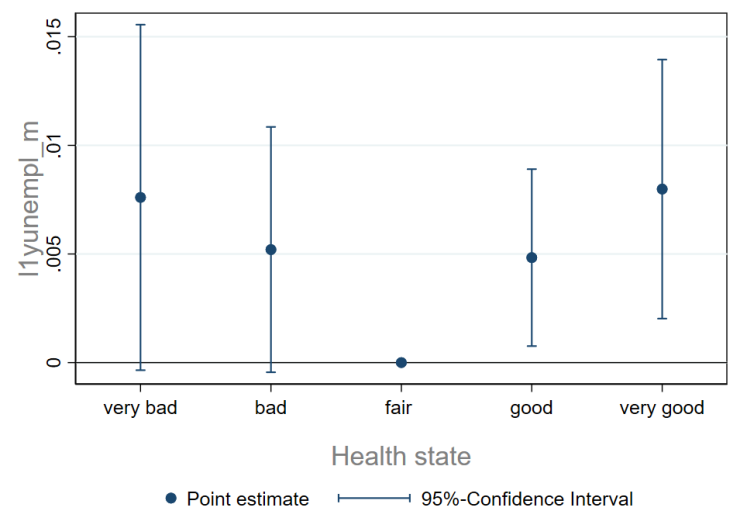

(a) The effect of youth unemployment at different states of health

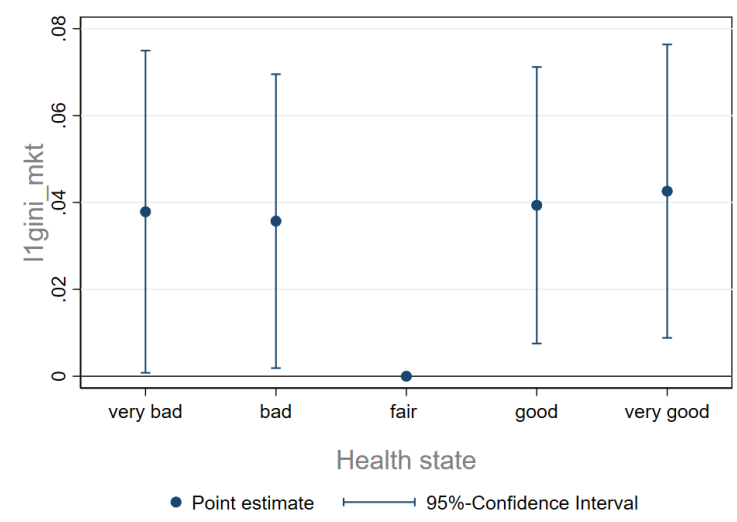

(b) The effect of market Gini at different states of health

Figure 5: Health interaction terms. Note: Values are calculated using the results of table 4 in which interaction terms are included. Figure 5a shows the calculation of the total youth unemployment effect for different states of health, column (2) of 4 . Figure $5 \mathrm{~b}$ presents calculations of total market Gini, column (3) of 4 .

The total effect of unemployment does not show significant heterogeneity with respect to the health state (see figure 11). However, the total effect of marekt income inequality in figure $5 \mathrm{~b}$ shows a positive and significant coefficient for every health state. This indicates that being in a very good

\footnotetext{
${ }^{27}$ It is also possible that the rich are only interested in reducing inequality because otherwise there will be political uprising and unrest. I address this concern in 3.5
} 
Table 3: Income interaction results

\begin{tabular}{|c|c|c|c|c|c|c|c|c|c|c|c|c|}
\hline & \multicolumn{3}{|c|}{$\begin{array}{c}(1) \\
\text { Net Gini }\end{array}$} & \multicolumn{3}{|c|}{$\begin{array}{c}(2) \\
\text { Mkt. Gini }\end{array}$} & \multicolumn{3}{|c|}{$\begin{array}{c}(3) \\
\text { Unempl. }\end{array}$} & \multicolumn{3}{|c|}{$\begin{array}{c}\text { (4) } \\
\text { Y. unempl. }\end{array}$} \\
\hline & Coef. & Stdv. & $\mathrm{p}$ & Coef. & Stdv. & $\mathrm{p}$ & Coef. & Stdv. & $\mathrm{p}$ & Coef. & Stdv. & $\mathrm{p}$ \\
\hline Income 1 & $0.243^{* *}$ & 0.090 & 0.012 & 0.111 & 0.156 & 0.486 & 0.022 & 0.026 & 0.392 & 0.050 & 0.031 & 0.121 \\
\hline Income 2 & $0.236^{* *}$ & 0.097 & 0.022 & 0.035 & 0.234 & 0.882 & 0.024 & 0.037 & 0.526 & 0.027 & 0.038 & 0.485 \\
\hline Income 3 & $0.211^{* *}$ & 0.085 & 0.020 & 0.124 & 0.198 & 0.536 & $0.095^{* *}$ & 0.037 & 0.015 & $0.096^{* *}$ & 0.039 & 0.020 \\
\hline Income 4 & $0.281 * * *$ & 0.087 & 0.003 & 0.044 & 0.166 & 0.794 & 0.002 & 0.035 & 0.950 & 0.007 & 0.032 & 0.827 \\
\hline Income 6 & 0.052 & 0.094 & 0.586 & 0.025 & 0.201 & 0.902 & -0.029 & 0.029 & 0.330 & -0.052 & 0.031 & 0.101 \\
\hline Income 7 & -0.138 & 0.095 & 0.155 & 0.089 & 0.261 & 0.736 & $-0.101^{* *}$ & 0.039 & 0.015 & $-0.128^{* * *}$ & 0.045 & 0.008 \\
\hline Income 8 & $-0.299^{*}$ & 0.152 & 0.060 & $-0.419 *$ & 0.212 & 0.058 & $-0.112^{* *}$ & 0.051 & 0.039 & $-0.161^{* * *}$ & 0.058 & 0.010 \\
\hline Income 9 & -0.267 & 0.163 & 0.114 & -0.188 & 0.238 & 0.438 & $-0.170^{* * *}$ & 0.049 & 0.002 & $-0.200^{* * *}$ & 0.056 & 0.001 \\
\hline Income 10 & $-0.691 * * *$ & 0.233 & 0.006 & -0.339 & 0.463 & 0.470 & $-0.426^{* * *}$ & 0.069 & 0.000 & $-0.439^{* * *}$ & 0.074 & 0.000 \\
\hline L.1 gini_disp & 0.013 & 0.031 & 0.687 & & & & & & & & & \\
\hline Income $1 \times$ L.1 gini_disp & $-0.007^{* *}$ & 0.003 & 0.012 & & & & & & & & & \\
\hline Income $2 \times$ L. 1 gini_disp & $-0.006^{*}$ & 0.003 & 0.072 & & & & & & & & & \\
\hline Income $3 \times$ L.1 gini_disp & $-0.005^{*}$ & 0.003 & 0.052 & & & & & & & & & \\
\hline Income $4 \times$ L.1 gini_disp & $-0.009^{* * *}$ & 0.003 & 0.003 & & & & & & & & & \\
\hline Income $6 \times$ L.1 gini_disp & -0.002 & 0.003 & 0.500 & & & & & & & & & \\
\hline Income $7 \times$ L.1 gini_disp & 0.002 & 0.003 & 0.501 & & & & & & & & & \\
\hline Income $8 \times$ L.1 gini_disp & 0.007 & 0.005 & 0.178 & & & & & & & & & \\
\hline Income $9 \times$ L.1 gini_disp & 0.004 & 0.006 & 0.481 & & & & & & & & & \\
\hline Income $10 \times$ L.1 gini_disp & 0.013 & 0.008 & 0.141 & & & & & & & & & \\
\hline L.1 gini_mkt & & & & $0.039 * *$ & 0.018 & 0.035 & & & & & & \\
\hline Income $1 \times$ L. 1 gini_mkt & & & & -0.002 & 0.003 & 0.610 & & & & & & \\
\hline Income $2 \times$ L.1 gini_mkt & & & & 0.000 & 0.005 & 0.957 & & & & & & \\
\hline Income $3 \times$ L.1 gini_mkt & & & & -0.001 & 0.004 & 0.724 & & & & & & \\
\hline Income $4 \times$ L.1 gini_mkt & & & & -0.001 & 0.003 & 0.837 & & & & & & \\
\hline Income $6 \times$ L.1 gini_mkt & & & & -0.001 & 0.004 & 0.850 & & & & & & \\
\hline Income $7 \times$ L.1 gini_mkt & & & & -0.003 & 0.006 & 0.545 & & & & & & \\
\hline Income $8 \times$ L.1 gini_mkt & & & & 0.007 & 0.004 & 0.136 & & & & & & \\
\hline Income $9 \times$ L. 1 gini_mkt & & & & 0.001 & 0.005 & 0.870 & & & & & & \\
\hline Income $10 \times$ L. 1 gini_mkt & & & & 0.000 & 0.010 & 0.978 & & & & & & \\
\hline L.1 unempl_m & & & & & & & 0.004 & 0.007 & 0.561 & & & \\
\hline Income $1 \times$ L.1 unempl_m & & & & & & & 0.001 & 0.003 & 0.683 & & & \\
\hline Income $2 \times$ L.1 unempl_m & & & & & & & 0.003 & 0.004 & 0.444 & & & \\
\hline Income $3 \times$ L.1 unempl_m & & & & & & & -0.005 & 0.004 & 0.190 & & & \\
\hline Income $4 \times$ L.1 unempl_m & & & & & & & 0.001 & 0.004 & 0.791 & & & \\
\hline Income $6 \times$ L.1 unempl_m & & & & & & & 0.002 & 0.003 & 0.399 & & & \\
\hline Income $7 \times$ L.1 unempl_m & & & & & & & 0.003 & 0.005 & 0.457 & & & \\
\hline Income $8 \times$ L.1 unempl_m & & & & & & & 0.003 & 0.006 & 0.591 & & & \\
\hline Income $9 \times$ L.1 unempl_m & & & & & & & 0.003 & 0.006 & 0.622 & & & \\
\hline Income $10 \times$ L.1 unempl_m & & & & & & & 0.014 & 0.009 & 0.142 & & & \\
\hline L.1 yunempl_m & & & & & & & & & & 0.003 & 0.003 & 0.255 \\
\hline Income 1 × L.1 yunempl_m & & & & & & & & & & -0.001 & 0.002 & 0.603 \\
\hline Income $2 \times$ L.1 yunempl_m & & & & & & & & & & 0.001 & 0.002 & 0.503 \\
\hline Income 3 × L.1 yunempl_m & & & & & & & & & & -0.002 & 0.002 & 0.221 \\
\hline Income $4 \times$ L.1 yunempl_m & & & & & & & & & & 0.001 & 0.002 & 0.707 \\
\hline Income $6 \times$ L.1 yunempl_m & & & & & & & & & & $0.003^{*}$ & 0.002 & 0.075 \\
\hline Income 7 × L.1 yunempl_m & & & & & & & & & & 0.003 & 0.002 & 0.159 \\
\hline Income 8 × L.1 yunempl_m & & & & & & & & & & 0.005 & 0.004 & 0.206 \\
\hline Income $9 \times$ L.1 yunempl_m & & & & & & & & & & 0.004 & 0.004 & 0.322 \\
\hline Income $10 \times$ L. 1 yunempl_m & & & & & & & & & & 0.007 & 0.004 & 0.121 \\
\hline $\mathrm{r} 2$ & 0.1570 & & & 0.1566 & & & 0.1568 & & & 0.1572 & & \\
\hline $\mathrm{N}$ & 84252 & & & 84252 & & & 82809 & & & 80883 & & \\
\hline Year FE & $\checkmark$ & & & $\checkmark$ & & & $\checkmark$ & & & $\checkmark$ & & \\
\hline Country FE & $\checkmark$ & & & $\checkmark$ & & & $\checkmark$ & & & $\checkmark$ & & \\
\hline Region FE & $\checkmark$ & & & $\checkmark$ & & & $\checkmark$ & & & $\checkmark$ & & \\
\hline All controls & $\checkmark$ & & & $\checkmark$ & & & $\checkmark$ & & & $\checkmark$ & & \\
\hline
\end{tabular}

Note: The table shows the results estimating equation (2). Data is weighted (design weight). The fifth income class and the fair health class serve as the reference category. All available controls are included with additional controls such as the martial status, the occupation type, religion and the current main activity, which are included. Standard errors are clustered on the country level.*** Significant at the $1 \%$ level.** Significant at the $5 \%$ level.* Significant at the $10 \%$ level. 
and good health state increases the demand for redistribution when inequality rises, although being healthy decreases the demand for redistribution. The total effect of youth unemployment shows a significant and positive effect for the healthy ones, whereas being sick, the effect is not significant. The pattern is very similar and related to income-dependent fairness concerns: when one is unhealthy and is rather preoccupied with ones' own situation, one has no interest in worrying about about social problems, since an illness can result in self-preoccupation. When, on the other hand, one is healthy, one has enough capacity to deal with social problems. In contrast, the positive partial derivative of inequality for individuals with a "very good" health state is consistent with "health-dependent fairness concerns", triggered by changes in market inequality (H3).

Table 4: Health interactions

\begin{tabular}{|c|c|c|c|c|c|c|c|c|c|c|c|c|}
\hline & \multicolumn{3}{|c|}{ (1) } & \multicolumn{3}{|c|}{$\overline{(2)}$} & \multicolumn{3}{|c|}{ (3) } & \multicolumn{3}{|c|}{$\overline{(4)}$} \\
\hline & Coef. & Stdv. & $\mathrm{p}$ & Coef. & Stdv. & $\mathrm{p}$ & Coef. & Stdv. & $\mathrm{p}$ & Coef. & Stdv. & $\mathrm{p}$ \\
\hline Health 1 & 0.098 & 0.225 & 0.666 & 0.119 & "0.349 & 0.736 & 0.017 & 0.082 & 0.835 & 0.033 & 0.110 & 0.765 \\
\hline Health 2 & 0.071 & 0.150 & 0.640 & 0.137 & 0.211 & 0.523 & 0.009 & 0.031 & 0.776 & -0.012 & 0.028 & 0.684 \\
\hline Health 4 & $-0.142^{* *}$ & 0.061 & 0.026 & -0.118 & 0.180 & 0.517 & $-0.060^{*}$ & 0.031 & 0.063 & $-0.077^{* *}$ & 0.032 & 0.023 \\
\hline Health 5 & $-0.369^{* *}$ & 0.138 & 0.013 & -0.309 & 0.327 & 0.353 & $-0.128^{* *}$ & 0.049 & 0.015 & $-0.163^{* * *}$ & 0.049 & 0.003 \\
\hline L.1 gini_disp & 0.011 & 0.031 & 0.720 & & & & & & & & & \\
\hline Health $1 \times$ L.1 gini_disp & 0.000 & 0.007 & 0.969 & & & & & & & & & \\
\hline Health $2 \times$ L. 1 gini_disp & -0.002 & 0.005 & 0.733 & & & & & & & & & \\
\hline Health $4 \times$ L.1 gini_disp & 0.003 & 0.002 & 0.193 & & & & & & & & & \\
\hline Health $5 \times$ L. 1 gini_disp & $0.010^{*}$ & 0.005 & 0.076 & & & & & & & & & \\
\hline L.1 gini_mkt & & & & $0.038^{* *}$ & 0.017 & 0.029 & & & & & & \\
\hline Health $1 \times$ L. 1 gini_mkt & & & & -0.000 & 0.007 & 0.963 & & & & & & \\
\hline Health $2 \times$ L.1 gini_mkt & & & & -0.002 & 0.004 & 0.566 & & & & & & \\
\hline Health $4 \times$ L.1 gini_mkt & & & & 0.001 & 0.004 & 0.763 & & & & & & \\
\hline Health $5 \times$ L. 1 gini_mkt & & & & 0.004 & 0.007 & 0.531 & & & & & & \\
\hline L.1 unempl_m & & & & & & & 0.006 & 0.006 & 0.338 & & & \\
\hline Health $1 \times$ L.1 unempl_m & & & & & & & 0.010 & 0.008 & 0.199 & & & \\
\hline Health $2 \times$ L.1 unempl_m & & & & & & & 0.001 & 0.003 & 0.762 & & & \\
\hline Health $4 \times$ L.1 unempl_m & & & & & & & -0.000 & 0.004 & 0.921 & & & \\
\hline Health $5 \times$ L.1 unempl_m & & & & & & & 0.004 & 0.007 & 0.527 & & & \\
\hline L.1 yunempl_m & & & & & & & & & & $0.004^{*}$ & 0.002 & 0.096 \\
\hline Health $1 \times$ L. 1 yunempl_m & & & & & & & & & & 0.003 & 0.004 & 0.369 \\
\hline Health $2 \times$ L.1 yunempl_m & & & & & & & & & & 0.001 & 0.001 & 0.414 \\
\hline Health $4 \times$ L.1 yunempl_m & & & & & & & & & & 0.001 & 0.002 & 0.711 \\
\hline Health $5 \times$ L.1 yunempl_m & & & & & & & & & & 0.004 & 0.003 & 0.255 \\
\hline $\mathrm{r} 2$ & 0.1538 & & & 0.1541 & & & 0.1542 & & & 0.1544 & & \\
\hline $\mathrm{N}$ & 84252 & & & 84252 & & & 82809 & & & 80883 & & \\
\hline Year FE & $\checkmark$ & & & $\checkmark$ & & & $\checkmark$ & & & $\checkmark$ & & \\
\hline Country FE & $\checkmark$ & & & $\checkmark$ & & & $\checkmark$ & & & $\checkmark$ & & \\
\hline Region FE & $\checkmark$ & & & $\checkmark$ & & & $\checkmark$ & & & $\checkmark$ & & \\
\hline All controls & $\checkmark$ & & & $\checkmark$ & & & $\checkmark$ & & & $\checkmark$ & & \\
\hline
\end{tabular}

Note: The table shows results estimating equation (2). Data is weighted (design weight). All available controls are included with additional controls such as the martial status, the occupation type, religion and the current main activity, which are included. Standard errors are clustered on the country level.*** Significant at the $1 \%$ level.** Significant at the $5 \%$ level.* Significant at the $10 \%$ level.

The causality could also be reversed: If the dependent variable question is understood in an absolute sense, societies who are more willing to redistribute (and have consequently less inequality) 
could be healthier (see Smith (1999) for a discussion). However, if the more equal societies are healthier, then I would expect the overall coefficient for "being healthy" to be positive as well. But the effect is negative (see also table 22). Furthermore, all EU countries have government-subsidized health insurance. Thus, due to the universal health care in the EU, I exclude the possibility of reverse causality 28

Fairness concerns, measured by the general interest in "helping others" complement H2 and H3. I estimate a series of interaction terms for "helping others" and "volunteering" with "health" and "income." Table A.10 presents the results and figure 6 illustrates marginal effects for helping others at different states of health and income.

Fairness concerns, measured by "helping others" (column 1), have a positive and significant effect on preferences for redistribution. If there is a general interest in helping others, i.e. if it is not relevant who is the benefactor, but only the final result counts (that the disadvantaged will be helped), the positive effect is in line with the predictions. Fairness concerns, measured by "helping others", increase preferences for redistribution. The effect is higher for the rich than for the poor, (i.e. the partial derivative with respect to "helping others" which depends on income), see figure 6a. For the very poor, the effect is not significant. Similarly, the fairness concerns of the healthy are significantly higher than the fairness concerns of the sick (column 3), see figure 6b. Results are consistent with "income and health-dependent fairness concerns".

The effect of "volunteering" does not vary significantly with health nor with income.

\subsection{What would the rich and healthy finally vote for?}

Results show that income-- and health-dependent fairness concerns exist and counteract monetary incentives to vote for redistribution. To see if a certain level of inequality or (youth) unemployment may negate income and health effects, I calculate the income and health effect at the respective lowest

\footnotetext{
${ }^{28}$ Furthermore, Smith $(1999)$ investigates the hypothesis that inequality has a negative influence on health and does not find evidence. Deaton (2003) complements this finding and provides evidence that it is not true that income inequality itself is a major determinant of a population's health. It is rather poverty which has an effect on the health of the poor and not the rich becoming richer.
} 


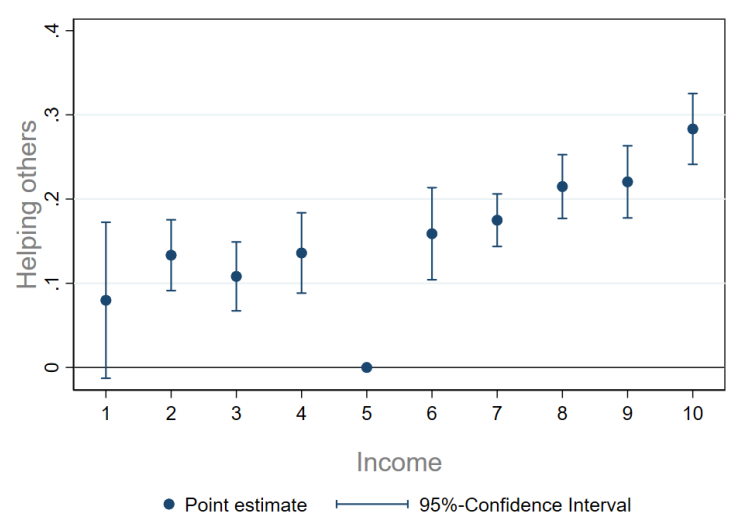

(a) The effect of "helping others" at different income levels

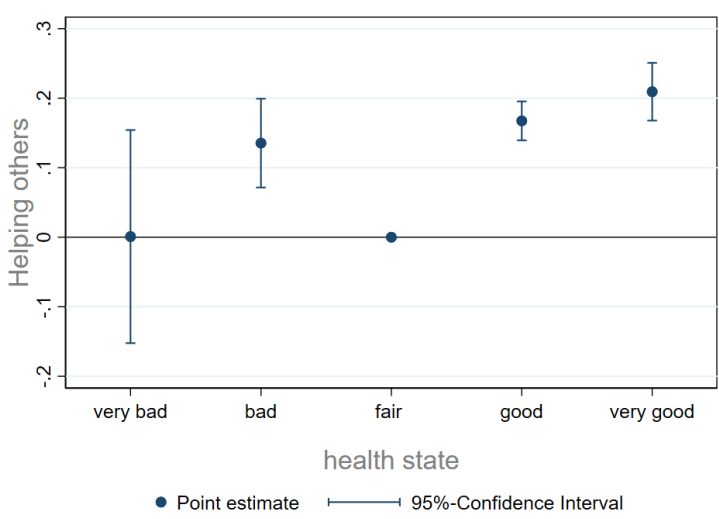

(b) The effect of "helping others" at different health levels

Note: Values are calculated using the results of table A.10 in which interaction terms are included. Figure 6a shows calculation of the total "helping others" at different income levels. Figure 6b presents calculations of total "helping others" effect at different states of health.

and highest levels of income inequality and (youth) unemployment presented in figure $7^{29}$

The income effect evaluated at lowest and highest net income inequality levels for the rich respondents is always negative, see figure $7 \mathrm{~b}$. For the lowest net Gini level (red area), the effect is more negative than for the highest level (blue area). At a high net income inequality rate, the effect is not significant. At high levels of net income inequality, even the rich might vote in favor of redistribution. Figure $7 \mathrm{a}$ shows that different levels of the market Gini do not change the income effect significantly - there is no variation with respect to highest and lowest market Gini levels.

The effect of income evaluated at different youth unemployment levels adds to this (figure $7 \mathrm{c}$ ). At low youth unemployment rates (red area), the income effect is negative. However, at very high youth unemployment rates (blue area), even the relatively rich have a demand for redistribution (6th - 8th income class).

Figure 8 presents the effect of the health, evaluated at the lowest and highest level of youth unemployment, to see which levels might change the sign of the different health.

At low levels of youth unemployment (red areas), being in a good health state has a significant

\footnotetext{
${ }^{29}$ I focus on the two extreme values (min and $\max$ ) to illustrate if someone could be in favor of redistribution at very high inequality and youth unemployment levels. I do not know how people perceive inequality and youth unemployment, but I assume that at very extreme values, the level of inequality or youth unemployment is probably much more noticeable than at medium levels.
} 


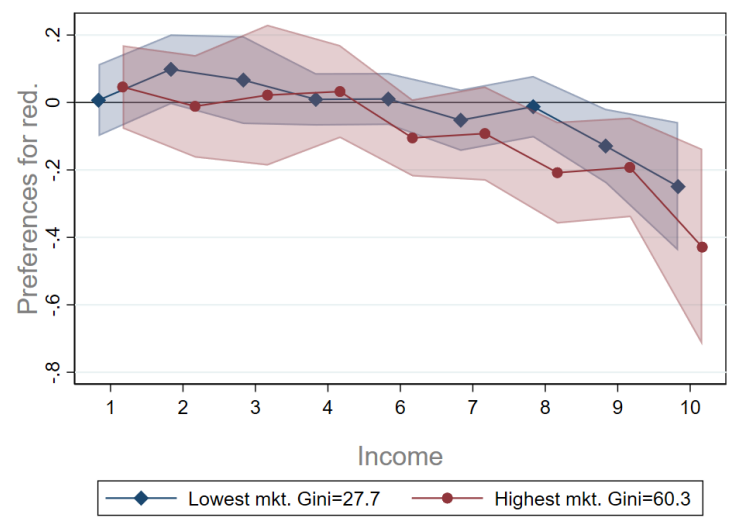

(a) Income effect at market Gini levels

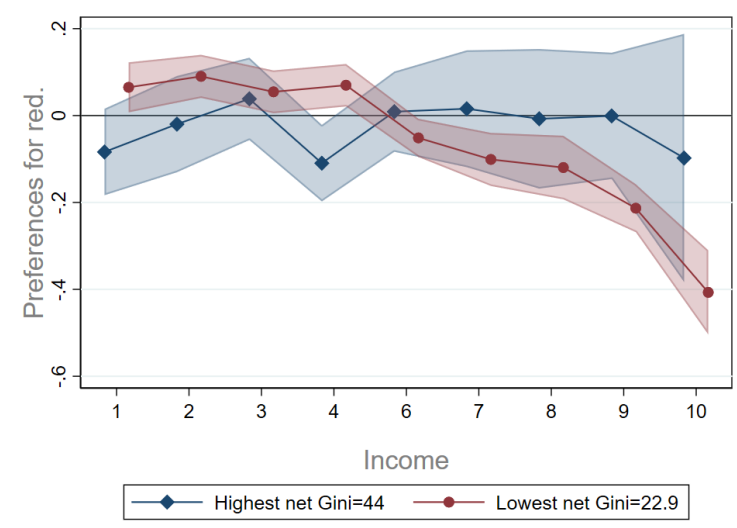

(b) Income effect at net Gini levels

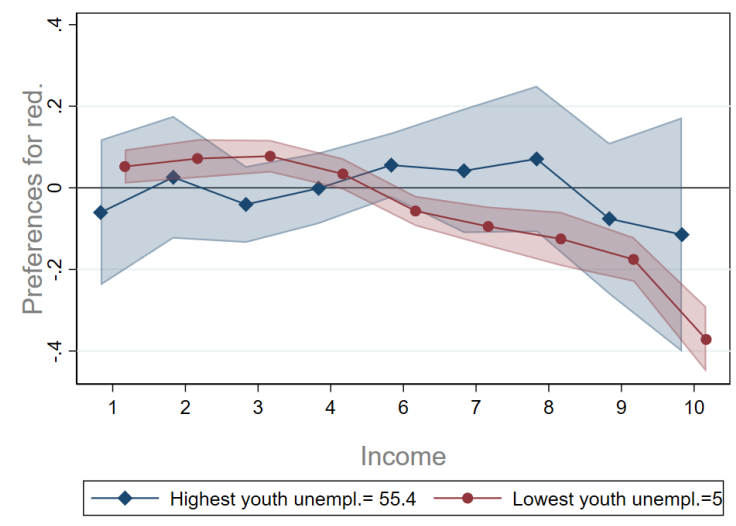

(c) Income effect at youth unemployment levels

Figure 7: Income effects evaluated at highest and lowest market / net Gini and youth unemployment levels. Note: The graphs show point estimates and $90 \%$ confidence intervals from the estimation results presented in table 3 . The shaded areas indicate the $90 \%$ pointwise confidence bands and the circles point estimates.

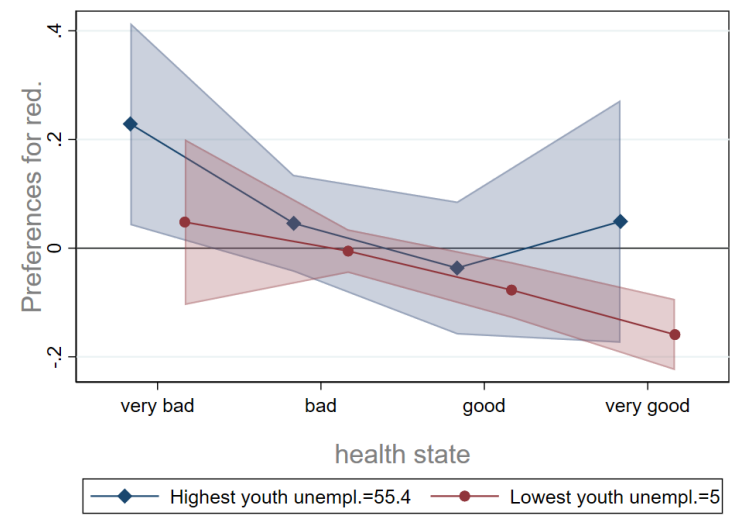

(a) The effect of health at different youth unemployment levels

Figure 8: Health interaction terms. Note: Values are calculated using the results of table 4 in which interaction terms are included. The shaded areas indicate the $90 \%$ pointwise confidence bands and the circles point estimates. 
negative effect on preferences for redistribution ( see figure 8a). However, at high levels of youth unemployment, the point estimates show a positive and insignificant effect. Fairness concerns and the self-centered motive, which potentially drive the effect of health on preferences for redistribution, might cancel each other out.

Health, when evaluated at different unemployment or inequality levels does not reveal any different pattern (figure 15).

\subsection{Different measures of inequality}

Inequality is associated with higher preferences for redistribution. However, more complexity lies behind this statement. One has to decide if the calculations of income inequality include government help, which could moderate the change (market vs. net income inequality). Furthermore, it is not clear which monetary inequalities (wealth or income) between whom matter, i.e. the poor and the middle class, the middle class and the wealthy, or the $99 \%$ and the $1 \%$ ?

The results show that market inequality matters in preference for redistribution, but not net income inequality. To learn more about the differences in inequality measures, I use an additional pre-tax/ pre-redistribution indicator, namely Top $1 \%$ income shares and Top $1 \%$ wealth concentration of the WID.world Database (World Inequality Database, 2019). Data for Top 1\% wealth shares is, however, only available for France, Russia and Great Britain. Results are reported in table 5 . An increase in of Top $1 \%$ income concentration does not increase the demand for redistribution - the effect is not significant for any of the income and health classes.

Although the wealth inequality data is imperfect and provisional (see Alvaredo et al. (2017)), there is a clear pattern: An increase in Top $1 \%$ wealth shares decreases the demand for redistribution for the lower income classes(first - 8th) as illustrated in figure??. Missing trust in the government might explain the pattern. However, the effect does not change once we include "trust in the government" (see 12a). The result suggests that confidence in redistribution efficiency is lost if wealth inequality increases. The effect of an increase in wealth or Top $1 \%$ income inequality does not vary at different states of health. 
Table 5: Different inequality measures

\begin{tabular}{|c|c|c|c|c|c|c|c|c|c|c|c|c|}
\hline & \multicolumn{3}{|c|}{ (1) } & \multicolumn{3}{|c|}{ (2) } & \multicolumn{3}{|c|}{ (3) } & \multicolumn{3}{|c|}{ (4) } \\
\hline & Coef. & Stdv. & $\mathrm{p}$ & Coef. & Stdv. & $\mathrm{p}$ & Coef. & Stdv. & $\mathrm{p}$ & Coef. & Stdv. & $\mathrm{p}$ \\
\hline Income 1 & $0.080^{* *}$ & 0.033 & 0.023 & 0.145 & 0.063 & 0.104 & $0.033^{*}$ & 0.018 & 0.081 & -0.045 & 0.030 & 0.229 \\
\hline Income 2 & 0.071 & 0.042 & 0.103 & 0.126 & 0.083 & 0.226 & $0.069^{* * *}$ & 0.016 & 0.000 & 0.044 & 0.039 & 0.341 \\
\hline Income 3 & -0.003 & 0.041 & 0.939 & $0.216^{* * *}$ & 0.018 & 0.001 & $0.052^{* * *}$ & 0.017 & 0.004 & $0.108^{* *}$ & 0.024 & 0.020 \\
\hline Income 4 & 0.027 & 0.032 & 0.402 & $0.266^{* *}$ & 0.080 & 0.044 & $0.032^{* *}$ & 0.015 & 0.043 & -0.024 & 0.059 & 0.704 \\
\hline Income 6 & -0.058 & 0.039 & 0.153 & $0.155^{*}$ & 0.052 & 0.059 & $-0.032^{* *}$ & 0.014 & 0.032 & -0.040 & 0.037 & 0.357 \\
\hline Income 7 & $-0.094^{*}$ & 0.049 & 0.067 & 0.079 & 0.054 & 0.240 & $-0.065^{* * *}$ & 0.019 & 0.002 & $-0.095^{*}$ & 0.035 & 0.072 \\
\hline Income 8 & $-0.126^{* *}$ & 0.056 & 0.034 & 0.096 & 0.053 & 0.171 & $-0.082^{* * *}$ & 0.021 & 0.000 & $-0.148^{*}$ & 0.055 & 0.075 \\
\hline Income 9 & $-0.153^{* * *}$ & 0.054 & 0.008 & $-0.352^{* *}$ & 0.075 & 0.018 & $-0.155^{* * *}$ & 0.018 & 0.000 & $-0.238^{* * *}$ & 0.028 & 0.003 \\
\hline Income 10 & $-0.309^{* * *}$ & 0.097 & 0.004 & $-0.346^{*}$ & 0.132 & 0.079 & $-0.322^{* * *}$ & 0.029 & 0.000 & $-0.411^{* * *}$ & 0.038 & 0.002 \\
\hline L.1 lp99p100 & -0.363 & 0.807 & 0.657 & & & & -0.444 & 0.808 & 0.588 & & & \\
\hline Income $1 \times$ L.1 lp99p100 & $-0.497^{*}$ & 0.252 & 0.059 & & & & & & & & & \\
\hline Income $2 \times$ L.1 lp99p100 & -0.022 & 0.384 & 0.954 & & & & & & & & & \\
\hline Income $3 \times$ L.1 lp99p100 & $0.589^{*}$ & 0.314 & 0.072 & & & & & & & & & \\
\hline Income $4 \times$ L.1 lp99p100 & 0.058 & 0.244 & 0.813 & & & & & & & & & \\
\hline Income $6 \times$ L.1 lp99p100 & 0.277 & 0.425 & 0.521 & & & & & & & & & \\
\hline Income $7 \times$ L.1 lp99p100 & 0.305 & 0.543 & 0.579 & & & & & & & & & \\
\hline Income $8 \times$ L.1 lp99p100 & 0.469 & 0.541 & 0.394 & & & & & & & & & \\
\hline Income $9 \times$ L.1 lp99p100 & -0.024 & 0.668 & 0.972 & & & & & & & & & \\
\hline Income $10 \times$ L. 1 lp99p100 & -0.135 & 1.026 & 0.896 & & & & & & & & & \\
\hline Health 1 & $0.114^{* *}$ & 0.046 & 0.019 & 0.060 & 0.076 & 0.487 & 0.104 & 0.107 & 0.342 & -0.444 & 0.376 & 0.322 \\
\hline Health 2 & 0.018 & 0.017 & 0.306 & 0.060 & 0.061 & 0.403 & 0.068 & 0.048 & 0.172 & -0.160 & 0.168 & 0.412 \\
\hline Health 4 & $-0.066^{* * *}$ & 0.012 & 0.000 & -0.019 & 0.042 & 0.675 & $-0.090^{* * *}$ & 0.028 & 0.003 & -0.052 & 0.101 & 0.638 \\
\hline Health 5 & $-0.102^{* * *}$ & 0.018 & 0.000 & -0.093 & 0.052 & 0.175 & $-0.149 * * *$ & 0.044 & 0.002 & -0.217 & 0.106 & 0.134 \\
\hline L.1 p99p100_wealth & & & & -0.409 & 0.760 & 0.628 & & & & -1.006 & 0.695 & 0.243 \\
\hline Income $1 \times$ L.1 p99p100_wealth & & & & $-0.735^{* *}$ & 0.205 & 0.037 & & & & & & \\
\hline Income $2 \times$ L.1 p99p100_wealth & & & & -0.314 & 0.175 & 0.171 & & & & & & \\
\hline Income $3 \times$ L.1 p99p100_wealth & & & & $-0.407 * * *$ & 0.032 & 0.001 & & & & & & \\
\hline Income $4 \times$ L.1 p99p100_wealth & & & & $-1.070^{* *}$ & 0.188 & 0.011 & & & & & & \\
\hline Income $6 \times$ L.1 p99p100_wealth & & & & $-0.735^{* *}$ & 0.140 & 0.013 & & & & & & \\
\hline Income $7 \times$ L.1 p99p100_wealth & & & & $-0.658^{* *}$ & 0.188 & 0.040 & & & & & & \\
\hline Income $8 \times$ L.1 p99p100_wealth & & & & $-0.938 * * *$ & 0.154 & 0.009 & & & & & & \\
\hline Income $9 \times$ L.1 p99p100_wealth & & & & 0.475 & 0.208 & 0.107 & & & & & & \\
\hline Income $10 \times$ L.1 p99p100_wealth & & & & -0.227 & 0.413 & 0.621 & & & & & & \\
\hline Health $1 \times$ L.1 lp99p100 & & & & & & & 0.111 & 1.087 & 0.919 & & & \\
\hline Health $2 \times$ L.1 lp99p100 & & & & & & & -0.513 & 0.484 & 0.299 & & & \\
\hline Health $4 \times$ L.1 lp99p100 & & & & & & & 0.250 & 0.257 & 0.340 & & & \\
\hline Health $5 \times$ L.1 lp99p100 & & & & & & & 0.508 & 0.401 & 0.216 & & & \\
\hline Health $1 \times$ L.1 p99p100_wealth & & & & & & & & & & 1.696 & 1.162 & 0.241 \\
\hline Health $2 \times$ L.1 p99p100_wealth & & & & & & & & & & 0.711 & 0.376 & 0.155 \\
\hline Health $4 \times$ L.1 p99p100_wealth & & & & & & & & & & 0.101 & 0.224 & 0.683 \\
\hline Health $5 \times$ L.1 p99p100_wealth & & & & & & & & & & 0.507 & 0.451 & 0.343 \\
\hline $\mathrm{r} 2$ & 0.1593 & & & 0.1443 & & & 0.1593 & & & 0.1436 & & \\
\hline $\mathrm{N}$ & 78222 & & & 9876 & & & 78222 & & & 9876 & & \\
\hline Year FE & $\checkmark$ & & & $\checkmark$ & & & $\checkmark$ & & & $\checkmark$ & & \\
\hline Country FE & $\checkmark$ & & & $\checkmark$ & & & $\checkmark$ & & & $\checkmark$ & & \\
\hline Region FE & $\checkmark$ & & & $\checkmark$ & & & $\checkmark$ & & & $\checkmark$ & & \\
\hline All controls & $\checkmark$ & & & $\checkmark$ & & & $\checkmark$ & & & $\checkmark$ & & \\
\hline
\end{tabular}

Note: The table shows the results estimating equation (2) with additional inequality measures. Data is weighted (design weight). The fifth income class and the fair health class serve as the reference category. All available controls are included with additional controls such as the martial status, the occupation type, religion and the current main activity, which are included. Standard errors are clustered on the country level.*** Significant at the $1 \%$ level. ${ }^{* *}$ Significant at the $5 \%$ level.* Significant at the $10 \%$ level. 


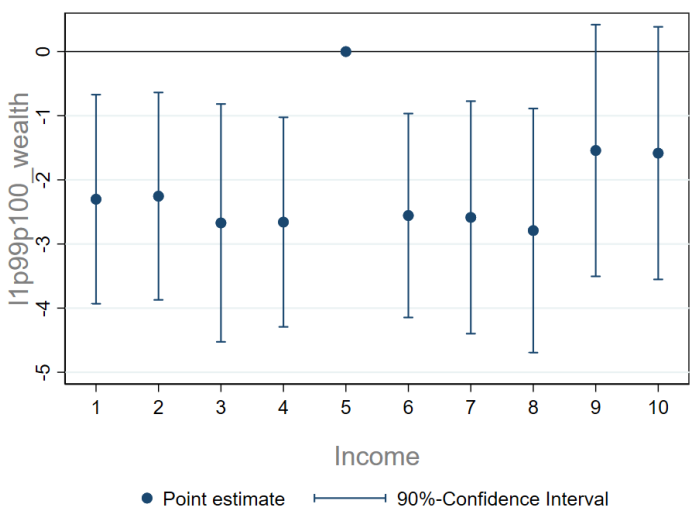

Figure 9: Top 1\% wealth at different income levels. Note: Values are calculated using the results of table 5 in which interaction terms are included. Figure ?? shows calculation of the total Top 1\% wealth effect for different income levels.

It is instructive to learn that different indicators of inequality affect preference for redistribution differently. The results present effects of different aggregated macro inequality levels on preferences for redistribution but not how respondents perceive inequality. How inequality matters in preferences for redistribution is certainly a question of access to information and the ability to process it. I abstract from potential misperceptions of the income distribution which may have substantial implications for the determination of policy outcomes (see Cruces et al. (2013)).

\subsection{Robustness analysis}

I estimate different specifications to gain insights into the sensitivity of the model with respect to used controls. As I am aware of potential mulitcollinearity problems with political variables (trust, leftist orientation, union membership), I have estimated the main models without the respective controls. Results including the controls remain valid (see table A.12, column (1)). The included political covariates indicating union membership or leftist party orientation have a significant, positive effect on preferences for redistribution in line with Kerr (2014) and Alesina and Ferrara (2005). Results are also robust to using survey round dummies instead of year dummies (see table A.13).

In addition, I test the stability of the results to the specification choice. I apply an Ordered Probit model to see if this specification changes the results compared to the linear model. Results are estimated by Maximum Likelihood Estimation and presented in table A.14. The magnitude of the 
OP coefficients does not have a simple interpretation; however, the sign of the effect and statistical significance agree with the linear model.

In the main analysis, I am using one-period lags. Table A.15 demonstrates results when using a three-period lag structure of the country-level variables and table A.16 presents four-period lags. The coefficients and significance do not change.

Following Dimick et al. (2016), it could be the case that the level of crime could influence my estimates as a potential concern of the rich, unconnected to altruism, for the negative externalities of inequality (see for example Cloward and Piven (1972)). In table A.17, I use data from the Eurostat database (Eurostat, 2019) on total intentional homicides to proxy for crime. Results remain valid.

To test in a broad sense whether welfare state regimes per se matter, and with respect to fairness concerns, the different countries are classified by constructing different dummy variables, using the welfare classifications of Ferrera (1996) extended by Esping-Andersen (1990). Welfare states are differentiated according to the quality of social rights, social stratification, and the arrangements between market, state and family. The following categories are used: "Nordic," "Liberal," "Continental," "Southern" and "Eastern and Central." I use being a "Southern country" as the base category. Table A.18 presents the results, which leave the core result unchanged.

\section{Concluding remarks}

The growing importance of rising inequality and its increasing public discussion strengthens government incentives to reduce income inequality. Analysis to determine where the support for redistribution comes from is desirable.

This paper concentrates on fairness concerns in preferences for redistribution. Linking European survey data to aggregated country level indicators, I show that market inequality and youth unemployment increase the demand for redistribution. Fairness concerns are triggered by market income inequality and youth unemployment (H1). In addition, mean impacts would miss a great deal. There are fairness concerns in voting for redistribution which vary not only with income (i.e. "incomedependent-altruism" as suggested by Dimick et al. (2016)) but also with the subjective health state, 
which I call "health- dependent fairness concerns". A subjective health and high income levels decreases the demand for redistribution, the effect of changes in market income inequality and youth unemployment are positive for the rich and healthy (H2 - H3). In addition, fairness concerns measured by the interest in "helping others" varies with income and health as well. Furthermore, the effect of having children is positive for net recipients, but for net payers, the effect is negative. The results are robust to the inclusion of a rich set of controls and various specifications. However, an increase in Top $1 \%$ wealth concentration decreases the demand for redistribution.

The results show that societal issues such as high youth unemployment and increasing market inequality are relevant and should be actively used to gain approval for unpopular issues such as tax increases to finance redistribution. This applies also to the rich part of society, who generally dislike redistribution. Although this paper concentrates on fairness concerns in preferences for redistribution, fairness concerns might have similar implications for a wider range of political decisions e.g. public good provision. When rich and healthy individuals negatively valuate high levels of inequality and youth unemployment, they might consider higher public good provision in form of education as fair and desirable.

Behind inequality and how it is understood lies a morass of complexities. I find that it is only market inequality which increase the demand for redistribution. However, Top $1 \%$ wealth concentration seems to decrease the demand for redistribution. It is not clear why one measure first and foremost addresses only fairness concerns. In addition, this paper is only part of the story as I do focuses on the demand for redistribution, and I ignore how (or even if) this demand is translated into policy. Further research should focus on the complexity of inequality, how it is understood and perceived and consequently how it matters in preferences for redistribution. 


\section{Acknowledgements}

I am greatful for helpful comments by Malcom Fairbrother, David Bartram, Nicole Simpson, Marcus Roller, Andreas Freitag, Thomas Heister, Kerstin Hansen and Johannes Maier. I have also benefited from comments received at the EPCS conference in Freiburg, April 2016 and the Economics Lunch 2016 at the University of Basel. Suggestions by Andreas Haufler, Annie Tubadji, and Kurt Schmidheiny greatly improved the paper. I thank Beat Hintermann for very helpful comments and valuable input. 


\section{References}

Ackert, Lucy F., Jorge Martinez-Vasquez and Mark Rider (2007). "Social preferences and tax policy design: some experimental evidence." Economic Inquiry 45(3): 487-501.

Alesina, Alberto and George-Marios Angeletos (2005). "Fairness and redistribution." American Economic Review 95(4): 960-980.

Alesina, Alberto and Eliana La Ferrara (2005). "Preferences for Redistribution in the Land of Opportunities." Journal of Public Economics 89(5): 897-931.

Alesina, Alberto and Nicola Fuchs-Schndeln (2007). "Goodbye Lenin (or Not?): The Effect of Communism on People's Preferences." American Economic Review 97(4): 1507-1528, September.

Alesina, Alberto and Paola Giuliano (2011a). "Family ties and political participation." Journal of the European Economic Association 9(5): 817-839.

(2011b). "Preferences for redistribution." in Handbook of social economics. 1 Elsevier: 93-131.

Alesina and Roberto Perotti (1996). "Income distribution, political instability, and investment." European Economic Review 40(6): 1203-1228.

Alesina, Alberto, Edward Glaeser and Edward Ludwig Glaeser (2004). Fighting poverty in the US and Europe: A world of difference. Oxford University Press.

Alesina, Alberto, Stefanie Stantcheva and Edoardo Teso (2018). "Intergenerational mobility and preferences for redistribution." American Economic Review 108(2): 521-54.

Alvaredo, Facundo, Lucas Chancel, Thomas Piketty, Emmanuel Saez and Gabriel Zucman (2017). "Global Inequality Dynamics: New Findings from WID.world." American Economic Review 107(5): 404-09, May.

Andreoni, James (1988). "Privately provided public goods in a large economy: the limits of altruism." Journal of Public Economics 35(1): 57-73. 
_ (1989). "Giving with impure altruism: Applications to charity and Ricardian equivalence." Journal of Political Economy 97(6): 1447-1458.

Benabou, Roland and Efe A Ok (2001). "Social mobility and the demand for redistribution: the POUM hypothesis." Quarterly Journal of Economics 116(2): 447-487.

Browning, Martin (1992). "Children and household economic behavior." Journal of Economic Literature 30(3): $1434-1475$.

Bundesamt fuer Statistik Schweiz (2019). "Unemployment rate by gender, nationality and age. Annual average." https://www.bfs.admin.ch/bfs/de/home/statistiken.html, September.

Clark, Andrew E and Conchita D'Ambrosio (2015). "Attitudes to income inequality: experimental and survey evidence." in Handbook of income distribution. 2 Elsevier: 1147-1208.

Cloward, Richard A and Frances Fox Piven (1972). Regulating the poor: The functions of public welfare. Tavistock Publications.

Corneo, Giacomo and Hans Peter Gruener (2000). "Social limits to redistribution." American Economic Review 90(5): 1491-1507.

(2002). "Individual preferences for political redistribution." Journal of Public Economics 83(1): $83-107$.

Cruces, Guillermo, Ricardo Perez-Truglia and Martin Tetaz (2013). "Biased perceptions of income distribution and preferences for redistribution: Evidence from a survey experiment." Journal of Public Economics 98: 100-112.

Deaton, Angus (2003). "Health, Inequality, and Economic Development." Journal of Economic Literature 41(1): 113-158, March.

Dimick, Matthew, David Rueda and Daniel Stegmueller (2016). "The Altruistic Rich? Inequality and Other-Regarding Preferences for Redistribution in the US." Quarterly Journal of Political Science 11(4): $385-439$. 
Dotti, Valerio (2020). "Income inequality, size of government, and tax progressivity: A positive theory." European Economic Review 121, p. 103327.

Durante, Ruben, Louis Putterman and Joël Weele (2014). "Preferences for redistribution and perception of fairness: An experimental study." Journal of the European Economic Association 12(4): $1059-1086$.

Esping-Andersen, Gosta (1990). The three worlds of welfare capitalism. Princeton Princeton University Press.

European Social Survey (2014). "Weighting European Social Survey Data." report, European Social Survey.

(2016). "ESS 1-7 Data file edition 1.0. NSD - Norwegian Centre for Research Data, Norway - Data Archive and distributor of ESS data for ESS ERIC.."

Eurostat, European Commission (2017). "Unemployment rates, yearly averages." https://appsso.eurostat.ec.europa.eu, May.

(2019). "Recorded offences by offence category, police data." https://appsso.eurostat.ec.europa.eu, August.

Fehr, Ernst and Klaus M. Schmidt (1999). "A Theory of Fairness, Competition, and Cooperation." The Quarterly Journal of Economics 114(3): 817-868.

Fehr, Ernst and Klaus M Schmidt (2003). "Theories of Fairness and Reciprocity: Evidence and Economic Applications." Advances in Economics and Econometrics: Theory and Applications, Eighth World Congress 1(35): $208-257$.

Ferrera, Maurizio (1996). "The 'Southern Model' of Welfare in Social Europe." Journal of European Social Policy 6(1): 17-37.

Finkelstein, Amy, Erzo FP Luttmer and Matthew J Notowidigdo (2009). "Approaches to estimat- 
ing the health state dependence of the utility function." American Economic Review: Papers 85 Proceedings 99(2): 116-21.

Finkelstein, Amy, Erzo Luttmer and Matthew J. Notowidigdo (2013). "What good is wealth without health? The effect of health on the marginal utility of consumption." Journal of the European Economic Association 11(suppl_1): 221-258.

Fong, Christina (2001). "Social preferences, self-interest, and the demand for redistribution." Journal of Public Economics 82(2): 225-246.

Galasso, Vincenzo (2003). "Redistribution and fairness: a note." European Journal of Political Economy 19(4): 885-892.

Gallice, Andrea and Edoardo Grillo (2018). "Economic and social-class voting in a model of redistribution with social concerns." Journal of the European Economic Association Online First.

Gelman, Andrew (2007). "Struggles with Survey Weighting and Regression Modeling." Statistical Sience 22(2): 153-164.

Giuliano, Paola and Antonio Spilimbergo (2014). "Growing up in a Recession." The Review of Economic Studies 81(2): 787-817.

Graubard, Barry I and Edward L Korn (1996). "Modelling the sampling design in the analysis of health surveys." Statistical Methods in Medical Research 5(3): 263-281.

Guillaud, Elvire (2013). "Preferences for redistribution: an empirical analysis over 33 countries." The Journal of Economic Inequality 11(1): 57-78.

Hoechtl, Wolfgang, Rupert Sausgruber and Jean-Robert Tyran (2012). "Inequality aversion and voting on redistribution." European Economic Review 56(7): 1406-1421.

Houle, Christian (2017). "Inequality, ethnic diversity, and redistribution." The Journal of Economic Inequality 15(1): 1-23.

International Labour Office (2016). "World Employment and Social Outlook 2016: Trends for youth." 
Kerr, William R (2014). "Income inequality and social preferences for redistribution and compensation differentials." Journal of Monetary Economics 66: 62-78.

Klor, Esteban F and Moses Shayo (2010). "Social identity and preferences over redistribution." Journal of Public Economics 94(3-4): 269-278.

Kuziemko, Ilyana, Michael I. Norton, Emmanuel Saez and Stefanie Stantcheva (2015). "How Elastic Are Preferences for Redistribution? Evidence from Randomized Survey Experiments." American Economic Review 105(4): 1478-1508.

Luttmer, Erzo F. P. and Monica Singhal (2011). "Culture, Context, and the Taste for Redistribution." American Economic Journal: Economic Policy 3(1): 157-79.

Meltzer, Allan H and Scott F Richard (1981). "A rational theory of the size of government." Journal of Political Economy 89(5): 914-927.

Murray, Matthew N, Langchuan Peng and Rudy Santore (2018). "How does inequality aversion affect inequality and redistribution?" The Journal of Economic Inequality 16(4): 507-525.

Nekby, Lena and Per Pettersson-Lidbom (2017). "Revisiting the relationship between ethnic diversity and preferences for redistribution: Comment." The Scandinavian Journal of Economics 119(2): $268-287$.

OECD (2017). "Unemployment rate (indicator)." https://stats.oecd.org/index.aspx?queryid=36324.

Okun, Arthur M. (2015). Equality and Efficiency: The Big Tradeoff. Brookings Institution Press.

Piketty, Thomas (1995). "Social mobility and redistributive politics." Quarterly Journal of Economics 110(3): 551-584.

Pittau, Maria Grazia, Riccardo Massari and Roberto Zelli (2013). "Hierarchical Modelling of Disparities in Preferences for Redistribution." Oxford Bulletin of Economics and Statistics 75(4): 556-584.

Riedl, Maximilian and Ingo Geishecker (2014). "Keep it simple: estimation strategies for ordered response models with fixed effects." Journal of Applied Statistics 41(11): 2358-2374. 
Roth, Christopher and Johannes Wohlfart (2018). "Experienced inequality and preferences for redistribution." Journal of Public Economics 167: 251-262.

Saint Paul, Gilles and Thierry Verdier (1996). "Inequality, redistribution and growth: A challenge to the conventional political economy approach." European Economic Review 3(40): 719-728.

Sinn, Hans-Werner (1995). "A Theory of the Welfare State." The Scandinavian Journal of Economics 97(4): 495-526.

(1996). "Social insurance, incentives and risk taking." International Tax and Public Finance 3(3): $259-280$.

Smith, James P (1999). "Healthy bodies and thick wallets: the dual relation between health and economic status." Journal of Economic Perspectives 13(2): 145-166.

Solt, Frederick (2019). "The Standardized World Income Inequality Database, Version 8."

talkstats.com (2014). "European Social Survey - income variable." http://www.talkstats.com/threads/european-social-survey-income-variable.44664/. Message No. 10.

Tyran, Jean-Robert and Rupert Sausgruber (2006). "A little fairness may induce a lot of redistribution in democracy." European Economic Review 50(2): 469-485.

Van Praag, B, D Romanov and A Ferrer-i Carbonell (2010). "Happiness and financial satisfaction in Israel: Effects of religiosity ethnicity and war." Journal of Economic Psychology 31(6): 1008 - 1020.

Viscusi, W. Kip (2019). "Utility functions for mild and severe health risks." Journal of Risk and Uncertainty 58(2): 143-166, Jun.

Viscusi, W. Kip and William N. Evans (1990). "Utility Functions That Depend on Health Status: Estimates and Economic Implications." American Economic Review 80(3): 353-374.

World Bank (2015). "World Development Indicators." http://data.worldbank.org/indicator/NY.GDP.MKTP.CD. 
World Inequality Database (2019). "WID.world, Top 1

shares." https://wid.world/data/, August.

Yamamura, Eiji (2012). "Social capital, household income, and preferences for income redistribution."

European Journal of Political Economy 28(4): 498-511.

\section{A Appendix}

\section{A.1 Additional results and figures}

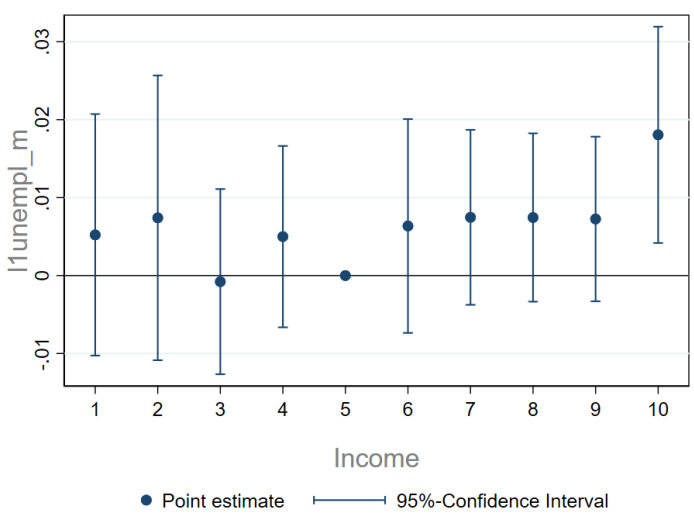

(a) The effect of unemployment at different income levels

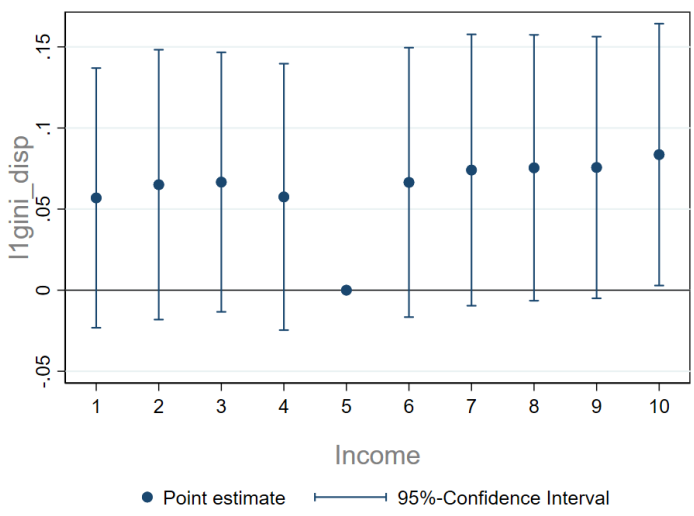

(b) The effect of net Gini at different income levels, excluding age $>64$

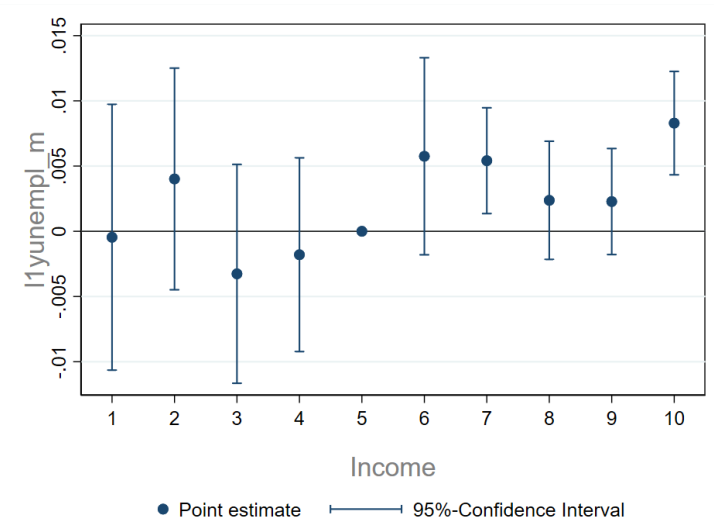

(c) The effect of youth unemployment at different income levels, excluding age $>64$

Figure 10: Additional income interaction terms. Note: Figure 10a shows the calculation of the total net Gini effect at different income levels, column (3) of 3. Figure $10 \mathrm{~b}$ presents the calculations of total net Gini effect and 10c shows calculation of the total youth unemployment effect for different income levels, but excluding seniors. 
Table A.6: Summary statistics

\begin{tabular}{|c|c|c|c|c|}
\hline & mean & sd & $\min$ & $\max$ \\
\hline income & 5.33 & 2.82 & 1.000 & 10.000 \\
\hline hlth & 3.76 & 0.93 & 1.000 & 5.000 \\
\hline agea & 47.74 & 18.46 & 13.000 & 123.000 \\
\hline childever1 & 0.68 & 0.47 & 0.000 & 1.000 \\
\hline lnhhsz & 0.88 & 0.54 & 0.000 & 3.091 \\
\hline discrimination & 0.07 & 0.25 & 0.000 & 1.000 \\
\hline female & 0.54 & 0.50 & 0.000 & 1.000 \\
\hline pdjobev & 0.90 & 0.29 & 0.000 & 1.000 \\
\hline metro & 0.34 & 0.47 & 0.000 & 1.000 \\
\hline selfempl & 0.10 & 0.30 & 0.000 & 1.000 \\
\hline advent & 0.38 & 0.49 & 0.000 & 1.000 \\
\hline socialmob & 0.54 & 0.50 & 0.000 & 1.000 \\
\hline eduyrs & 12.22 & 4.07 & 0.000 & 56.000 \\
\hline act_-_work & 0.49 & 0.50 & 0.000 & 1.000 \\
\hline act__edu & 0.08 & 0.28 & 0.000 & 1.000 \\
\hline act_-uel & 0.04 & 0.20 & 0.000 & 1.000 \\
\hline act__ued & 0.02 & 0.13 & 0.000 & 1.000 \\
\hline act__dis & 0.02 & 0.15 & 0.000 & 1.000 \\
\hline act__ret & 0.24 & 0.43 & 0.000 & 1.000 \\
\hline act__mil & 0.00 & 0.04 & 0.000 & 1.000 \\
\hline act__hswk & 0.09 & 0.29 & 0.000 & 1.000 \\
\hline act__oth & 0.01 & 0.11 & 0.000 & 1.000 \\
\hline mar__marr & 0.53 & 0.50 & 0.000 & 1.000 \\
\hline mar__divs & 0.14 & 0.35 & 0.000 & 1.000 \\
\hline mar_-wid & 0.18 & 0.38 & 0.000 & 1.000 \\
\hline mar__nevm & 0.15 & 0.36 & 0.000 & 1.000 \\
\hline mar_mis & 0.02 & 0.13 & 0.000 & 1.000 \\
\hline occ__armf & 0.00 & 0.06 & 0.000 & 1.000 \\
\hline occ__mngt & 0.08 & 0.28 & 0.000 & 1.000 \\
\hline occ__prof & 0.14 & 0.34 & 0.000 & 1.000 \\
\hline occ__tech & 0.15 & 0.36 & 0.000 & 1.000 \\
\hline Occ__clrk & 0.11 & 0.31 & 0.000 & 1.000 \\
\hline Occ $\_$_srvc & 0.15 & 0.36 & 0.000 & 1.000 \\
\hline occ__agri & 0.04 & 0.19 & 0.000 & 1.000 \\
\hline $\mathrm{occ}_{--} \mathrm{crft}$ & 0.13 & 0.34 & 0.000 & 1.000 \\
\hline occ__oprt & 0.08 & 0.28 & 0.000 & 1.000 \\
\hline occ__eocc & 0.12 & 0.32 & 0.000 & 1.000 \\
\hline rel__none & 0.38 & 0.49 & 0.000 & 1.000 \\
\hline rel__cath & 0.30 & 0.46 & 0.000 & 1.000 \\
\hline rel_-prot & 0.13 & 0.34 & 0.000 & 1.000 \\
\hline rel__orth & 0.09 & 0.29 & 0.000 & 1.000 \\
\hline rel__ochr & 0.01 & 0.11 & 0.000 & 1.000 \\
\hline rel__jew & 0.03 & 0.17 & 0.000 & 1.000 \\
\hline rel__islm & 0.03 & 0.18 & 0.000 & 1.000 \\
\hline rel__othn & 0.01 & 0.07 & 0.000 & 1.000 \\
\hline trust & 5.03 & 2.71 & 0.000 & 10.000 \\
\hline union_ev & 0.42 & 0.49 & 0.000 & 1.000 \\
\hline union_cur & 0.18 & 0.39 & 0.000 & 1.000 \\
\hline volu & 0.07 & 0.25 & 0.000 & 1.000 \\
\hline help & 0.66 & 0.47 & 0.000 & 1.000 \\
\hline 11gini_disp & 29.72 & 4.43 & 22.900 & 44.000 \\
\hline 11gini_mkt & 47.46 & 5.52 & 27.700 & 60.300 \\
\hline 11unempl_m & 8.42 & 3.95 & 2.547 & 26.092 \\
\hline 11yunempl_m & 18.68 & 9.22 & 5.000 & 55.475 \\
\hline 11lp99p100 & 0.09 & 0.03 & 0.048 & 0.246 \\
\hline 11p99p100_wealth & 0.27 & 0.07 & 0.168 & 0.393 \\
\hline 11GDP_pC_US & 33023.70 & 11210.66 & 11170.929 & 69458.883 \\
\hline murder & 344.28 & 674.76 & 1.000 & 4879.000 \\
\hline cntry_num & 15.75 & 9.12 & 1.000 & 32.000 \\
\hline year & 2008.50 & 3.93 & 2002.000 & 2015.000 \\
\hline region_all & 21.61 & 66.60 & 1.000 & 423.000 \\
\hline welstate & 3.37 & 1.48 & 1.000 & 5.000 \\
\hline essround & 4.04 & 1.93 & 1.000 & 7.000 \\
\hline
\end{tabular}

Table A.7: Note: The table presents the summary statistics of all variables used. 
Table A.8: Baseline regression, continuous health and income

\begin{tabular}{|c|c|c|c|c|c|c|c|c|c|c|c|c|}
\hline & \multicolumn{3}{|c|}{ (1) } & \multicolumn{3}{|c|}{$\overline{(2)}$} & \multicolumn{3}{|c|}{ (3) } & \multicolumn{3}{|c|}{ (4) } \\
\hline & Coef. & Stdv. & $\mathrm{p}$ & Coef. & Stdv. & $\mathrm{p}$ & Coef. & Stdv. & $\mathrm{p}$ & Coef. & Stdv. & $\mathrm{p}$ \\
\hline Income & $-0.036^{* * *}$ & 0.004 & 0.000 & $-0.036^{* * *}$ & 0.004 & 0.000 & $-0.036^{* * *}$ & 0.004 & 0.000 & $-0.036^{* * *}$ & 0.004 & 0.000 \\
\hline Health & $-0.047^{* * *}$ & 0.007 & 0.000 & $-0.046^{* * *}$ & 0.007 & 0.000 & $-0.046^{* * *}$ & 0.007 & 0.000 & $-0.046^{* * *}$ & 0.007 & 0.000 \\
\hline L.1 gini_disp & 0.019 & 0.033 & 0.570 & & & & & & & & & \\
\hline L.1 gini_mkt & & & & $0.042^{* *}$ & 0.016 & 0.013 & & & & & & \\
\hline L.1 unempl_m & & & & & & & 0.007 & 0.005 & 0.164 & & & \\
\hline L.1 yunempl_m & & & & & & & & & & $0.005^{* *}$ & 0.002 & 0.011 \\
\hline Year FE & $\checkmark$ & & & $\checkmark$ & & & $\checkmark$ & & & $\checkmark$ & & \\
\hline Country FE & $\checkmark$ & & & $\checkmark$ & & & $\checkmark$ & & & $\checkmark$ & & \\
\hline Region FE & $\checkmark$ & & & $\checkmark$ & & & $\checkmark$ & & & $\checkmark$ & & \\
\hline Add. controls & $\checkmark$ & & & $\checkmark$ & & & $\checkmark$ & & & $\checkmark$ & & \\
\hline $\mathrm{r} 2$ & 0.1534 & & & 0.1539 & & & 0.1539 & & & 0.1541 & & \\
\hline $\mathrm{N}$ & 84252 & & & 84252 & & & 82810 & & & 80883 & & \\
\hline
\end{tabular}

Table A.9: Note: The table shows the results estimating equation (1) with continuous health and income variables. The dependent variable is preference for redistribution. The fifth income class and the fair health class serve as the reference category. Additional controls are the martial status, the occupation type, religion and the current main activity, which are included. Data is weighted (design weight). Standard errors are clustered on the country level.*** Significant at the $1 \%$ level. $^{* *}$ Significant at the $5 \%$ level.* Significant at the $10 \%$ level.

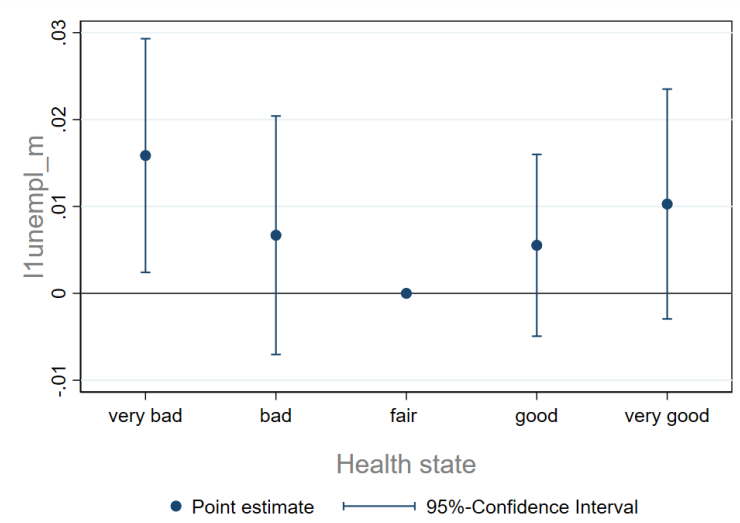

(a) The effect of unemployment at different health levels

Figure 11: Additional health interaction terms. The figure shows additional health interaction terms. Values are calculated using the results of table 4 in which interaction terms are included. Figure $11 \mathrm{~b}$ shows calculation of the total net Gini effect for different health states levels. Figure 11a presents the effect of youth unemployment at different health states.

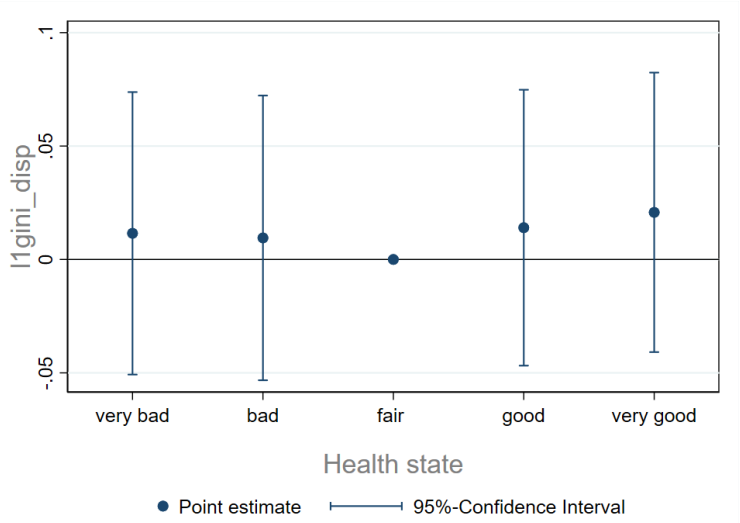

(b) The effect of net Gini at different health levels 


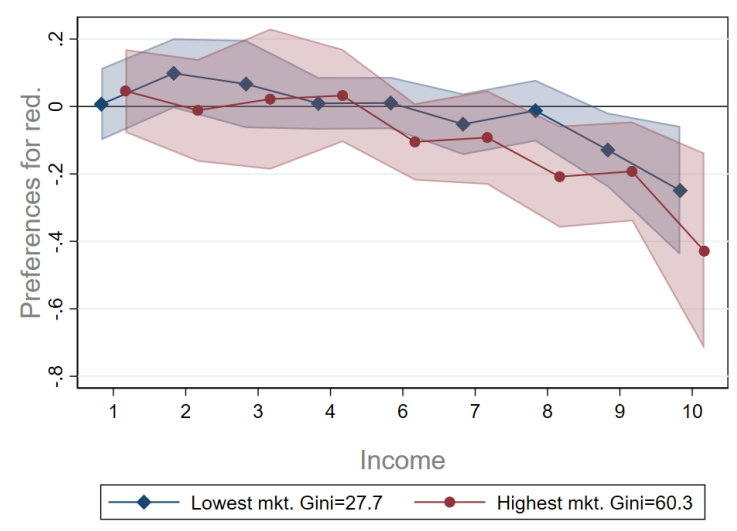

Note: The figure shows additional income interaction terms evaluated at highest and lowest unemployment and mkt. Gini levels.

Figure 12: Top 1\% wealth and income interaction terms including a trust variable

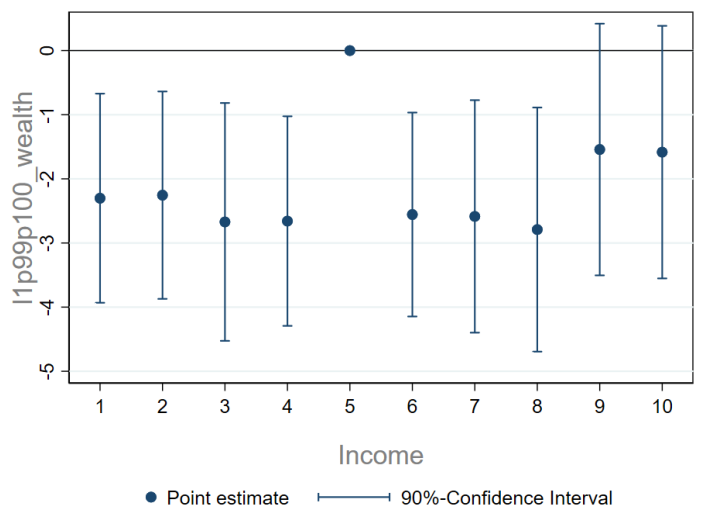

(a) The effect of Top $1 \%$ wealth shares at different income levels when we control for trust

Figure 13: The effect of income at different mkt. Gini levels. Note: Values are calculated using the results of table 5 in which interaction terms are included. Figure ?? shows calculation of the total Top $1 \%$ wealth effect for different income levels. 
Table A.10: Interaction Helping others and volunteering

\begin{tabular}{|c|c|c|c|c|c|c|c|c|c|c|c|c|}
\hline & \multicolumn{3}{|c|}{ (1) } & \multicolumn{3}{|c|}{ (2) } & \multicolumn{3}{|c|}{ (3) } & \multicolumn{3}{|c|}{ (4) } \\
\hline & Coef. & Stdv. & $\mathrm{p}$ & Coef. & Stdv. & $\mathrm{p}$ & Coef. & Stdv. & $\mathrm{p}$ & Coef. & Stdv. & $\mathrm{p}$ \\
\hline Income 1 & $0.075^{*}$ & 0.038 & 0.062 & 0.021 & 0.019 & 0.276 & 0.024 & 0.019 & 0.232 & 0.014 & 0.020 & 0.475 \\
\hline Income 2 & $0.070^{* * *}$ & 0.020 & 0.002 & $0.052^{* * *}$ & 0.018 & 0.007 & $0.057^{* * *}$ & 0.018 & 0.004 & $0.051^{* *}$ & 0.018 & 0.011 \\
\hline Income 3 & $0.080^{* * *}$ & 0.025 & 0.003 & $0.046^{* * *}$ & 0.016 & 0.007 & $0.049^{* * *}$ & 0.016 & 0.004 & $0.046^{* * *}$ & 0.016 & 0.008 \\
\hline Income 4 & 0.034 & 0.024 & 0.170 & 0.018 & 0.017 & 0.278 & 0.018 & 0.017 & 0.306 & 0.015 & 0.019 & 0.438 \\
\hline Income 6 & -0.035 & 0.026 & 0.193 & $-0.035^{* * *}$ & 0.012 & 0.010 & $-0.034^{* *}$ & 0.013 & 0.018 & $-0.039 * *$ & 0.015 & 0.016 \\
\hline Income 7 & $-0.077 * * *$ & 0.022 & 0.002 & $-0.067 * * *$ & 0.017 & 0.001 & $-0.067 * * *$ & 0.018 & 0.001 & $-0.069 * * *$ & 0.020 & 0.001 \\
\hline Income 8 & $-0.125^{* * *}$ & 0.025 & 0.000 & $-0.089^{* * *}$ & 0.019 & 0.000 & $-0.087^{* * *}$ & 0.020 & 0.000 & $-0.095^{* * *}$ & 0.022 & 0.000 \\
\hline Income 9 & $-0.191 * * *$ & 0.021 & 0.000 & $-0.152^{* * *}$ & 0.018 & 0.000 & $-0.153^{* * *}$ & 0.018 & 0.000 & $-0.151^{* * *}$ & 0.018 & 0.000 \\
\hline Income 10 & $-0.395^{* * *}$ & 0.024 & 0.000 & $-0.317^{* * *}$ & 0.029 & 0.000 & $-0.318^{* * *}$ & 0.029 & 0.000 & $-0.319^{* * *}$ & 0.031 & 0.000 \\
\hline Helping 1 & $0.159^{* * *}$ & 0.020 & 0.000 & $0.173^{* * *}$ & 0.012 & 0.000 & & & & & & \\
\hline Income $1 \times$ Helping 1 & -0.079 & 0.053 & 0.143 & & & & & & & & & \\
\hline Income $2 \times$ Helping 1 & -0.026 & 0.029 & 0.379 & & & & & & & & & \\
\hline Income $3 \times$ Helping 1 & $-0.051^{*}$ & 0.028 & 0.077 & & & & & & & & & \\
\hline Income $4 \times$ Helping 1 & -0.023 & 0.025 & 0.365 & & & & & & & & & \\
\hline Income $6 \times$ Helping 1 & -0.000 & 0.031 & 0.990 & & & & & & & & & \\
\hline Income $7 \times$ Helping 1 & 0.016 & 0.023 & 0.492 & & & & & & & & & \\
\hline Income $8 \times$ Helping 1 & $0.056^{*}$ & 0.031 & 0.080 & & & & & & & & & \\
\hline Income $9 \times$ Helping 1 & $0.061 * * *$ & 0.020 & 0.005 & & & & & & & & & \\
\hline Income $10 \times$ Helping 1 & $0.124^{* * *}$ & 0.029 & 0.000 & & & & & & & & & \\
\hline Health 1 & $0.117^{* *}$ & 0.044 & 0.013 & $0.230^{* * *}$ & 0.065 & 0.001 & $0.116^{* * *}$ & 0.039 & 0.006 & $0.113^{* *}$ & 0.043 & 0.013 \\
\hline Health 2 & 0.022 & 0.018 & 0.218 & 0.048 & 0.031 & 0.131 & 0.017 & 0.018 & 0.339 & 0.020 & 0.017 & 0.258 \\
\hline Health 4 & $-0.062^{* * *}$ & 0.011 & 0.000 & $-0.059^{* * *}$ & 0.018 & 0.003 & $-0.064^{* * *}$ & 0.011 & 0.000 & $-0.064^{* * *}$ & 0.011 & 0.000 \\
\hline Health 5 & $-0.102^{* * *}$ & 0.018 & 0.000 & $-0.126^{* * *}$ & 0.022 & 0.000 & $-0.099^{* * *}$ & 0.018 & 0.000 & $-0.099^{* * *}$ & 0.018 & 0.000 \\
\hline Health $1 \times$ Helping 1 & & & & $-0.172^{* *}$ & 0.081 & 0.042 & & & & & & \\
\hline Health $2 \times$ Helping 1 & & & & -0.038 & 0.030 & 0.213 & & & & & & \\
\hline Health $4 \times$ Helping 1 & & & & -0.006 & 0.020 & 0.781 & & & & & & \\
\hline Health $5 \times$ Helping 1 & & & & $0.036^{*}$ & 0.020 & 0.078 & & & & & & \\
\hline Volunteering 1 & & & & & & & 0.014 & 0.039 & 0.728 & -0.041 & 0.047 & 0.386 \\
\hline Health $1 \times$ Volunteering 1 & & & & & & & -0.109 & 0.210 & 0.608 & & & \\
\hline Health $2 \times$ Volunteering 1 & & & & & & & 0.059 & 0.064 & 0.369 & & & \\
\hline Health $4 \times$ Volunteering 1 & & & & & & & -0.005 & 0.039 & 0.893 & & & \\
\hline Health $5 \times$ Volunteering 1 & & & & & & & -0.006 & 0.027 & 0.814 & & & \\
\hline Income $1 \times$ Volunteering 1 & & & & & & & & & & $0.152^{*}$ & 0.079 & 0.064 \\
\hline Income $2 \times$ Volunteering 1 & & & & & & & & & & 0.101 & 0.077 & 0.200 \\
\hline Income $3 \times$ Volunteering 1 & & & & & & & & & & 0.042 & 0.042 & 0.327 \\
\hline Income $4 \times$ Volunteering 1 & & & & & & & & & & 0.045 & 0.065 & 0.495 \\
\hline Income $6 \times$ Volunteering 1 & & & & & & & & & & 0.082 & 0.086 & 0.353 \\
\hline Income $7 \times$ Volunteering 1 & & & & & & & & & & 0.036 & 0.076 & 0.638 \\
\hline Income $8 \times$ Volunteering 1 & & & & & & & & & & $0.121^{* * *}$ & 0.042 & 0.008 \\
\hline Income $9 \times$ Volunteering 1 & & & & & & & & & & -0.014 & 0.060 & 0.822 \\
\hline Income $10 \times$ Volunteering 1 & & & & & & & & & & 0.018 & 0.064 & 0.787 \\
\hline $\mathrm{r} 2$ & 0.1625 & & & 0.1620 & & & 0.1557 & & & 0.1559 & & \\
\hline $\mathrm{N}$ & 83979 & & & 83979 & & & 84252 & & & 84252 & & \\
\hline Year FE & $\checkmark$ & & & $\checkmark$ & & & $\checkmark$ & & & $\checkmark$ & & \\
\hline Country FE & $\checkmark$ & & & $\checkmark$ & & & $\checkmark$ & & & $\checkmark$ & & \\
\hline Region FE & $\checkmark$ & & & $\checkmark$ & & & $\checkmark$ & & & $\checkmark$ & & \\
\hline All controls & $\checkmark$ & & & $\checkmark$ & & & $\checkmark$ & & & $\checkmark$ & & \\
\hline
\end{tabular}

Note: The table presents estimation results interacting "helping others" and "volunteering" with income and health. Data is weighted (design weight). The fifth income class and the fair health class serve as the reference category. All available controls are included with additional controls such as the martial status, the occupation type, religion and the current main activity, which are included. Standard errors are clustered on the country level. ${ }^{* * *}$ Significant at the $1 \%$ level. $^{* *}$ Significant at the $5 \%$ level.* Significant at the $10 \%$ level. 


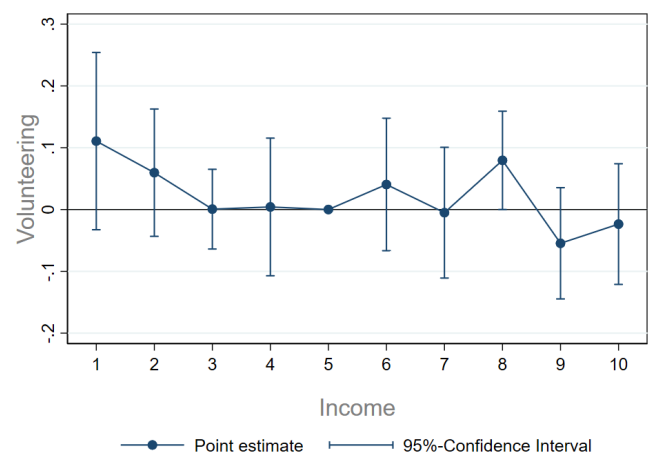

Figure 14: Volunteering and income 
Table A.11: Interaction having children and income

\begin{tabular}{|c|c|c|c|}
\hline & \multicolumn{3}{|c|}{ Having children \& income } \\
\hline & Coef. & $S t d v$. & $p$ \\
\hline Income 1 & 0.077 & 0.048 & 0.122 \\
\hline Income 2 & $0.107^{* * *}$ & 0.033 & 0.003 \\
\hline Income 3 & $0.083^{* *}$ & 0.033 & 0.016 \\
\hline Income 4 & $0.077^{* *}$ & 0.033 & 0.026 \\
\hline Income 6 & -0.006 & 0.031 & 0.848 \\
\hline Income 7 & -0.017 & 0.026 & 0.514 \\
\hline Income 8 & -0.037 & 0.030 & 0.230 \\
\hline Income 9 & $-0.091^{* * *}$ & 0.025 & 0.001 \\
\hline Income 10 & $-0.220 * * *$ & 0.033 & 0.000 \\
\hline Children & $0.117^{* * *}$ & 0.034 & 0.002 \\
\hline Income $1 \times$ Children & -0.056 & 0.055 & 0.315 \\
\hline Income $2 \times$ Children & -0.056 & 0.038 & 0.147 \\
\hline Income $3 \times$ Children & -0.043 & 0.033 & 0.208 \\
\hline Income $4 \times$ Children & $-0.071^{* *}$ & 0.034 & 0.045 \\
\hline Income $6 \times$ Children & -0.035 & 0.039 & 0.367 \\
\hline Income $7 \times$ Children & $-0.067^{*}$ & 0.035 & 0.069 \\
\hline Income $8 \times$ Children & -0.064 & 0.045 & 0.167 \\
\hline Income $9 \times$ Children & $-0.080^{*}$ & 0.041 & 0.064 \\
\hline Income $10 \times$ Children & $-0.134^{* * *}$ & 0.040 & 0.002 \\
\hline $\mathrm{r} 2$ & 0.1531 & & \\
\hline $\mathrm{N}$ & 85474 & & \\
\hline Year FE & $\checkmark$ & & \\
\hline Country FE & $\checkmark$ & & \\
\hline Region FE & $\checkmark$ & & \\
\hline All controls & $\checkmark$ & & \\
\hline
\end{tabular}

Note: The table shows the effect of "having children" at different income levels. Data is weighted (design weight). Standard errors are clustered on the country level.*** Significant at the $1 \%$ level. ** Significant at the $5 \%$ level.* Significant at the $10 \%$ level. 


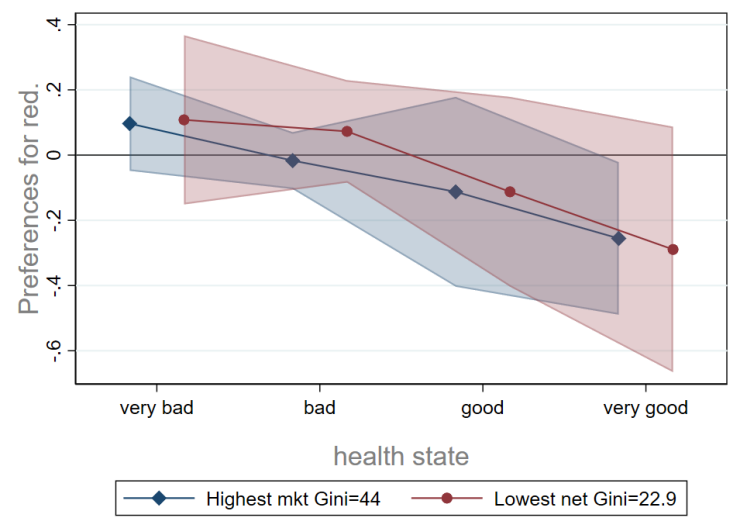

(a) The effect of health at net Gini levels

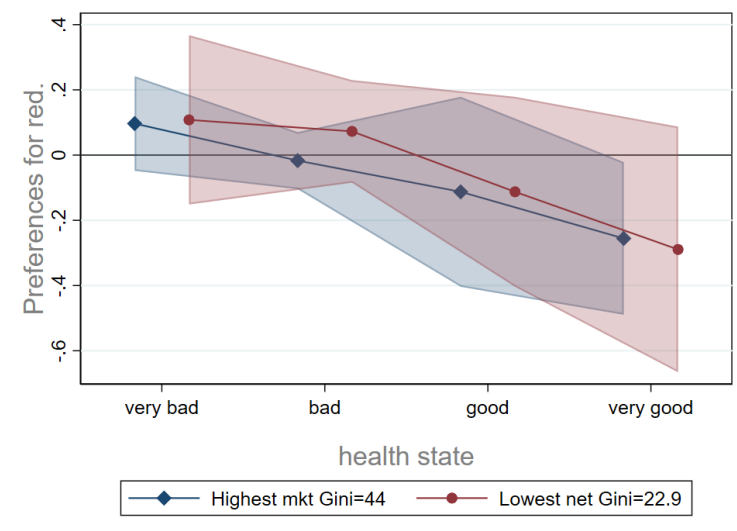

(b) The effect of health at different mkt. Gini levels

Figure 15: Additional health interaction terms evaluated at lowest and highest levels. Note: Values are calculated using the results of table 4 in which interaction terms are included. The shaded areas indicate the $90 \%$ pointwise confidence bands and the circles point estimates.

\section{A.2 Robustness analysis}


Table A.12: Political variables

\begin{tabular}{|c|c|c|c|c|c|c|c|c|c|c|c|c|}
\hline & \multicolumn{3}{|c|}{ (1) } & \multicolumn{2}{|r|}{$(2)$} & & \multicolumn{2}{|r|}{ (3) } & & Y. & $\begin{array}{l}(4) \\
\text { inempl. }\end{array}$ & \\
\hline & Coef. & Stdv. & $\mathrm{p}$ & Coef. & Stdv. & $\mathrm{p}$ & Coef. & Stdv. & $\mathrm{p}$ & Coef. & Stdv. & $\mathrm{p}$ \\
\hline Income 1 & $0.035^{*}$ & 0.020 & 0.093 & $0.039^{*}$ & 0.020 & 0.064 & 0.120 & 0.199 & 0.553 & $0.081^{* *}$ & 0.033 & 0.022 \\
\hline Income 2 & $0.059^{* * *}$ & 0.018 & 0.004 & $0.063^{* * *}$ & 0.018 & 0.002 & -0.056 & 0.226 & 0.807 & $0.083^{* *}$ & 0.039 & 0.043 \\
\hline Income 3 & $0.050 * * *$ & 0.015 & 0.003 & $0.051^{* * *}$ & 0.016 & 0.003 & 0.006 & 0.276 & 0.983 & $0.083^{* * *}$ & 0.029 & 0.009 \\
\hline Income 4 & 0.022 & 0.017 & 0.216 & $0.030^{*}$ & 0.016 & 0.075 & 0.075 & 0.194 & 0.702 & 0.041 & 0.029 & 0.177 \\
\hline Income 6 & $-0.036^{* * *}$ & 0.012 & 0.008 & $-0.032^{* *}$ & 0.013 & 0.016 & -0.173 & 0.161 & 0.291 & $-0.063^{* *}$ & 0.025 & 0.018 \\
\hline Income 7 & $-0.065^{* * *}$ & 0.016 & 0.000 & $-0.063^{* * *}$ & 0.017 & 0.001 & -0.147 & 0.192 & 0.450 & $-0.107^{* *}$ & 0.039 & 0.010 \\
\hline Income 8 & $-0.086^{* * *}$ & 0.019 & 0.000 & $-0.080 * * *$ & 0.019 & 0.000 & $-0.347^{*}$ & 0.199 & 0.092 & $-0.144^{* * *}$ & 0.051 & 0.009 \\
\hline Income 9 & $-0.150 * * *$ & 0.016 & 0.000 & $-0.151^{* * *}$ & 0.017 & 0.000 & -0.189 & 0.212 & 0.380 & $-0.170 * * *$ & 0.044 & 0.001 \\
\hline Income 10 & $-0.306^{* * *}$ & 0.028 & 0.000 & $-0.302^{* * *}$ & 0.029 & 0.000 & -0.493 & 0.405 & 0.235 & $-0.384^{* * *}$ & 0.066 & 0.000 \\
\hline Health 1 & $0.103^{* *}$ & 0.043 & 0.024 & $0.094^{* *}$ & 0.045 & 0.047 & & & & & & \\
\hline Health 2 & 0.018 & 0.017 & 0.312 & 0.011 & 0.018 & 0.546 & & & & & & \\
\hline Health 4 & $-0.055^{* * *}$ & 0.011 & 0.000 & $-0.056^{* * *}$ & 0.012 & 0.000 & & & & & & \\
\hline Health 5 & $-0.089 * * *$ & 0.018 & 0.000 & $-0.091 * * *$ & 0.018 & 0.000 & & & & & & \\
\hline Health & & & & & & & $-0.042^{* * *}$ & 0.007 & 0.000 & $-0.043^{* * *}$ & 0.007 & 0.000 \\
\hline Trust in legal system & $-0.018^{* * *}$ & 0.003 & 0.000 & $-0.018^{* * *}$ & 0.003 & 0.000 & $-0.018 * * *$ & 0.003 & 0.000 & $-0.018^{* * *}$ & 0.003 & 0.000 \\
\hline Union member, ever & $0.097^{* * *}$ & 0.014 & 0.000 & $0.098^{* * *}$ & 0.014 & 0.000 & $0.096^{* * *}$ & 0.014 & 0.000 & $0.097 * * *$ & 0.014 & 0.000 \\
\hline Union member, cur. & $0.073^{* * *}$ & 0.022 & 0.003 & $0.073^{* * *}$ & 0.023 & 0.004 & $0.073^{* * *}$ & 0.022 & 0.003 & $0.073^{* * *}$ & 0.023 & 0.003 \\
\hline Volunteering & -0.009 & 0.022 & 0.684 & 0.000 & 0.023 & 1.000 & -0.009 & 0.022 & 0.676 & 0.000 & 0.023 & 0.987 \\
\hline Helping & $0.171^{* * *}$ & 0.009 & 0.000 & $0.171^{* * *}$ & 0.009 & 0.000 & $0.171^{* * *}$ & 0.009 & 0.000 & $0.171^{* * *}$ & 0.009 & 0.000 \\
\hline L.1 gini_mkt & $0.042^{* *}$ & 0.016 & 0.012 & & & & $0.041^{* *}$ & 0.017 & 0.021 & & & \\
\hline L.1 yunempl_m & & & & $0.005^{* *}$ & 0.002 & 0.014 & & & & $0.004 *$ & 0.002 & 0.062 \\
\hline Income $1 \times$ L. 1 gini_mkt & & & & & & & -0.002 & 0.004 & 0.687 & & & \\
\hline Income $2 \times$ L.1 gini_mkt & & & & & & & 0.002 & 0.005 & 0.623 & & & \\
\hline Income $3 \times$ L.1 gini_mkt & & & & & & & 0.001 & 0.006 & 0.875 & & & \\
\hline Income $4 \times$ L.1 gini_mkt & & & & & & & -0.001 & 0.004 & 0.781 & & & \\
\hline Income $6 \times$ L.1 gini_mkt & & & & & & & 0.003 & 0.003 & 0.400 & & & \\
\hline Income $7 \times$ L.1 gini_mkt & & & & & & & 0.002 & 0.004 & 0.671 & & & \\
\hline Income $8 \times$ L.1 gini_mkt & & & & & & & 0.005 & 0.004 & 0.195 & & & \\
\hline Income $9 \times$ L.1 gini_mkt & & & & & & & 0.001 & 0.005 & 0.859 & & & \\
\hline Income $10 \times$ L.1 gini_mkt & & & & & & & 0.004 & 0.009 & 0.649 & & & \\
\hline Income $1 \times$ L.1 yunempl_m & & & & & & & & & & -0.003 & 0.002 & 0.288 \\
\hline Income $2 \times$ L.1 yunempl_m & & & & & & & & & & -0.001 & 0.002 & 0.613 \\
\hline Income $3 \times$ L.1 yunempl_m & & & & & & & & & & -0.002 & 0.001 & 0.196 \\
\hline Income $4 \times$ L.1 yunempl_m & & & & & & & & & & -0.001 & 0.001 & 0.639 \\
\hline Income $6 \times$ L.1 yunempl_m & & & & & & & & & & 0.002 & 0.001 & 0.117 \\
\hline Income $7 \times$ L.1 yunempl_m & & & & & & & & & & 0.003 & 0.002 & 0.240 \\
\hline Income $8 \times$ L.1 yunempl_m & & & & & & & & & & 0.004 & 0.003 & 0.160 \\
\hline Income $9 \times$ L.1 yunempl_m & & & & & & & & & & 0.001 & 0.003 & 0.670 \\
\hline Income $10 \times$ L.1 yunempl_m & & & & & & & & & & 0.005 & 0.004 & 0.228 \\
\hline $\mathrm{r} 2$ & 0.1670 & & & 0.1675 & & & 0.1670 & & & 0.1677 & & \\
\hline $\mathrm{N}$ & 82746 & & & 79606 & & & 82746 & & & 79606 & & \\
\hline Year FE & $\bar{\nabla} \checkmark$ & & & $\bar{\nabla} \checkmark$ & & & $\bar{l} \checkmark$ & & & $\bar{\nabla} \checkmark$ & & \\
\hline Country FE & $\checkmark$ & & & $\checkmark$ & & & $\checkmark$ & & & $\checkmark$ & & \\
\hline Region FE & $\checkmark$ & & & $\checkmark$ & & & $\checkmark$ & & & $\checkmark$ & & \\
\hline All controls & $\checkmark$ & & & $\checkmark$ & & & $\checkmark$ & & & $\checkmark$ & & \\
\hline
\end{tabular}

Note: The table presents robustness tests (1) including political variables. Data is weighted (design weight). Standard errors are clustered on the country level. *** Significant at the $1 \%$ level. Significant at the $5 \%$ level.* Significant at the $10 \%$ level. 
Table A.13: Survey round FE

\begin{tabular}{|c|c|c|c|c|c|c|c|c|c|c|c|c|}
\hline & \multicolumn{3}{|c|}{ (1) } & \multicolumn{2}{|r|}{ (2) } & & \multicolumn{3}{|c|}{ (3) } & \multicolumn{3}{|c|}{ (4) } \\
\hline & Coef. & Stdv. & $\mathrm{p}$ & Coef. & Stdv. & $\mathrm{p}$ & Coef. & Stdv. & $\mathrm{p}$ & Coef. & Stdv. & $\mathrm{p}$ \\
\hline Income 1 & 0.023 & 0.019 & 0.242 & 0.027 & 0.019 & 0.174 & 0.056 & 0.188 & 0.770 & $0.063^{*}$ & 0.035 & 0.087 \\
\hline Income 2 & $0.058 * * *$ & 0.018 & 0.003 & $0.062 * * *$ & 0.018 & 0.002 & -0.103 & 0.222 & 0.647 & $0.078^{*}$ & 0.039 & 0.054 \\
\hline Income 3 & $0.050 * * *$ & 0.016 & 0.004 & $0.051^{* * *}$ & 0.016 & 0.005 & -0.011 & 0.304 & 0.970 & $0.090^{* * *}$ & 0.031 & 0.007 \\
\hline Income 4 & 0.018 & 0.018 & 0.308 & 0.026 & 0.016 & 0.118 & 0.064 & 0.192 & 0.740 & 0.039 & 0.029 & 0.189 \\
\hline Income 6 & $-0.033^{* *}$ & 0.013 & 0.018 & $-0.032^{* *}$ & 0.014 & 0.031 & -0.205 & 0.165 & 0.227 & $-0.068^{* *}$ & 0.028 & 0.020 \\
\hline Income 7 & $-0.067 * * *$ & 0.017 & 0.001 & $-0.064^{* * *}$ & 0.018 & 0.002 & -0.123 & 0.201 & 0.546 & $-0.110^{* *}$ & 0.040 & 0.010 \\
\hline Income 8 & $-0.087^{* * *}$ & 0.020 & 0.000 & $-0.082^{* * *}$ & 0.020 & 0.000 & $-0.371^{*}$ & 0.215 & 0.096 & $-0.147 * *$ & 0.055 & 0.012 \\
\hline Income 9 & $-0.153^{* * *}$ & 0.017 & 0.000 & $-0.153^{* * *}$ & 0.018 & 0.000 & -0.243 & 0.224 & 0.286 & $-0.187 * * *$ & 0.047 & 0.000 \\
\hline Income 10 & $-0.318^{* * *}$ & 0.029 & 0.000 & $-0.315^{* * *}$ & 0.029 & 0.000 & -0.586 & 0.421 & 0.175 & $-0.400 * * *$ & 0.068 & 0.000 \\
\hline Health 1 & $0.109^{* *}$ & 0.042 & 0.016 & $0.105^{* *}$ & 0.046 & 0.030 & & & & & & \\
\hline Health 2 & 0.019 & 0.018 & 0.288 & 0.010 & 0.018 & 0.570 & & & & & & \\
\hline Health 4 & $-0.064^{* * *}$ & 0.011 & 0.000 & $-0.066^{* * *}$ & 0.011 & 0.000 & & & & & & \\
\hline Health 5 & $-0.099 * * *$ & 0.018 & 0.000 & $-0.102^{* * *}$ & 0.018 & 0.000 & & & & & & \\
\hline Health & & & & & & & $-0.047 * * *$ & 0.007 & 0.000 & $-0.048^{* * *}$ & 0.007 & 0.000 \\
\hline L.1 gini_mkt & $0.046^{* *}$ & 0.018 & 0.015 & & & & $0.044^{* *}$ & 0.019 & 0.027 & & & \\
\hline L.1 yunempl_m & & & & $0.005^{* *}$ & 0.002 & 0.021 & & & & $0.004^{*}$ & 0.002 & 0.098 \\
\hline Income $1 \times$ L.1 gini_mkt & & & & & & & -0.001 & 0.004 & 0.866 & & & \\
\hline Income $2 \times$ L. 1 gini_mkt & & & & & & & 0.003 & 0.005 & 0.480 & & & \\
\hline Income $3 \times$ L. 1 gini_mkt & & & & & & & 0.001 & 0.006 & 0.842 & & & \\
\hline Income $4 \times$ L.1 gini_mkt & & & & & & & -0.001 & 0.004 & 0.808 & & & \\
\hline Income $6 \times$ L.1 gini_mkt & & & & & & & 0.004 & 0.003 & 0.314 & & & \\
\hline Income $7 \times$ L.1 gini_mkt & & & & & & & 0.001 & 0.004 & 0.786 & & & \\
\hline Income $8 \times$ L.1 gini_mkt & & & & & & & 0.006 & 0.004 & 0.192 & & & \\
\hline Income $9 \times$ L.1 gini_mkt & & & & & & & 0.002 & 0.005 & 0.699 & & & \\
\hline Income $10 \times$ L.1 gini_mkt & & & & & & & 0.006 & 0.009 & 0.531 & & & \\
\hline Income $1 \times$ L.1 yunempl_m & & & & & & & & & & -0.002 & 0.003 & 0.389 \\
\hline Income $2 \times$ L.1 yunempl_m & & & & & & & & & & -0.001 & 0.002 & 0.679 \\
\hline Income $3 \times$ L.1 yunempl_m & & & & & & & & & & -0.002 & 0.001 & 0.118 \\
\hline Income $4 \times$ L.1 yunempl_m & & & & & & & & & & -0.001 & 0.001 & 0.584 \\
\hline Income $6 \times$ L.1 yunempl_m & & & & & & & & & & $0.002^{*}$ & 0.001 & 0.086 \\
\hline Income $7 \times$ L.1 yunempl_m & & & & & & & & & & 0.003 & 0.002 & 0.235 \\
\hline Income $8 \times$ L.1 yunempl_m & & & & & & & & & & 0.004 & 0.003 & 0.179 \\
\hline Income $9 \times$ L.1 yunempl_m & & & & & & & & & & 0.002 & 0.003 & 0.471 \\
\hline Income $10 \times$ L.1 yunempl_m & & & & & & & & & & 0.005 & 0.004 & 0.227 \\
\hline $\mathrm{r} 2$ & 0.1558 & & & 0.1559 & & & 0.1558 & & & 0.1561 & & \\
\hline $\mathrm{N}$ & 84252 & & & 80883 & & & 84252 & & & 80883 & & \\
\hline Survey FE & $\checkmark$ & & & $\checkmark$ & & & $\checkmark$ & & & $\checkmark$ & & \\
\hline Country FE & $\checkmark$ & & & $\checkmark$ & & & $\checkmark$ & & & $\checkmark$ & & \\
\hline Region FE & $\checkmark$ & & & $\checkmark$ & & & $\checkmark$ & & & $\checkmark$ & & \\
\hline All controls & $\checkmark$ & & & $\checkmark$ & & & $\checkmark$ & & & $\checkmark$ & & \\
\hline
\end{tabular}

Note: The table presents robustness tests (2) including survey round FE. Data is weighted (design weight). Standard errors are clustered on the country level. *** Significant at the $1 \%$ level. Significant at the $5 \%$ level.* Significant at the $10 \%$ level. 
Table A.14: Ordered Probit model

\begin{tabular}{|c|c|c|c|c|c|c|c|c|c|c|c|c|}
\hline & \multicolumn{3}{|c|}{ (1) } & \multicolumn{3}{|c|}{$\overline{~(2)}$} & \multicolumn{3}{|c|}{ (3) } & \multicolumn{3}{|c|}{ (4) } \\
\hline & Coef. & Stdv. & $\mathrm{p}$ & Coef. & Stdv. & $\mathrm{p}$ & Coef. & Stdv. & $\mathrm{p}$ & Coef. & Stdv. & $\mathrm{p}$ \\
\hline Income 1 & 0.031 & 0.024 & 0.204 & 0.035 & 0.024 & 0.158 & 0.184 & 0.232 & 0.428 & 0.067 & 0.045 & 0.142 \\
\hline Income 2 & $0.066^{* * *}$ & 0.021 & 0.002 & $0.071^{* * *}$ & 0.021 & 0.001 & -0.109 & 0.244 & 0.653 & 0.069 & 0.042 & 0.106 \\
\hline Income 3 & $0.054^{* * *}$ & 0.019 & 0.004 & $0.054^{* * *}$ & 0.019 & 0.005 & 0.027 & 0.369 & 0.941 & $0.083^{* * *}$ & 0.032 & 0.009 \\
\hline Income 4 & 0.015 & 0.019 & 0.448 & 0.023 & 0.018 & 0.209 & 0.093 & 0.199 & 0.641 & 0.036 & 0.029 & 0.216 \\
\hline Income 6 & $-0.039 * * *$ & 0.015 & 0.008 & $-0.038^{* *}$ & 0.016 & 0.014 & -0.289 & 0.202 & 0.153 & $-0.074 * * *$ & 0.029 & 0.010 \\
\hline Income 7 & $-0.076^{* * *}$ & 0.018 & 0.000 & $-0.072^{* * *}$ & 0.019 & 0.000 & -0.120 & 0.226 & 0.595 & $-0.113^{* * *}$ & 0.038 & 0.003 \\
\hline Income 8 & $-0.096^{* * *}$ & 0.020 & 0.000 & $-0.090 * * *$ & 0.021 & 0.000 & $-0.376^{*}$ & 0.224 & 0.093 & $-0.139 * * *$ & 0.050 & 0.006 \\
\hline Income 9 & $-0.165^{* * *}$ & 0.018 & 0.000 & $-0.165^{* * *}$ & 0.019 & 0.000 & -0.243 & 0.236 & 0.303 & $-0.176^{* * *}$ & 0.041 & 0.000 \\
\hline Income 10 & $-0.325^{* * *}$ & 0.030 & 0.000 & $-0.320 * * *$ & 0.030 & 0.000 & -0.452 & 0.414 & 0.275 & $-0.361^{* * *}$ & 0.061 & 0.000 \\
\hline Health 1 & $0.171^{* * *}$ & 0.049 & 0.000 & $0.167^{* * *}$ & 0.053 & 0.002 & & & & & & \\
\hline Health 2 & $0.038^{*}$ & 0.022 & 0.089 & 0.025 & 0.022 & 0.248 & & & & & & \\
\hline Health 4 & $-0.081^{* * *}$ & 0.012 & 0.000 & $-0.083^{* * *}$ & 0.012 & 0.000 & & & & & & \\
\hline Health 5 & $-0.103^{* * *}$ & 0.019 & 0.000 & $-0.108^{* * *}$ & 0.019 & 0.000 & & & & & & \\
\hline Health & & & & & & & $-0.055^{* * *}$ & 0.007 & 0.000 & $-0.055^{* * *}$ & 0.008 & 0.000 \\
\hline L.1 gini_mkt & $0.049^{* * *}$ & 0.018 & 0.007 & & & & $0.047^{* *}$ & 0.019 & 0.014 & & & \\
\hline L.1 yunempl_m & & & & $0.006^{* * *}$ & 0.002 & 0.006 & & & & $0.006^{* *}$ & 0.003 & 0.028 \\
\hline Income $1 \times$ L.1 gini_mkt & & & & & & & -0.003 & 0.005 & 0.530 & & & \\
\hline Income $2 \times$ L.1 gini_mkt & & & & & & & 0.004 & 0.005 & 0.472 & & & \\
\hline Income $3 \times$ L.1 gini_mkt & & & & & & & 0.001 & 0.008 & 0.942 & & & \\
\hline Income $4 \times$ L.1 gini_mkt & & & & & & & -0.002 & 0.004 & 0.689 & & & \\
\hline Income $6 \times$ L.1 gini_mkt & & & & & & & 0.005 & 0.004 & 0.220 & & & \\
\hline Income $7 \times$ L.1 gini_mkt & & & & & & & 0.001 & 0.005 & 0.847 & & & \\
\hline Income $8 \times$ L.1 gini_mkt & & & & & & & 0.006 & 0.005 & 0.205 & & & \\
\hline Income $9 \times$ L.1 gini_mkt & & & & & & & 0.002 & 0.005 & 0.741 & & & \\
\hline Income $10 \times$ L.1 gini_mkt & & & & & & & 0.003 & 0.009 & 0.754 & & & \\
\hline Income $1 \times$ L.1 yunempl_m & & & & & & & & & & -0.002 & 0.003 & 0.574 \\
\hline Income $2 \times$ L.1 yunempl_m & & & & & & & & & & 0.000 & 0.003 & 0.941 \\
\hline Income $3 \times$ L.1 yunempl_m & & & & & & & & & & -0.002 & 0.002 & 0.296 \\
\hline Income $4 \times$ L.1 yunempl_m & & & & & & & & & & -0.001 & 0.002 & 0.598 \\
\hline Income $6 \times$ L.1 yunempl_m & & & & & & & & & & 0.002 & 0.001 & 0.128 \\
\hline Income $7 \times$ L.1 yunempl_m & & & & & & & & & & 0.003 & 0.002 & 0.249 \\
\hline Income $8 \times$ L.1 yunempl_m & & & & & & & & & & 0.003 & 0.003 & 0.263 \\
\hline Income $9 \times$ L.1 yunempl_m & & & & & & & & & & 0.001 & 0.002 & 0.771 \\
\hline Income $10 \times$ L.1 yunempl_m & & & & & & & & & & 0.003 & 0.004 & 0.474 \\
\hline cut1 & $2.025^{* *}$ & 0.863 & 0.019 & -0.192 & 0.231 & 0.404 & $1.777^{*}$ & 0.915 & 0.052 & -0.356 & 0.236 & 0.132 \\
\hline cut2 & $3.037 * * *$ & 0.880 & 0.001 & $0.824^{* * *}$ & 0.212 & 0.000 & $2.789^{* * *}$ & 0.931 & 0.003 & $0.661^{* * *}$ & 0.216 & 0.002 \\
\hline cut3 & $3.570^{* * *}$ & 0.882 & 0.000 & $1.352^{* * *}$ & 0.209 & 0.000 & $3.322^{* * *}$ & 0.933 & 0.000 & $1.189^{* * *}$ & 0.212 & 0.000 \\
\hline cut4 & $4.839^{* * *}$ & 0.893 & 0.000 & $2.634^{* * *}$ & 0.206 & 0.000 & $4.591^{* * *}$ & 0.942 & 0.000 & $2.471^{* * *}$ & 0.208 & 0.000 \\
\hline $\mathrm{N}$ & 84252 & & & 80883 & & & 84252 & & & 80883 & & \\
\hline Year FE & $\checkmark$ & & & $\checkmark$ & & & $\checkmark$ & & & $\checkmark$ & & \\
\hline Country FE & $\checkmark$ & & & $\checkmark$ & & & $\checkmark$ & & & $\checkmark$ & & \\
\hline Region FE & $\checkmark$ & & & $\checkmark$ & & & $\checkmark$ & & & $\checkmark$ & & \\
\hline All controls & $\checkmark$ & & & $\checkmark$ & & & $\checkmark$ & & & $\checkmark$ & & \\
\hline
\end{tabular}

Note: The table presents robustness test (3) using a Ordered Probit model. Data is weighted (design weight). Standard errors are clustered on the country level. *** Significant at the $1 \%$ level. ** Significant at the $5 \%$ level.* Significant at the $10 \%$ level. 
Table A.15: Three year lags

\begin{tabular}{|c|c|c|c|c|c|c|c|c|c|c|c|c|}
\hline & \multicolumn{3}{|c|}{ (1) } & \multicolumn{3}{|c|}{ 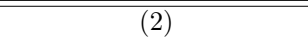 } & \multicolumn{3}{|c|}{ (3) } & \multicolumn{3}{|c|}{ (4) } \\
\hline & Coef. & Stdv. & $\mathrm{p}$ & Coef. & Stdv. & $\mathrm{p}$ & Coef. & Stdv. & $\mathrm{p}$ & Coef. & Stdv. & $\mathrm{p}$ \\
\hline Income 1 & $0.035^{*}$ & 0.020 & 0.093 & $0.039^{*}$ & 0.020 & 0.064 & 0.109 & 0.199 & 0.588 & $0.082^{* *}$ & 0.035 & 0.028 \\
\hline Income 2 & $0.059 * * *$ & 0.018 & 0.004 & $0.063^{* * *}$ & 0.018 & 0.002 & -0.056 & 0.226 & 0.806 & $0.084^{* *}$ & 0.039 & 0.039 \\
\hline Income 3 & $0.049^{* * *}$ & 0.015 & 0.003 & $0.051^{* * *}$ & 0.016 & 0.003 & 0.001 & 0.276 & 0.997 & $0.079^{* *}$ & 0.029 & 0.012 \\
\hline Income 4 & 0.022 & 0.017 & 0.217 & $0.030^{*}$ & 0.016 & 0.075 & 0.070 & 0.192 & 0.717 & 0.045 & 0.029 & 0.140 \\
\hline Income 6 & $-0.036^{* * *}$ & 0.012 & 0.008 & $-0.032^{* *}$ & 0.012 & 0.016 & -0.177 & 0.158 & 0.272 & $-0.065^{* *}$ & 0.025 & 0.015 \\
\hline Income 7 & $-0.065^{* * *}$ & 0.016 & 0.000 & $-0.063^{* * *}$ & 0.017 & 0.001 & -0.154 & 0.191 & 0.428 & $-0.107 * * *$ & 0.039 & 0.010 \\
\hline Income 8 & $-0.086^{* * *}$ & 0.019 & 0.000 & $-0.081 * * *$ & 0.019 & 0.000 & $-0.352^{*}$ & 0.197 & 0.085 & $-0.145^{* * *}$ & 0.052 & 0.009 \\
\hline Income 9 & $-0.150 * * *$ & 0.016 & 0.000 & $-0.151 * * *$ & 0.017 & 0.000 & -0.197 & 0.213 & 0.364 & $-0.179 * * *$ & 0.045 & 0.001 \\
\hline Income 10 & $-0.306^{* * *}$ & 0.028 & 0.000 & $-0.302^{* * *}$ & 0.029 & 0.000 & -0.490 & 0.408 & 0.240 & $-0.386^{* * *}$ & 0.066 & 0.000 \\
\hline Health 1 & $0.103^{* *}$ & 0.043 & 0.023 & $0.094^{* *}$ & 0.045 & 0.047 & & & & & & \\
\hline Health 2 & 0.018 & 0.017 & 0.304 & 0.011 & 0.018 & 0.547 & & & & & & \\
\hline Health 4 & $-0.055^{* * *}$ & 0.011 & 0.000 & $-0.056^{* * *}$ & 0.012 & 0.000 & & & & & & \\
\hline Health 5 & $-0.089^{* * *}$ & 0.018 & 0.000 & $-0.091 * * *$ & 0.018 & 0.000 & & & & & & \\
\hline Health & & & & & & & $-0.042^{* * *}$ & 0.007 & 0.000 & $-0.043^{* * *}$ & 0.007 & 0.000 \\
\hline L.3 gini_mkt & $0.041^{* *}$ & 0.016 & 0.014 & & & & $0.040^{* *}$ & 0.017 & 0.025 & & & \\
\hline L.3 yunempl_m & & & & $0.005^{* *}$ & 0.002 & 0.021 & & & & $0.004^{*}$ & 0.002 & 0.092 \\
\hline Income $1 \times$ L.3 gini_mkt & & & & & & & -0.002 & 0.004 & 0.724 & & & \\
\hline Income $2 \times$ L. 3 gini_mkt & & & & & & & 0.002 & 0.005 & 0.621 & & & \\
\hline Income $3 \times$ L. 3 gini_mkt & & & & & & & 0.001 & 0.006 & 0.862 & & & \\
\hline Income $4 \times$ L. 3 gini_mkt & & & & & & & -0.001 & 0.004 & 0.798 & & & \\
\hline Income $6 \times$ L. 3 gini_mkt & & & & & & & 0.003 & 0.003 & 0.378 & & & \\
\hline Income $7 \times$ L.3 gini_mkt & & & & & & & 0.002 & 0.004 & 0.644 & & & \\
\hline Income $8 \times$ L. 3 gini_mkt & & & & & & & 0.006 & 0.004 & 0.182 & & & \\
\hline Income $9 \times$ L. 3 gini_mkt & & & & & & & 0.001 & 0.005 & 0.832 & & & \\
\hline Income $10 \times$ L.3 gini_mkt & & & & & & & 0.004 & 0.009 & 0.656 & & & \\
\hline Income $1 \times$ L.3 yunempl_m & & & & & & & & & & -0.003 & 0.002 & 0.291 \\
\hline Income $2 \times$ L.3 yunempl_m & & & & & & & & & & -0.001 & 0.002 & 0.586 \\
\hline Income $3 \times$ L.3 yunempl_m & & & & & & & & & & -0.002 & 0.001 & 0.253 \\
\hline Income $4 \times$ L.3 yunempl_m & & & & & & & & & & -0.001 & 0.001 & 0.521 \\
\hline Income $6 \times$ L.3 yunempl_m & & & & & & & & & & 0.002 & 0.001 & 0.112 \\
\hline Income $7 \times$ L.3 yunempl_m & & & & & & & & & & 0.003 & 0.002 & 0.243 \\
\hline Income $8 \times$ L.3 yunempl_m & & & & & & & & & & 0.004 & 0.003 & 0.163 \\
\hline Income $9 \times$ L.3 yunempl_m & & & & & & & & & & 0.002 & 0.003 & 0.553 \\
\hline Income $10 \times$ L. 3 yunempl_m & & & & & & & & & & 0.005 & 0.004 & 0.216 \\
\hline $\mathrm{r} 2$ & 0.1670 & & & 0.1674 & & & 0.1670 & & & 0.1677 & & \\
\hline $\mathrm{N}$ & 82744 & & & 79602 & & & 82744 & & & 79602 & & \\
\hline Year FE & $\checkmark$ & & & $\checkmark$ & & & $\checkmark$ & & & $\checkmark$ & & \\
\hline Country FE & $\checkmark$ & & & $\checkmark$ & & & $\checkmark$ & & & $\checkmark$ & & \\
\hline Region FE & $\checkmark$ & & & $\checkmark$ & & & $\checkmark$ & & & $\checkmark$ & & \\
\hline All controls & $\checkmark$ & & & $\checkmark$ & & & $\checkmark$ & & & $\checkmark$ & & \\
\hline
\end{tabular}

Note: The table presents robustness tests (4) including three year lags. Data is weighted (design weight). Standard errors are clustered on the country level. *** Significant at the $1 \%$ level. Significant at the $5 \%$ level.* Significant at the $10 \%$ level. 
Table A.16: Four year lags

\begin{tabular}{|c|c|c|c|c|c|c|c|c|c|c|c|c|}
\hline & \multicolumn{3}{|c|}{ (1) } & \multicolumn{3}{|c|}{ (2) } & \multicolumn{3}{|c|}{ (3) } & \multicolumn{2}{|r|}{ (4) } & \\
\hline & Coef. & Stdv. & $\mathrm{p}$ & Coef. & Stdv. & $\mathrm{p}$ & Coef. & Stdv. & $\mathrm{p}$ & Coef. & Stdv. & $\mathrm{p}$ \\
\hline Income1 & $0.035^{*}$ & 0.020 & 0.093 & $0.039^{*}$ & 0.020 & 0.063 & 0.114 & 0.197 & 0.567 & $0.083^{* *}$ & 0.035 & 0.027 \\
\hline Income2 & $0.059^{* * *}$ & 0.018 & 0.004 & $0.063^{* * *}$ & 0.018 & 0.002 & -0.055 & 0.228 & 0.809 & $0.080 * *$ & 0.039 & 0.048 \\
\hline Income3 & $0.050^{* * *}$ & 0.015 & 0.003 & $0.051^{* * *}$ & 0.016 & 0.003 & 0.010 & 0.277 & 0.971 & $0.079^{* *}$ & 0.030 & 0.014 \\
\hline Income4 & 0.022 & 0.017 & 0.216 & $0.030^{*}$ & 0.016 & 0.074 & 0.066 & 0.192 & 0.734 & 0.032 & 0.029 & 0.284 \\
\hline Income6 & $-0.036^{* * *}$ & 0.012 & 0.008 & $-0.032^{* *}$ & 0.012 & 0.016 & -0.172 & 0.158 & 0.285 & $-0.068^{* *}$ & 0.025 & 0.011 \\
\hline Income7 & $-0.065^{* * *}$ & 0.016 & 0.000 & $-0.063^{* * *}$ & 0.017 & 0.001 & -0.163 & 0.191 & 0.401 & $-0.113^{* * *}$ & 0.038 & 0.006 \\
\hline Income8 & $-0.086^{* * *}$ & 0.019 & 0.000 & $-0.081^{* * *}$ & 0.019 & 0.000 & $-0.354^{*}$ & 0.198 & 0.085 & $-0.150 * * *$ & 0.050 & 0.006 \\
\hline Income9 & $-0.150^{* * *}$ & 0.016 & 0.000 & $-0.151^{* * *}$ & 0.017 & 0.000 & -0.188 & 0.215 & 0.390 & $-0.175^{* * *}$ & 0.044 & 0.000 \\
\hline Income10 & $-0.306^{* * *}$ & 0.028 & 0.000 & $-0.302^{* * *}$ & 0.029 & 0.000 & -0.493 & 0.407 & 0.236 & $-0.385^{* * *}$ & 0.065 & 0.000 \\
\hline Health1 & $0.103^{* *}$ & 0.043 & 0.023 & $0.094^{* *}$ & 0.045 & 0.047 & & & & & & \\
\hline Health2 & 0.018 & 0.017 & 0.303 & 0.011 & 0.018 & 0.549 & & & & & & \\
\hline Health4 & $-0.055^{* * *}$ & 0.011 & 0.000 & $-0.056^{* * *}$ & 0.012 & 0.000 & & & & & & \\
\hline Health5 & $-0.089^{* * *}$ & 0.018 & 0.000 & $-0.091^{* * *}$ & 0.018 & 0.000 & & & & & & \\
\hline Health & & & & & & & $-0.042^{* * *}$ & 0.007 & 0.000 & $-0.043^{* * *}$ & 0.007 & 0.000 \\
\hline L.4 gini_mkt & $0.041^{* *}$ & 0.015 & 0.014 & & & & $0.039^{* *}$ & 0.016 & 0.025 & & & \\
\hline L.4 yunempl_m & & & & $0.005^{* *}$ & 0.002 & 0.025 & & & & 0.003 & 0.002 & 0.130 \\
\hline Income1 $\times$ L.4 gini_mkt & & & & & & & -0.002 & 0.004 & 0.703 & & & \\
\hline Income $2 \times$ L.4 gini_mkt & & & & & & & 0.002 & 0.005 & 0.626 & & & \\
\hline Income $3 \times$ L.4 gini_mkt & & & & & & & 0.001 & 0.006 & 0.887 & & & \\
\hline Income $4 \times$ L.4 gini_mkt & & & & & & & -0.001 & 0.004 & 0.816 & & & \\
\hline Income $6 \times$ L.4 gini_mkt & & & & & & & 0.003 & 0.003 & 0.395 & & & \\
\hline Income $7 \times$ L.4 gini_mkt & & & & & & & 0.002 & 0.004 & 0.611 & & & \\
\hline Income $8 \times$ L.4 gini_mkt & & & & & & & 0.006 & 0.004 & 0.182 & & & \\
\hline Income $9 \times$ L.4 gini_mkt & & & & & & & 0.001 & 0.005 & 0.866 & & & \\
\hline Income10 $\times$ L.4 gini_mkt & & & & & & & 0.004 & 0.009 & 0.650 & & & \\
\hline Income1 $\times$ L.4 yunempl_m & & & & & & & & & & -0.003 & 0.002 & 0.292 \\
\hline Income $2 \times$ L. 4 yunempl_m & & & & & & & & & & -0.001 & 0.002 & 0.656 \\
\hline Income $3 \times$ L.4 yunempl_m & & & & & & & & & & -0.002 & 0.002 & 0.271 \\
\hline Income $4 \times$ L. 4 yunempl_m & & & & & & & & & & -0.000 & 0.001 & 0.918 \\
\hline Income $6 \times$ L. 4 yunempl_m & & & & & & & & & & $0.002^{*}$ & 0.001 & 0.071 \\
\hline Income $7 \times$ L.4 yunempl_m & & & & & & & & & & 0.003 & 0.002 & 0.181 \\
\hline Income8 $\times$ L.4 yunempl_m & & & & & & & & & & 0.004 & 0.003 & 0.124 \\
\hline Income $9 \times$ L.4 yunempl_m & & & & & & & & & & 0.001 & 0.003 & 0.591 \\
\hline Income10 × L.4 yunempl_m & & & & & & & & & & 0.005 & 0.004 & 0.219 \\
\hline $\mathrm{r} 2$ & 0.1670 & & & 0.1674 & & & 0.1670 & & & 0.1677 & & \\
\hline $\mathrm{N}$ & 82744 & & & 79603 & & & 82744 & & & 79603 & & \\
\hline $\mathrm{r} 2$ & 0.1670 & & & 0.1674 & & & 0.1670 & & & 0.1677 & & \\
\hline $\mathrm{N}$ & 82744 & & & 79602 & & & 82744 & & & 79602 & & \\
\hline Year FE & $\checkmark$ & & & $\checkmark$ & & & $\checkmark$ & & & $\checkmark$ & & \\
\hline Country FE & $\checkmark$ & & & $\checkmark$ & & & $\checkmark$ & & & $\checkmark$ & & \\
\hline Region FE & $\checkmark$ & & & $\checkmark$ & & & $\checkmark$ & & & $\checkmark$ & & \\
\hline All controls & $\checkmark$ & & & $\checkmark$ & & & $\checkmark$ & & & $\checkmark$ & & \\
\hline
\end{tabular}

Note: The table presents robustness tests (4) including three year lags. Data is weighted (design weight). Standard errors are clustered on the country level. *** Significant at the $1 \%$ level. Significant at the $5 \%$ level.* Significant at the $10 \%$ level. 
Table A.17: Including crime rates

\begin{tabular}{|c|c|c|c|c|c|c|c|c|c|c|c|c|}
\hline & \multicolumn{2}{|r|}{ (1) } & & \multicolumn{2}{|c|}{ (2) } & & \multicolumn{2}{|r|}{ (3) } & & Y. & \multicolumn{2}{|l|}{ (4) } \\
\hline & Coef. & Stdv. & $\mathrm{p}$ & Coef. & Stdv. & $\mathrm{p}$ & Coef. & Stdv. & $\mathrm{p}$ & Coef. & Stdv. & $\mathrm{p}$ \\
\hline Income 1 & $0.061^{* * *}$ & 0.021 & 0.007 & $0.063^{* * *}$ & 0.021 & 0.007 & 0.021 & 0.349 & 0.952 & $0.120^{* * *}$ & 0.036 & 0.003 \\
\hline Income 2 & $0.061^{* * *}$ & 0.014 & 0.000 & $0.063^{* * *}$ & 0.014 & 0.000 & -0.100 & 0.353 & 0.780 & 0.047 & 0.044 & 0.303 \\
\hline Income 3 & $0.057^{* * *}$ & 0.015 & 0.001 & $0.058^{* * *}$ & 0.015 & 0.001 & $0.455^{*}$ & 0.228 & 0.058 & $0.111^{* * *}$ & 0.037 & 0.006 \\
\hline Income 4 & $0.028^{* *}$ & 0.011 & 0.015 & $0.028^{* *}$ & 0.011 & 0.013 & 0.025 & 0.332 & 0.940 & $0.051^{* *}$ & 0.019 & 0.014 \\
\hline Income 6 & $-0.047^{* *}$ & 0.018 & 0.015 & $-0.047^{* *}$ & 0.019 & 0.018 & 0.182 & 0.271 & 0.508 & $-0.097^{* *}$ & 0.039 & 0.020 \\
\hline Income 7 & $-0.091^{* *}$ & 0.033 & 0.012 & $-0.091^{* *}$ & 0.034 & 0.013 & 0.731 & 0.431 & 0.103 & $-0.133^{*}$ & 0.072 & 0.077 \\
\hline Income 8 & $-0.107^{* * *}$ & 0.031 & 0.002 & $-0.110^{* * *}$ & 0.032 & 0.002 & 0.237 & 0.452 & 0.605 & $-0.179^{* *}$ & 0.067 & 0.013 \\
\hline Income 9 & $-0.184^{* * *}$ & 0.036 & 0.000 & $-0.187^{* * *}$ & 0.038 & 0.000 & 0.849 & 0.600 & 0.171 & $-0.214^{* *}$ & 0.090 & 0.027 \\
\hline Income 10 & $-0.338^{* * *}$ & 0.038 & 0.000 & $-0.343^{* * *}$ & 0.039 & 0.000 & 1.029 & 0.866 & 0.247 & $-0.364^{* * *}$ & 0.056 & 0.000 \\
\hline Health 1 & $0.182^{* * *}$ & 0.053 & 0.002 & $0.186^{* * *}$ & 0.053 & 0.002 & & & & & & \\
\hline Health 2 & 0.013 & 0.016 & 0.442 & 0.013 & 0.016 & 0.421 & & & & & & \\
\hline Health 4 & $-0.067^{* * *}$ & 0.014 & 0.000 & $-0.067^{* * *}$ & 0.014 & 0.000 & & & & & & \\
\hline Health 5 & $-0.106^{* * *}$ & 0.010 & 0.000 & $-0.106^{* * *}$ & 0.009 & 0.000 & & & & & & \\
\hline Health & & & & & & & $-0.052^{* * *}$ & 0.006 & 0.000 & $-0.053^{* * *}$ & 0.006 & 0.000 \\
\hline murder & $0.000^{* *}$ & 0.000 & 0.013 & $0.000^{* * *}$ & 0.000 & 0.000 & $0.000^{* *}$ & 0.000 & 0.019 & $0.000^{* * *}$ & 0.000 & 0.000 \\
\hline L.1 gini_mkt & $0.060^{* * *}$ & 0.016 & 0.001 & & & & $0.068^{* * *}$ & 0.018 & 0.001 & & & \\
\hline L.1 yunempl_m & & & & $0.007^{* *}$ & 0.003 & 0.017 & & & & $0.006^{* *}$ & 0.003 & 0.033 \\
\hline Income $1 \times$ L.1 gini_mkt & & & & & & & 0.001 & 0.007 & 0.909 & & & \\
\hline Income $2 \times$ L.1 gini_mkt & & & & & & & 0.003 & 0.007 & 0.652 & & & \\
\hline Income $3 \times$ L.1 gini_mkt & & & & & & & $-0.008^{*}$ & 0.005 & 0.087 & & & \\
\hline Income $4 \times$ L.1 gini_mkt & & & & & & & 0.000 & 0.007 & 0.996 & & & \\
\hline Income $6 \times$ L.1 gini_mkt & & & & & & & -0.005 & 0.006 & 0.417 & & & \\
\hline Income $7 \times$ L. 1 gini_mkt & & & & & & & $-0.017^{*}$ & 0.009 & 0.074 & & & \\
\hline Income $8 \times$ L.1 gini_mkt & & & & & & & -0.007 & 0.009 & 0.462 & & & \\
\hline Income $9 \times$ L. 1 gini_mkt & & & & & & & -0.021 & 0.012 & 0.102 & & & \\
\hline Income $10 \times$ L. 1 gini_mkt & & & & & & & -0.028 & 0.018 & 0.122 & & & \\
\hline Income $1 \times$ L.1 yunempl_m & & & & & & & & & & -0.003 & 0.002 & 0.188 \\
\hline Income $2 \times$ L.1 yunempl_m & & & & & & & & & & 0.001 & 0.002 & 0.688 \\
\hline Income $3 \times$ L. 1 yunempl_m & & & & & & & & & & $-0.003^{*}$ & 0.002 & 0.092 \\
\hline Income $4 \times$ L.1 yunempl_m & & & & & & & & & & -0.001 & 0.001 & 0.250 \\
\hline Income $6 \times$ L. 1 yunempl_m & & & & & & & & & & $0.003^{*}$ & 0.002 & 0.091 \\
\hline Income $7 \times$ L.1 yunempl_m & & & & & & & & & & 0.002 & 0.003 & 0.422 \\
\hline Income $8 \times$ L.1 yunempl_m & & & & & & & & & & 0.004 & 0.003 & 0.191 \\
\hline Income $9 \times$ L.1 yunempl_m & & & & & & & & & & 0.001 & 0.004 & 0.720 \\
\hline Income $10 \times$ L.1 yunempl_m & & & & & & & & & & 0.001 & 0.003 & 0.705 \\
\hline $\mathrm{r} 2$ & 0.1568 & & & 0.1561 & & & 0.1573 & & & 0.1562 & & \\
\hline $\mathrm{N}$ & 70424 & & & 70423 & & & 70424 & & & 70423 & & \\
\hline Year FE & $\checkmark$ & & & $\checkmark$ & & & $\checkmark$ & & & $\checkmark$ & & \\
\hline Country FE & $\checkmark$ & & & $\checkmark$ & & & $\checkmark$ & & & $\checkmark$ & & \\
\hline Region FE & $\checkmark$ & & & $\checkmark$ & & & $\checkmark$ & & & $\checkmark$ & & \\
\hline All controls & $\checkmark$ & & & $\checkmark$ & & & $\checkmark$ & & & $\checkmark$ & & \\
\hline
\end{tabular}

Note: The table presents robustness tests (4) including a variable capturing international homicides. Data is weighted (design weight). Standard errors are clustered on the country level. *** Significant at the $1 \%$ level. ** Significant at the $5 \%$ level.* Significant at the $10 \%$ level. 
Table A.18: Welfare state classification

\begin{tabular}{|c|c|c|c|c|c|c|c|c|c|c|c|c|}
\hline & \multicolumn{3}{|c|}{$\begin{array}{c}(1) \\
\text { Mkt. Gini }\end{array}$} & \multicolumn{3}{|c|}{$\begin{array}{c}(2) \\
\text { Y. unempl. }\end{array}$} & \multicolumn{3}{|c|}{$\begin{array}{c}(3) \\
\text { Mkt. Gini }\end{array}$} & \multicolumn{3}{|c|}{$\begin{array}{c}(4) \\
\text { Y. unempl. }\end{array}$} \\
\hline & Coef. & Stdv. & $\mathrm{p}$ & Coef. & Stdv. & $\mathrm{p}$ & Coef. & Stdv. & $\mathrm{p}$ & Coef. & Stdv. & $\mathrm{p}$ \\
\hline Welfare state (ref.: Southern) & & & & & & & & & & & & \\
\hline Nordic & $0.331^{* *}$ & 0.123 & 0.012 & 0.109 & 0.117 & 0.358 & $0.333^{* *}$ & 0.122 & 0.011 & 0.115 & 0.116 & 0.331 \\
\hline Liberal & 0.041 & 0.162 & 0.802 & $0.413^{* * *}$ & 0.143 & 0.007 & 0.045 & 0.165 & 0.786 & $0.423^{* * *}$ & 0.141 & 0.006 \\
\hline Continental & $0.172^{* * *}$ & 0.046 & 0.001 & $0.207^{* * *}$ & 0.048 & 0.000 & $0.174^{* * *}$ & 0.046 & 0.001 & $0.210^{* * *}$ & 0.049 & 0.000 \\
\hline Eastern and Central & $0.665^{* * *}$ & 0.128 & 0.000 & $0.529 * * *$ & 0.144 & 0.001 & $0.664^{* * *}$ & 0.127 & 0.000 & $0.541^{* * *}$ & 0.144 & 0.001 \\
\hline Income 1 & 0.023 & 0.019 & 0.243 & 0.026 & 0.019 & 0.179 & 0.080 & 0.190 & 0.678 & $0.063^{*}$ & 0.036 & 0.087 \\
\hline Income 2 & $0.057^{* * *}$ & 0.018 & 0.004 & $0.061^{* * *}$ & 0.018 & 0.002 & -0.105 & 0.220 & 0.638 & $0.076^{*}$ & 0.038 & 0.058 \\
\hline Income 3 & $0.049^{* * *}$ & 0.016 & 0.004 & $0.050^{* * *}$ & 0.016 & 0.004 & -0.016 & 0.300 & 0.958 & $0.089^{* * *}$ & 0.030 & 0.006 \\
\hline Income 4 & 0.018 & 0.017 & 0.310 & 0.026 & 0.016 & 0.116 & 0.052 & 0.190 & 0.786 & 0.038 & 0.029 & 0.201 \\
\hline Income 6 & $-0.034^{* *}$ & 0.013 & 0.016 & $-0.032^{* *}$ & 0.014 & 0.028 & -0.203 & 0.165 & 0.229 & $-0.068^{* *}$ & 0.028 & 0.022 \\
\hline Income 7 & $-0.068^{* * *}$ & 0.017 & 0.001 & $-0.064^{* * *}$ & 0.018 & 0.002 & -0.126 & 0.199 & 0.533 & $-0.108^{* *}$ & 0.039 & 0.011 \\
\hline Income 8 & $-0.087^{* * *}$ & 0.019 & 0.000 & $-0.082^{* * *}$ & 0.020 & 0.000 & $-0.374^{*}$ & 0.211 & 0.087 & $-0.145^{* *}$ & 0.054 & 0.012 \\
\hline Income 9 & $-0.153^{* * *}$ & 0.017 & 0.000 & $-0.153^{* * *}$ & 0.018 & 0.000 & -0.246 & 0.219 & 0.272 & $-0.185^{* * *}$ & 0.046 & 0.000 \\
\hline Income 10 & $-0.318^{* * *}$ & 0.028 & 0.000 & $-0.315^{* * *}$ & 0.029 & 0.000 & -0.581 & 0.420 & 0.178 & $-0.397^{* * *}$ & 0.067 & 0.000 \\
\hline Health 1 & $0.109 * *$ & 0.042 & 0.016 & $0.105^{* *}$ & 0.046 & 0.030 & $0.109^{* *}$ & 0.042 & 0.015 & $0.109^{* *}$ & 0.045 & 0.024 \\
\hline Health 2 & 0.019 & 0.017 & 0.272 & 0.011 & 0.018 & 0.549 & 0.020 & 0.017 & 0.263 & 0.013 & 0.018 & 0.474 \\
\hline Health 4 & $-0.064^{* * *}$ & 0.011 & 0.000 & $-0.066^{* * *}$ & 0.011 & 0.000 & $-0.065^{* * *}$ & 0.011 & 0.000 & $-0.067^{* * *}$ & 0.011 & 0.000 \\
\hline Health 5 & $-0.099^{* * *}$ & 0.018 & 0.000 & $-0.102^{* * *}$ & 0.018 & 0.000 & $-0.099 * * *$ & 0.018 & 0.000 & $-0.102^{* * *}$ & 0.018 & 0.000 \\
\hline L.1 gini_mkt & $0.041^{* *}$ & 0.016 & 0.013 & & & & $0.039^{* *}$ & 0.017 & 0.026 & & & \\
\hline L.1 yunempl_m & & & & $0.005^{* * *}$ & 0.002 & 0.010 & & & & $0.004^{*}$ & 0.002 & 0.057 \\
\hline Income $1 \times$ L. 1 gini_mkt & & & & & & & -0.001 & 0.004 & 0.774 & & & \\
\hline Income $2 \times$ L.1 gini_mkt & & & & & & & 0.003 & 0.005 & 0.474 & & & \\
\hline Income $3 \times$ L. 1 gini_mkt & & & & & & & 0.001 & 0.006 & 0.829 & & & \\
\hline Income $4 \times$ L.1 gini_mkt & & & & & & & -0.001 & 0.004 & 0.856 & & & \\
\hline Income $6 \times$ L.1 gini_mkt & & & & & & & 0.004 & 0.003 & 0.317 & & & \\
\hline Income $7 \times$ L.1 gini_mkt & & & & & & & 0.001 & 0.004 & 0.772 & & & \\
\hline Income $8 \times$ L.1 gini_mkt & & & & & & & 0.006 & 0.004 & 0.179 & & & \\
\hline Income $9 \times$ L. 1 gini_mkt & & & & & & & 0.002 & 0.005 & 0.683 & & & \\
\hline Income $10 \times$ L. 1 gini_mkt & & & & & & & 0.006 & 0.009 & 0.538 & & & \\
\hline Income $1 \times$ L.1 yunempl_m & & & & & & & & & & -0.002 & 0.003 & 0.380 \\
\hline Income $2 \times$ L. 1 yunempl_m & & & & & & & & & & -0.001 & 0.002 & 0.688 \\
\hline Income $3 \times$ L.1 yunempl_m & & & & & & & & & & -0.002 & 0.001 & 0.118 \\
\hline Income $4 \times$ L. 1 yunempl_m & & & & & & & & & & -0.001 & 0.001 & 0.609 \\
\hline Income $6 \times$ L. 1 yunempl_m & & & & & & & & & & $0.002 *$ & 0.001 & 0.094 \\
\hline Income $7 \times$ L.1 yunempl_m & & & & & & & & & & 0.003 & 0.002 & 0.246 \\
\hline Income $8 \times$ L.1 yunempl_m & & & & & & & & & & 0.004 & 0.003 & 0.187 \\
\hline Income $9 \times$ L. 1 yunempl_m & & & & & & & & & & 0.002 & 0.003 & 0.483 \\
\hline Income $10 \times$ L. 1 yunempl_m & & & & & & & & & & 0.005 & 0.004 & 0.239 \\
\hline $\mathrm{r} 2$ & 0.1562 & & & 0.1565 & & & 0.1563 & & & 0.1568 & & \\
\hline $\mathrm{N}$ & 84252 & & & 80883 & & & 84252 & & & 80883 & & \\
\hline Year FE & $\checkmark$ & & & $\checkmark$ & & & $\checkmark$ & & & $\checkmark$ & & \\
\hline Country FE & $\checkmark$ & & & $\checkmark$ & & & $\checkmark$ & & & $\checkmark$ & & \\
\hline Region FE & $\checkmark$ & & & $\checkmark$ & & & $\checkmark$ & & & $\checkmark$ & & \\
\hline All controls & $\checkmark$ & & & $\checkmark$ & & & $\checkmark$ & & & $\checkmark$ & & \\
\hline
\end{tabular}

Note: The table presents robustness tests (5) including a variable capturing welfare state classification. Data is weighted (design weight). Standard errors are clustered on the country level. ${ }^{* * *}$ Significant at the $1 \%$ level. ** Significant at the $5 \%$ level.* Significant at the $10 \%$ level. 